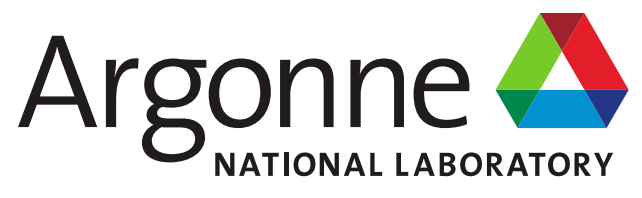

\title{
OVERVIEW OF ALUMINUM OXIDE PREDICTION MODELS FOR HIGH POWER RESEARCH REACTORS
}

Chemical and Fuel Cycle Technology Division 
About Argonne National Laboratory

Argonne is a U.S. Department of Energy laboratory managed by UChicago Argonne, LLC under contract DE-AC02-06CH11357. The Laboratory's main facility is outside Chicago, at 9700 South Cass Avenue, Argonne, Illinois 60439. For information about Argonne and its pioneering science and technology programs, see www.anl.gov.

\section{DOCUMENT AVAILABILITY}

Online Access: U.S. Department of Energy (DOE) reports produced after 1991 and a growing number of pre-1991 documents are available free via DOE's SciTech Connect (http://www.osti.gov/scitech/)

Reports not in digital format may be purchased by the public from the National Technical Information Service (NTIS):

U.S. Department of Commerce

National Technical Information Service 5301 Shawnee Rd

Alexandria, VA 22312

www.ntis.gov

Phone: (800) 553-NTIS (6847) or (703) 605-6000

Fax: (703) 605-6900

Email: morders@ntis.gov

Reports not in digital format are available to DOE and DOE contractors from the Office of Scientific and Technical Information (OSTI):

U.S. Department of Energy

Office of Scientific and Technical Information

P.O. Box 62

Oak Ridge, TN 37831-0062

www.osti.gov

Phone: (865) 576-8401

Fax: (865) 576-5728

Email: reports@osti.gov

Disclaimer

This report was prepared as an account of work sponsored by an agency of the United States Government. Neither the United States Government nor any agency thereof, nor UChicago Argonne, LLC, nor any of their employees or officers, makes any warranty, express or implied, or assumes any legal liability or responsibility for the accuracy, completeness, or usefulness of any information, apparatus, product, or process disclosed, or represents that its use would not infringe privately owned rights. Reference herein to any specific commercial product, process, or service by trade name, trademark, manufacturer, or otherwise, does not necessarily constitute or imply its endorsement, recommendation, or favoring by the United States Government or any agency thereof. The views and opinions of document authors expressed herein do not necessarily state or reflect those of the United States Government or any agency thereof, Argonne National Laboratory, or UChicago Argonne, LLC. 


\section{OVERVIEW OF ALUMINUM OXIDE PREDICTION MODELS FOR HIGH POWER RESEARCH REACTORS}

prepared by

Hee Taek Chae, Yeon Soo Kim, A.M. Yacout

Chemical and Fuel Cycle Technology Division, Argonne National Laboratory

September 2018 
(This page left intentionally blank) 


\section{Summary}

$\mathrm{UMo} / \mathrm{Al}$ dispersion fuel clad with aluminum alloy cladding is a primary candidate fuel form that is being developed for high power research and test reactors including European high power research reactors (EUHPRR). Oxidation of cladding is considerable due to high power application. One of the objectives of this report is to review the existing oxide prediction models and heat transfer correlations at cladding surface.

In this report, the models for aluminum cladding oxide growth were reviewed. Considering the difference in coolant flow conditions from the tests the model was originally based upon to those of EUHPRR, the heat transfer correlations from the bulk coolant to the cladding surface model including the Dittus-Boelter correlation, the Colburn correlation, the Sieder-Tate correlation, and the KAERI correlation were examined. The Dittus-Boelter correlation predicted the highest temperatures, hence highest oxide thicknesses were predicted. The ANL Model suited best with the Colburn correlation and the Sieder-Tate correlation. If the popular Dittus-Boelter correlation was used, the correction constant in the ANL Model needed to be reduced.

Between AG3NE and AlFeNi, AlFeNi appears to be slightly better in oxidation resistance than AG3NE. However, its magnitude is still in the uncertainty range. 


\section{Table of Contents}

Summary

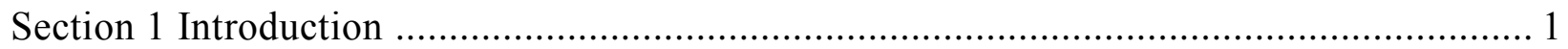

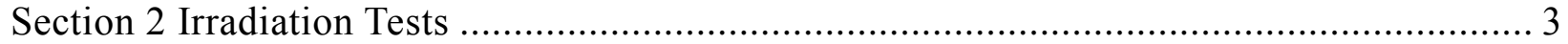

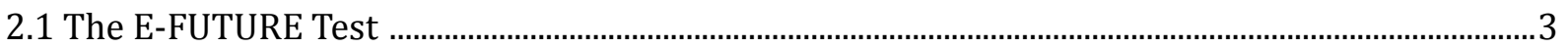

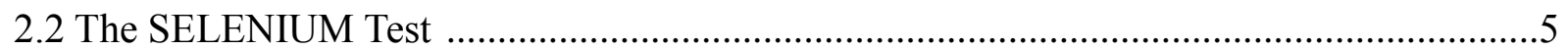

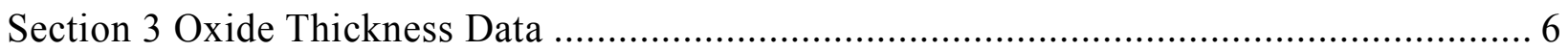

3.1 Aluminum Cladding Oxidation Mechanism ................................................................6

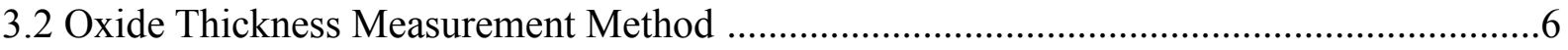

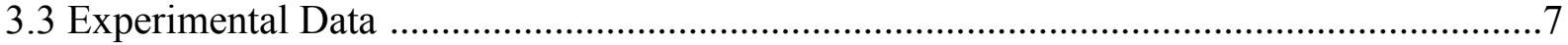

Section 4 Oxide Thickness Prediction Models …......................................................... 13

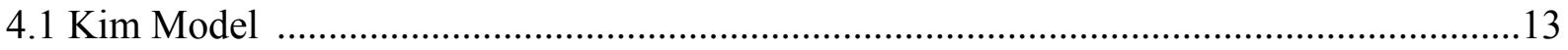

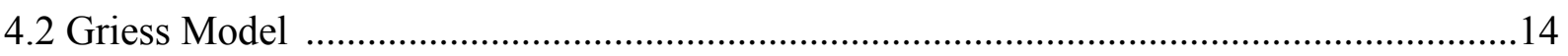

4.3 KAERI-modified Griess Model ...............................................................................

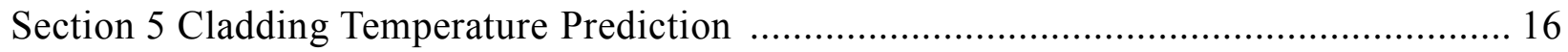

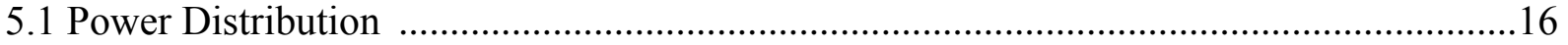

5.2 Correlations for Heat Transfer at Cladding Surface ……………………........................24

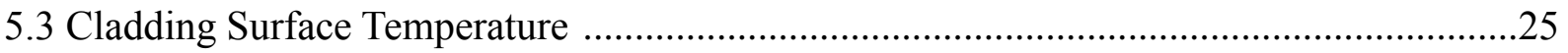

Section 6 Oxide Prediction and Model Revision …….................................................... 27

6.1 Model Comparison and Effect of Heat Transfer Coefficient ……………………….......2

6.2 Effect of Cladding Surface Temperature ………………................................................

6.3 Parametric Study of Heat Transfer Coefficient ……………………................................. 41

6.4 Correction Constant B in the Kim Model …………....................................................43

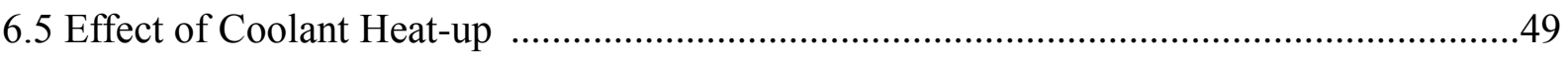

6.6 Effect of Cladding Type ………………………….................................................51

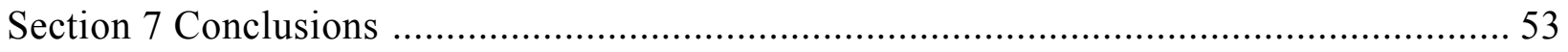

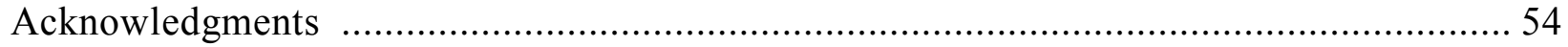

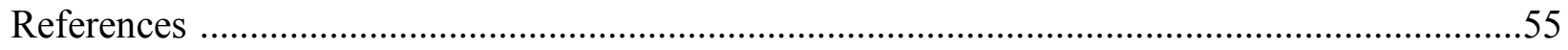




\section{List of Figures}

Figure 1 Schematic of the cross section of the E-FUTURE basket with four U7Mo fuel plates ... 4

Figure 2 Schematic of the E-FUTURE fuel plate and fuel meat .......................................... 4

Figure 3 Schematic of oxide thickness measurement locations. The dimensions are in $\mathrm{mm}$ and the point of origin is at the upper left corner of the plate. 8

Figure 4 Oxide layer thickness data for the fuel plate 4111 of the E-FUTURE experiment......... 9

Figure 5 Oxide layer thickness data for the fuel plate 4202 of the E-FUTURE experiment........ 10

Figure 6 Oxide layer thickness data for the fuel plate 6301 of the E-FUTURE experiment.........11

Figure 7 Oxide layer thickness data for the fuel plate 1221 of the SELENIUM experiment....... 12

Figure 8 Axial power distribution of the fuel plate 4111 of the E-FUTURE experiment............ 17

Figure 9 Axial power distribution of the fuel plate 4202 of the E-FUTURE experiment ........... 19

Figure 10 Axial power distribution of the fuel plate 6301 of the E-FUTURE experiment ......... 21

Figure 11 Axial power distribution of the fuel plate 1221 of the SELENIUM experiment ........ 23

Figure 12 Comparisons of Nusselt number and cladding surface temperature between heat transfer correlations for the E-FUTURE 6301 plate ......................................................... 26

Figure 13 Comparison of oxide thickness model predictions with measured data for fuel plate

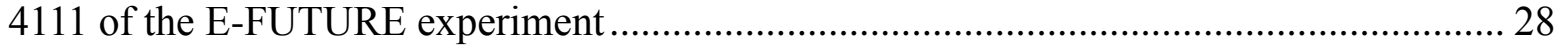

Figure 14 Comparison of oxide thickness model predictions with measured data for fuel plate 4202 of the E-FUTURE experiment.

Figure 15 Comparison of oxide thickness model predictions with measured data for fuel plate

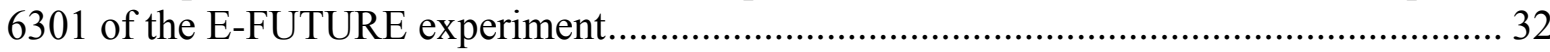

Figure 16 Comparison of oxide thickness model predictions with measured data for fuel plate 1221 of the SELENIUM experiment

Figure 17 Effect of cladding surface temperature on oxide thickness prediction in Kim model estimated for the fuel plate 4111 of the E-FUTURE experiment.

Figure 18 Effect of cladding surface temperature on oxide thickness prediction in ANL Model estimated for the fuel plate 4202 of the E-FUTURE experiment 
Figure 19 Effect of cladding surface temperature on oxide thickness prediction in Kim model estimated for the fuel plate 6301 of the E-FUTURE experiment.......................................... 39

Figure 20 Effect of cladding surface temperature on oxide thickness prediction in Kim model estimated for the fuel plate 1221 of the SELENIUM experiment

Figure 21 Effect of B of the Kim model coupled with the heat transfer correlations on oxide thickness prediction for the fuel plate 6301 of the E-FUTURE experiment .......................... 42

Figure 22 Comparison of coolant channel cross sections between RERTR miniplate tests and BR2 tests

Figure 23 Comparison of the Kim model with $\mathrm{B}=0.037$ and the Dittus-Boelter correlation with measured data for the fuel plate 4111 of the E-FUTURE experiment

Figure 24 Comparison of the Kim model with $\mathrm{B}=0.037$ and the Dittus-Boelter correlation with measured data for the fuel plate 4202 of the E-FUTURE experiment

Figure 25 Comparison of the Kim model with $\mathrm{B}=0.037$ and the Dittus-Boelter correlation with measured data for the fuel plate 6301 of the E-FUTURE experiment

Figure 26 Comparison of the Kim model with $\mathrm{B}=0.037$ and the Dittus-Boelter correlation with measured data for the fuel plate 1221 of the SELENIUM experiment

Figure 27 Comparison between the measured oxide thicknesses along the heated plate sides in the E-FUTURE experiment

Figure 28 Comparison between the measured oxide thicknesses along the cladding materials in the E-FUTURE experiment 


\section{List of Tables}

Table 1 Irradiation conditions for the E-FUTURE experiment ............................................. 3

Table 2 Irradiation conditions for the SELENIUM experiment .............................................. 5

Table 3 Axial heat flux distributions, $\mathrm{q}^{\prime \prime}\left(\mathrm{W} / \mathrm{cm}^{2}\right)$, on the cooling surface of the E-FUTURE plate

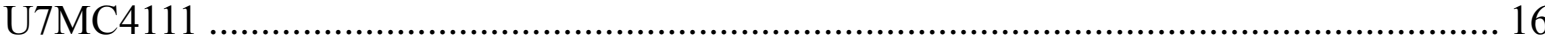

Table 4 Axial heat flux distributions, $\mathrm{q}^{\prime \prime}\left(\mathrm{W} / \mathrm{cm}^{2}\right)$, on the cooling surface of the E-FUTURE plate

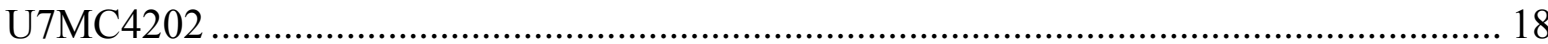

Table 5 Axial heat flux distributions, $\mathrm{q}^{\prime \prime}\left(\mathrm{W} / \mathrm{cm}^{2}\right)$, on the cooling surface of the E-FUTURE plate

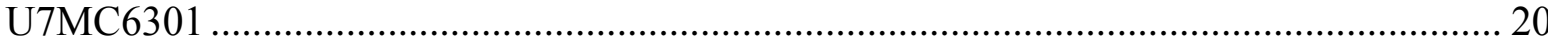

Table 6 Axial heat flux distributions, $\mathrm{q}^{\prime \prime}\left(\mathrm{W} / \mathrm{cm}^{2}\right)$, on the cooling surface of the SELENIUM plate

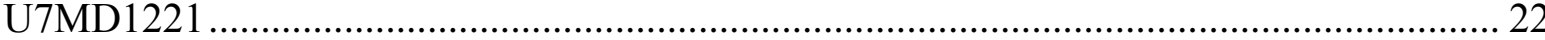

Table 7 Compositions (wt.\%) of aluminum cladding alloys [16] .......................................... 51 


\section{Section 1 Introduction}

For the conversion of the remaining European high performance research reactors (EUHPRR) using highly enriched uranium (HEU) to low enriched uranium (LEU), a high-density fuel is being developed. The primary candidate is UMo alloy particle dispersion in an Aluminum matrix (UMo/Al) with a meat density of up to $8.5 \mathrm{gU} / \mathrm{cm}^{3}$, viable for the use in the BR2, RHF, and JHR [1]. In order for this fuel to be qualified, stable and predictable fuel behavior, mechanical integrity of fuel plate, and dimensional stability of fuel plate must be demonstrated over the range of anticipated normal and off-normal operating conditions. In this regard, two traditionally used metrics to assess fuel performance are fuel meat swelling (or fuel plate thickness expansion) and cladding oxidation. The former performance topic has received extensive studies including experiment and modeling. The latter has had relatively less attention because no further development for cladding is pursued.

To develop and qualify UMo/Al dispersion fuel for EUHPRR, several tests at bounding power and burnup conditions for the EUHPRR including BR2, RHF and future JHR were conducted in the BR2. The E-FUTURE test was a selection test with Si addition in the matrix in which four flat, full size fuel plates with different manufacturing characteristics were irradiated [1,2]. The SELENIUM (Surface Engineering of Low Enriched Uranium-Molybdenum) test explored the efficacy of coating on the UMo particles to curb interaction between the fuel particles and aluminum matrix [3].

Aluminum alloy has well served for research reactor fuel cladding since its first use for the MTR in 1950s. Because the main purpose of research and test reactors is to produce neutrons rather than power, aluminum with a low neutron absorption cross section satisfies this purpose. Aluminum alloys also have high thermal conductivity. In slightly acidic coolant, aluminum alloy is an excellent material choice resistant to oxidation and corrosion in general. Before LEU fuel was considered, the research reactors adopted dispersion fuel forms with sparsely dispersed HEU fuel kernels. Hence, fuel temperatures were relatively low, so cladding oxidation was not a concern. However, when LEU fuel is considered for high power applications, cladding oxidation becomes a critical factor that elevates fuel temperature because its oxide, typically a Boehmite, has a thermal conductivity that is about two orders of magnitude lower than aluminum. For example, a $10-\mu \mathrm{m}$ thick oxide at a heat flux of $450 \mathrm{~W} / \mathrm{cm}^{2}$ increases the fuel temperature by approximately $20{ }^{\circ} \mathrm{C}$. Therefore, excessive oxidation can potentially degrade fuel performance. In this sense, providing a reliable model for cladding oxidation is crucial to help fuel design and accurately predict fuel behavior.

In 2008, to overcome the narrow applicable ranges of the existing models, a more versatile oxide prediction model was developed at ANL using existing data from out-of-pile and in-pile tests [4]. 
A review of the existing models became necessary before applied to the EUHPRR because of the high power designs for EUHPRR, different cladding alloy types, and different coolant geometry compared to the data used for the existing prediction models.

From the E-FUTURE and SELENIUM tests, systematically measured oxide data were available $[2,3]$. The frequently used oxide prediction models available in the literature were investigated by comparing with the measured data. Because the models were mostly developed based on the measured data at lower temperatures and powers (or heat fluxes) than the EU data, it is one of the objectives of this study to select a model that suits best the EUHPRR and determine whether a revision of the selected model is required.

Because the heat fluxes of the EU tests were demandingly high, it is important to accurately predict the temperature jump at the plate surface because cladding temperature is one of the key factors for cladding oxidation. The most frequently used models predicting the heat transfer coefficient at the cladding surface were examined, incorporating detailed thermal-hydraulic properties. Cladding surface temperature was then calculated and used for oxide thickness prediction.

In this report, the unique features of the full-size plate tests were discussed that may affect oxide growth kinetics. In addition, the effect of alloy types was also examined because the existing models were developed based on the measured data for mostly AA6061 whereas the EUHPRR uses AG3NET or AlFeNi. 


\section{Section 2 Irradiation Tests}

\subsection{The E-FUTURE-1 Test}

The irradiation of the E-FUTURE test, consisting of four full-size flat plates in a dedicated irradiation basket, started in March 2010 and ended in October 2010 in the BR2 reactor at SCKCEN [2]. The E-FUTURE plates contained UMo particles dispersed in an Al-Si matrix with a uranium density of $8 \mathrm{gU} / \mathrm{cm}^{3}$ in the fuel meat and $19.7 \%{ }^{235} \mathrm{U}$ enrichment. The fuel meat was clad with two different cladding types; AG3-NET as used in BR2 and AlFeNi as used in RHF. An important parameter for the E-FUTURE fuel plate is the Si content in the Al matrix, which was added to stabilize the interaction layer forming between the UMo and the Al matrix. Two Si contents (4 and $6 \mathrm{wt} \%)$ were selected for irradiation. The BOL maximum heat flux was 470 $\mathrm{W} / \mathrm{cm}^{2}$ and a maximum local burnup of $\sim 70 \% \mathrm{U} 235$ was achieved, as given in Table 1 . The EFUTURE irradiation showed excessive plate swelling in the high burnup region of the plates [2].

Table 1 Irradiation conditions for the E-FUTURE experiment

\begin{tabular}{|c|c|c|c|}
\hline $\begin{array}{c}\text { Reactor } \\
\text { cycle }\end{array}$ & Period & $\begin{array}{c}\text { Maximum }{ }^{235} \mathrm{U} \\
\text { BU (at.\%) }\end{array}$ & $\begin{array}{c}\text { Hot spot heat } \\
\text { flux }\left(\mathrm{W} / \mathrm{cm}^{2}\right)\end{array}$ \\
\hline $3 / 2010$ & day 1 (BOC) - day 26 (EOC) & 31 & 472 \\
\hline $4 / 2010$ & day 1 (BOC) - day 28 (EOC) & 55 & 336 \\
\hline $5 / 2010$ & day 1 (BOC) - day 20 (EOC) & 71 & 318 \\
\hline
\end{tabular}

A schematic cross-section view of the test basket and the fuel plates are shown in Figures 1 and 2. The coolant enters at the top of the irradiation basket with a nominal temperature of $38^{\circ} \mathrm{C}$ and flows downward with a nominal velocity of $12 \mathrm{~m} / \mathrm{s}$. The E-FUTURE plate power histories were obtained from BR2, which were calculated considering the changes in power, control rods position, possible scram events and the actual loading scheme of the uranium fission targets in the reactor core during the test [5]. The irradiation expanded over three BR2 cycles, during which the fuel burn-up and power changed significantly. Before the start of the last irradiation cycle, plate 6111 was rotated $180^{\circ}$ along the length axis, which exposed this plate to uniquely different conditions from the other plates (and atypical to the expected conditions of the final fuel design). Therefore, we decided to exclude this plate from the evaluation. 


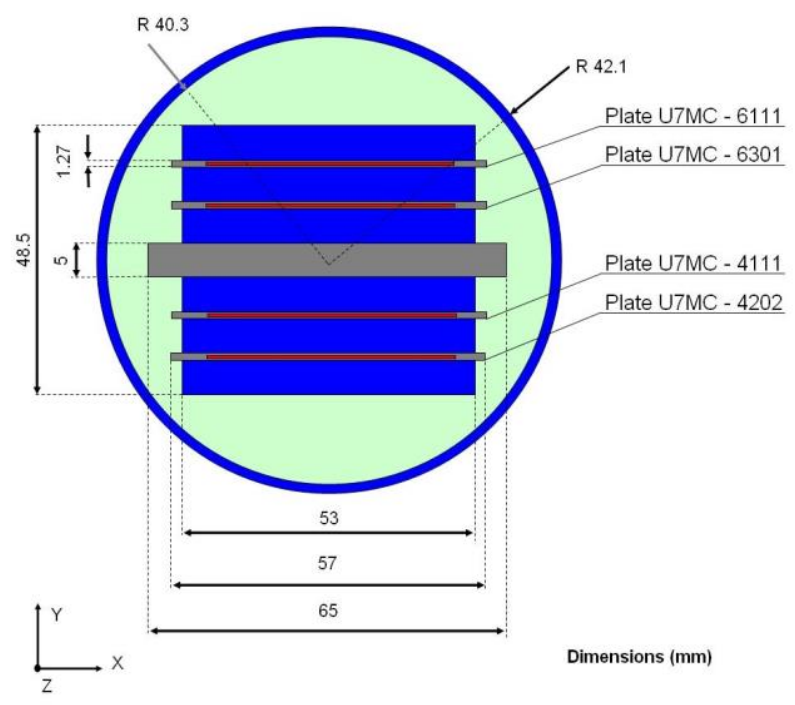

Figure 1 Schematic of the cross section of the E-FUTURE basket with four U7Mo fuel plates

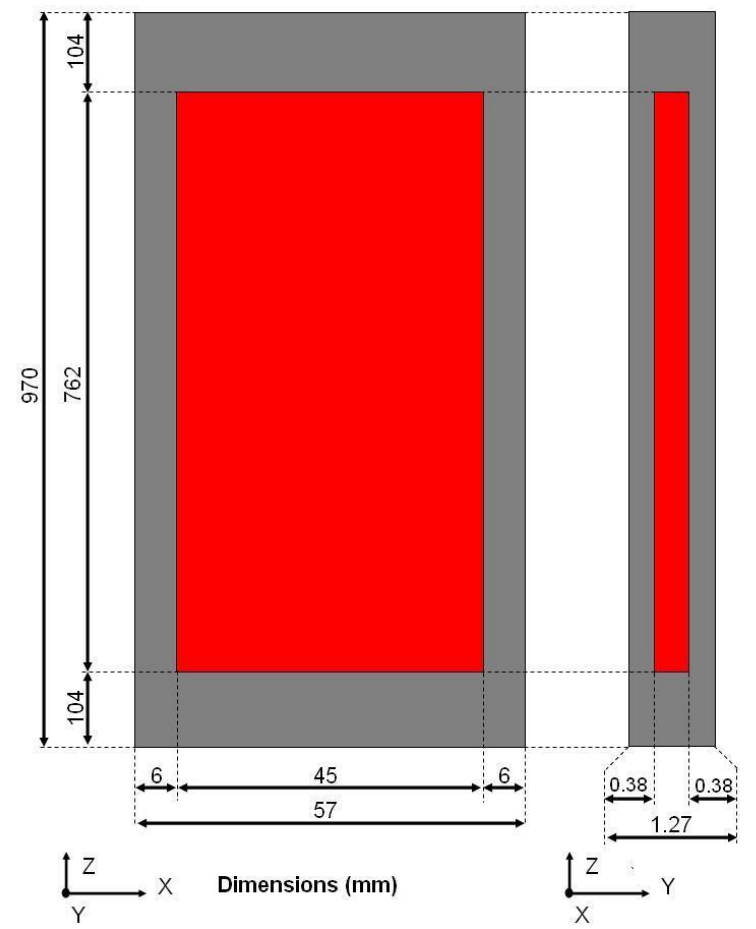

Figure 2 Schematic of the E-FUTURE fuel plate and fuel meat 


\subsection{The SELENIUM Test}

An alternative way to protect the UMo from excessive interaction with the Al matrix is to apply a $\mathrm{ZrN}$ or Si coating directly on the UMo particles. The efficacy of this method was examined in the Surface Engineering of Low Enriched Uranium-Molybdenum (SELENIUM) test [3]. The SELENIUM plates, one with ZrN coating and the other with Si-coating, were irradiated in the BR2 reactor at SCK $\cdot \mathrm{CEN}$ for three cycles: cycle 3 of 27 EFPD (Effective Full Power Day) and cycles 2 and 4 of 21 EFPD. The irradiation started on April 24 ${ }^{\text {th }}, 2012$ and ended on October $23^{\text {rd }}, 2012$. Both SELENIUM plates were irradiated at heat flux up to $\sim 470 \mathrm{~W} / \mathrm{cm}^{2}$ at BOC and $250 \mathrm{~W} / \mathrm{cm}^{2}$ at EOC, attaining a plate average burnup of $\sim 48 \% \mathrm{U}-235$ and a local maximum burnup slightly lower than 70\% U-235 [6], as summarized in Table 2.

Table 2 Irradiation conditions for the SELENIUM experiment

\begin{tabular}{|c|c|c|c|}
\hline $\begin{array}{c}\text { Reactor } \\
\text { cycle }\end{array}$ & Period & $\begin{array}{c}\text { Maximum } \\
\text { BU }[\text { at.\%] }\end{array}$ & $\begin{array}{c}\text { Hot spot heat } \\
\left.\text { flux [W/cm }{ }^{2}\right]\end{array}$ \\
\hline $2 / 2012$ & day 1 (BOC) - day 21 (EOC) & 27 & 466 \\
\hline $3 / 2012$ & day 1 (BOC) - day 27 (EOC) & 55 & 389 \\
\hline $4 / 2012$ & day 1 (BOC) - day 21 (EOC) & 70 & 294 \\
\hline
\end{tabular}




\section{Section 3 Oxide Thickness Data}

\subsection{Aluminum Cladding Oxidation Mechanism}

Aluminum alloys undergo oxidation if oxygen is available even at room temperature, producing a protective oxide $\left(\mathrm{Al}_{2} \mathrm{O}_{3}\right)$. However, the protective oxide degrades in water by the formation of various oxide-hydrates at the outer surface in time, leaving only a thin protective $\mathrm{Al}_{2} \mathrm{O}_{3}$ layer on the aluminum surface. The most frequently found oxide-hydrates in typical tests are boehmite $\left(\mathrm{Al}_{2} \mathrm{O}_{3} \cdot \mathrm{H}_{2} \mathrm{O}\right)$ and bayerite $\left(\mathrm{Al}_{2} \mathrm{O}_{3} \cdot 3 \mathrm{H}_{2} \mathrm{O}\right)$. Measured oxide is in reality mostly boehmite and contains relatively small portions of bayerite $\left(\mathrm{Al}_{2} \mathrm{O}_{3} \cdot 3 \mathrm{H}_{2} \mathrm{O}\right)$ and $\mathrm{Al}_{2} \mathrm{O}_{3}$. In this report, however, for convenience purposes the term 'oxide' is used for the combination of oxide-hydrates and oxide although it is a misnomer.

The bayerite is found at the outer surface of the boehmite layer, suggesting the following reaction is active.

$$
\mathrm{Al}_{2} \mathrm{O}_{3} \cdot \mathrm{H}_{2} \mathrm{O}+2 \mathrm{H}_{2} \mathrm{O} \rightarrow \mathrm{Al}_{2} \mathrm{O}_{3} \cdot 3 \mathrm{H}_{2} \mathrm{O}
$$

The boehmite is white when dry, and the bayerite is dark gray. Both are amorphous. The boehmite is more soluble in water than the bayerite is. This property gives the reason why some oxide surfaces are frequently uneven.

The density of boehmite is $3.02 \mathrm{~g} / \mathrm{cm}^{3}$ [7]. Using this information, one can calculate the ratio of the volume of the boehmite to the volume of the consumed Al (Pilling-Bedworth ratio). The calculated value is $\sim 2$, meaning that, for example, if $100 \mu \mathrm{m}$ oxide is measured, the corresponding Al consumption is $\sim 50 \mu \mathrm{m}$. Because of this high Pilling-Bedworth ratio, when it grows thicker under a high heat flux, the oxide becomes mechanically unstable increasing potential to a spallation.

\subsection{Oxide Thickness Measurement Method}

The oxide thicknesses were measured at SCK-CEN using the eddy current (EC) method [2]. The typical EC method includes a probe measuring the distance from the probe to the conductive material on the opposite side, in this case the aluminum alloy cladding. When in contact with the non-conductive oxide covering the surface of aluminum alloy cladding, therefore, the probe reads the oxide thickness.

Oxide thickness data of a plate were recorded every millimeter in 10 parallel lines 5-mm apart along the length of the plate starting from $6 \mathrm{~mm}$ to $51 \mathrm{~mm}$ measured from the cooler edge of the 
plate (see Figure 3). Before and after the measurement session, a calibration check is performed by measuring the reference to verify the stability and determine the uncertainty of the system, resulting in a typical overall measurement uncertainty of $\pm 3 \mu \mathrm{m}$, expressed at a $68 \%$ confidence level [2].

\subsection{Oxide Measurement Data}

Oxide thickness data of the E-FUTURE and SELENIUM tests are good examples for the study of oxide prediction models because they represent the bounding conditions of EUHPRR. During the PIE of the E-FUTURE and SELENIUM oxide thicknesses were systematically recorded. The locations of oxide thickness measurement were fairly consistent with those of the power calculation, so a comparison with the model prediction was readily executed.

The visual inspection of the irradiated plates showed that all four E-FUTURE plates showed significant swelling in the highest burnup region. Three plates (4111, 4202 and 6111) showed a clear blister in the peak power region, and plate 6301 also showed signs of incipient blistering [2].

A schematic of oxide thickness measurement line-scan locations is shown in Figure 3. Individual line scans from the upper and lower sides of each plate are illustrated in Figures $4-6$. The measured oxide thicknesses close to the pillowed area are in the range of $20-45 \mu \mathrm{m}$ for all plates. The top and bottom parts of all plates have a flat oxide profile of $5-10 \mu \mathrm{m}$ away from the pillowed region. The oxide thicknesses within the pillowed area (around $500 \mathrm{~mm}$ from meat top) are aberrant. Because the eddy current technique is highly sensitive to defects in the substrate material, these values should not be further interpreted. In a small area near the pillowing, the oxide appears to have spalled off. This is probably related to the extensive swelling in the pillowed zone creating high local stresses in the oxide layer [2].

The visual inspection for the SELENIUM plates showed a dark decolorization in some regions. This might indicate that the oxide in these regions was at the onset of spalling. At such a high heat flux, the stress in an oxide layer $\sim 35 \mu \mathrm{m}$ thick is high enough for cracks to develop. Similar to the E-FUTURE test, the same line scan locations were used. A typical oxide thickness profile of plate U7MD1221 [3] is shown in Figure 7. The data are for the line scan obtained at $41 \mathrm{~mm}$ (see Figure 3). The maximum oxide thickness was about $45 \mu \mathrm{m}$ in the peak power region. 


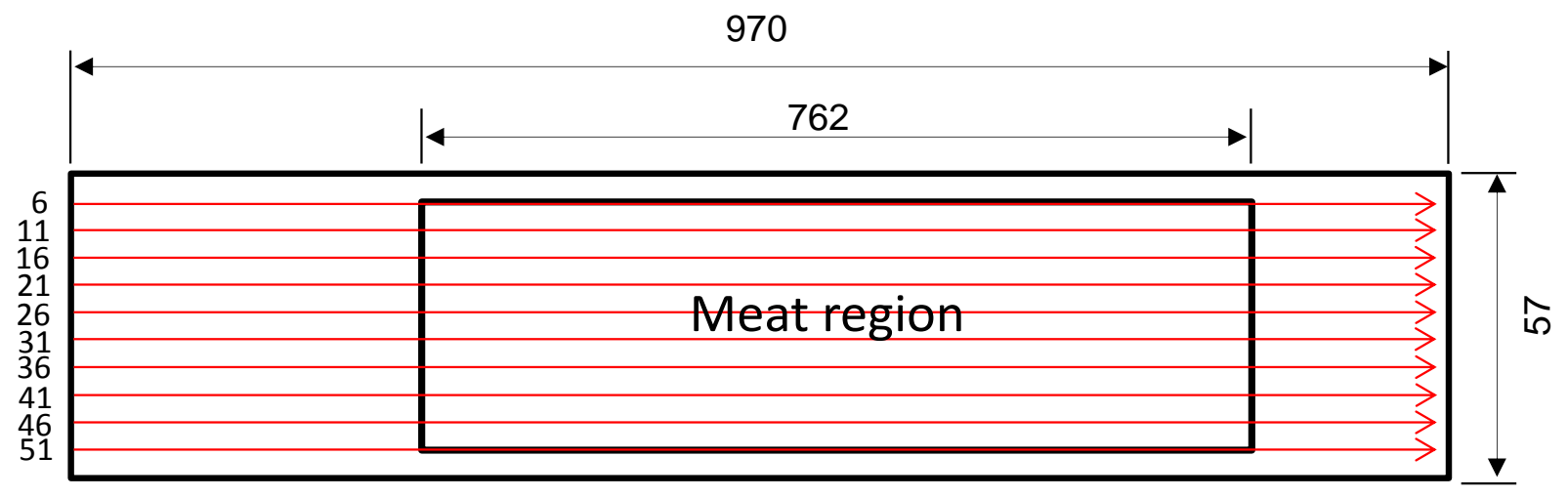

Figure 3 Schematic of oxide thickness measurement locations. The dimensions are in $\mathrm{mm}$ and the point of origin is at the upper left corner of the plate. 


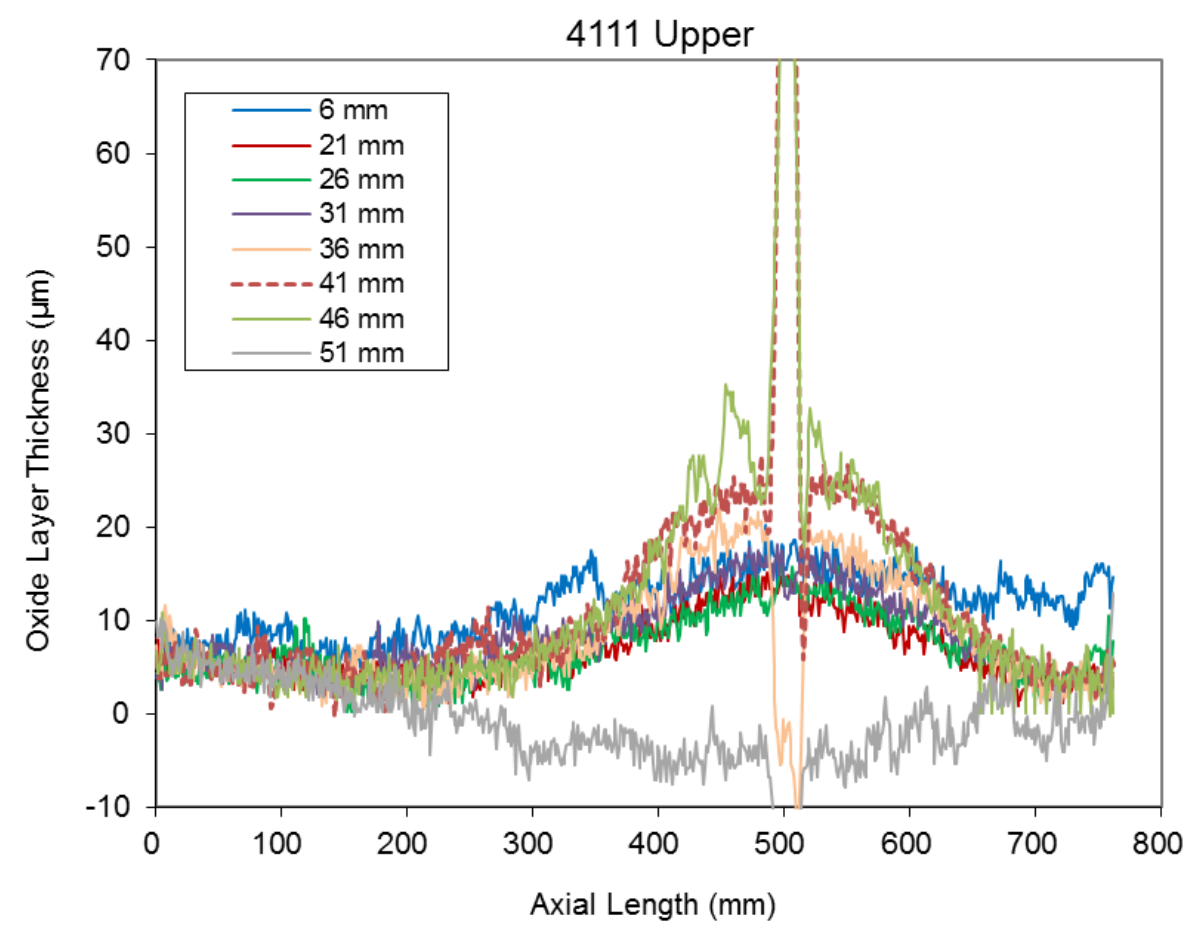

a) Upper side of fuel plate

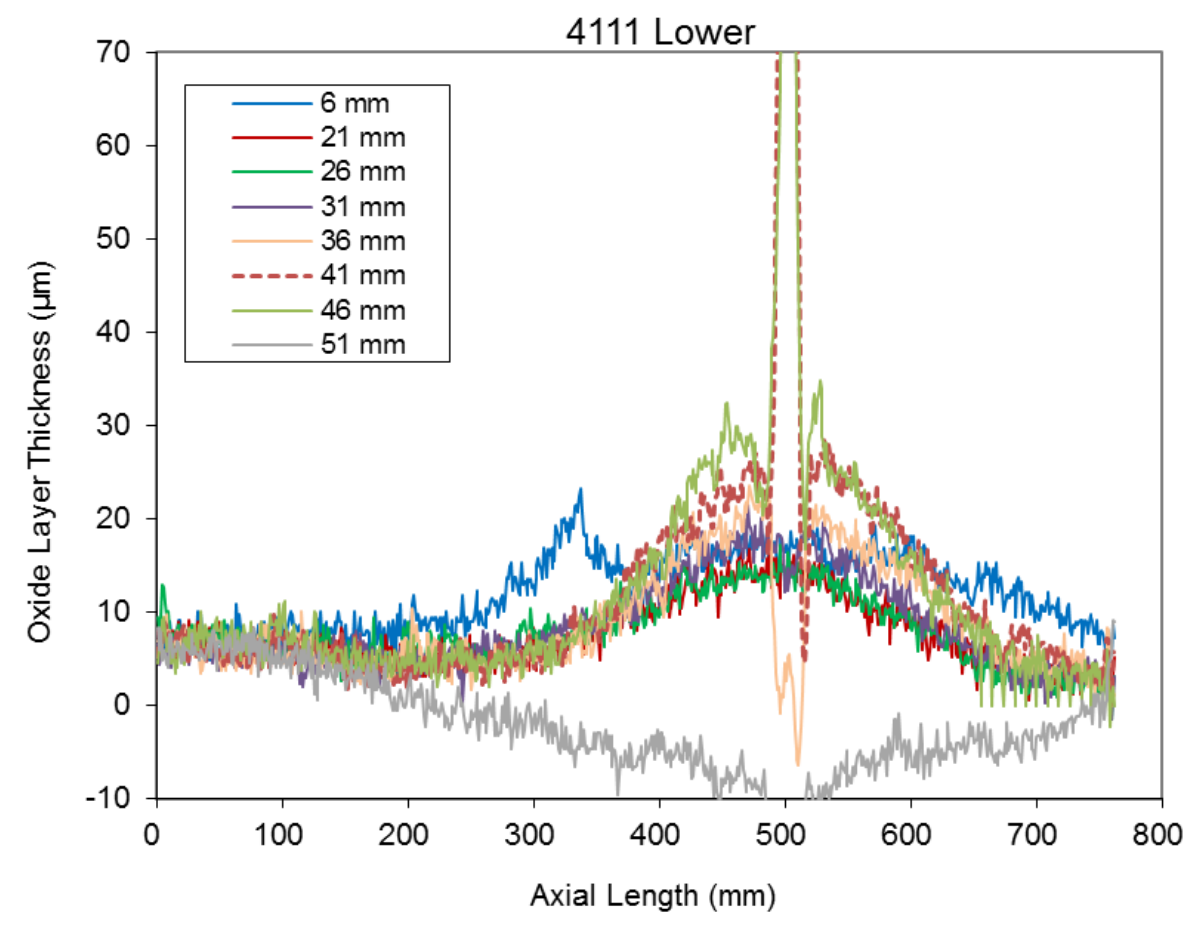

b) Lower side of fuel plate

Figure 4 Oxide layer thickness data for the fuel plate 4111 of the E-FUTURE experiment 


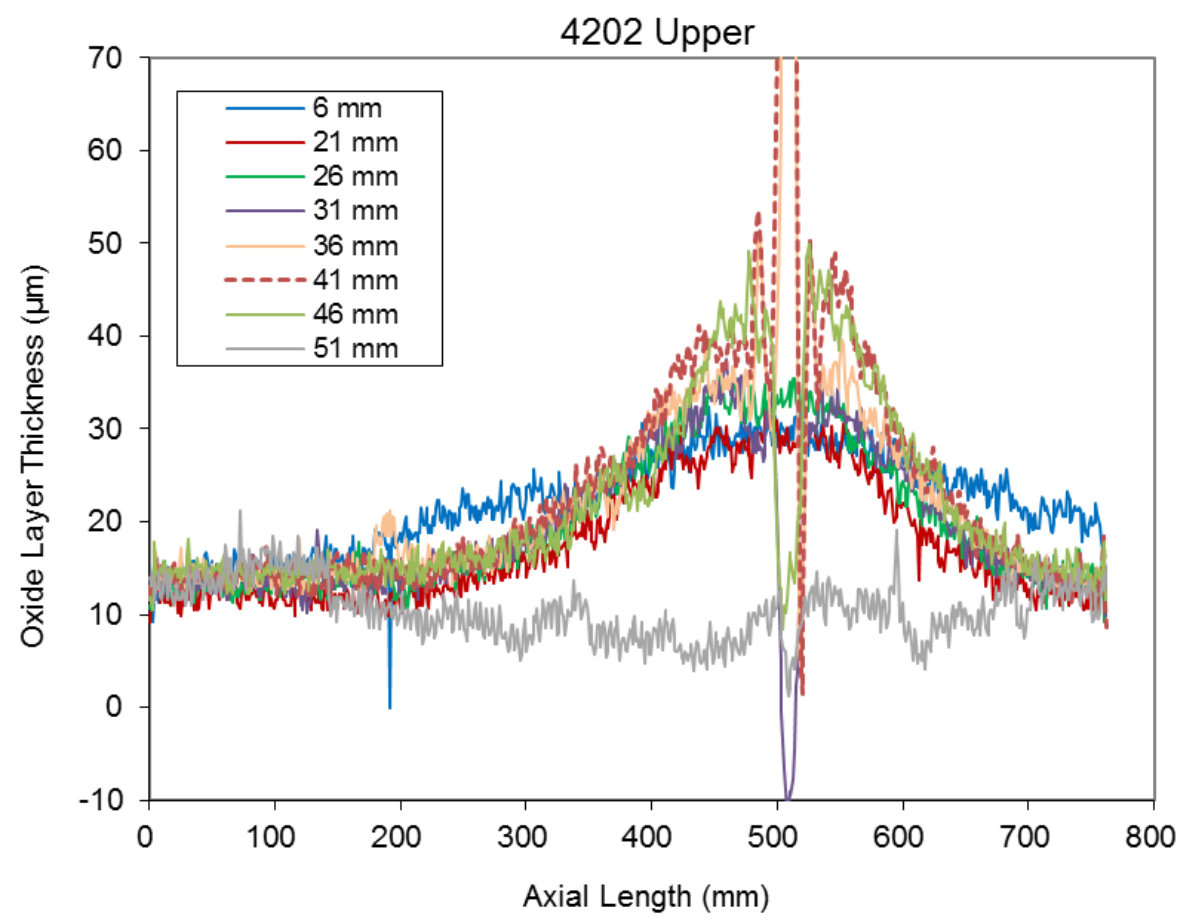

a) Upper side of fuel plate

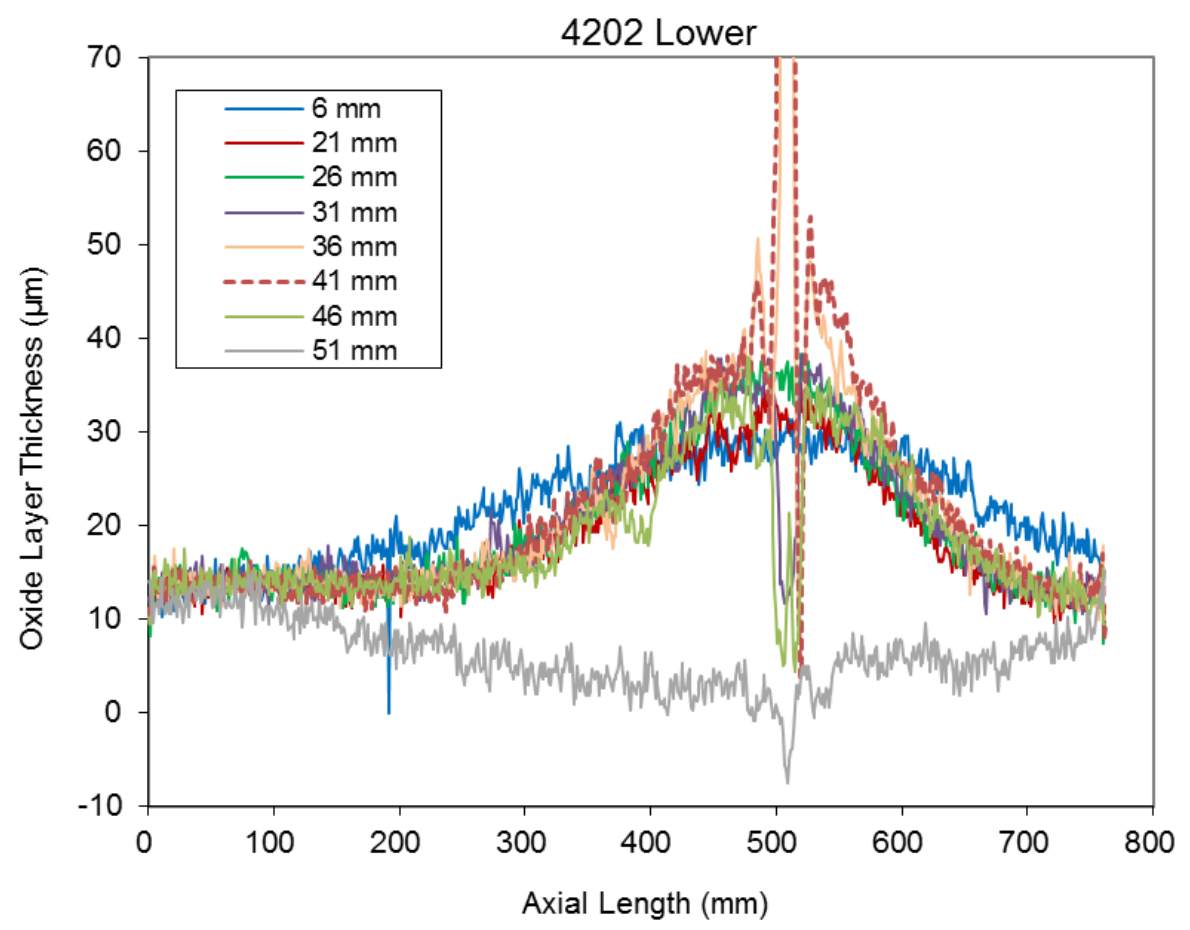

b) Lower side of fuel plate

Figure 5 Oxide layer thickness data for the fuel plate 4202 of the E-FUTURE experiment 


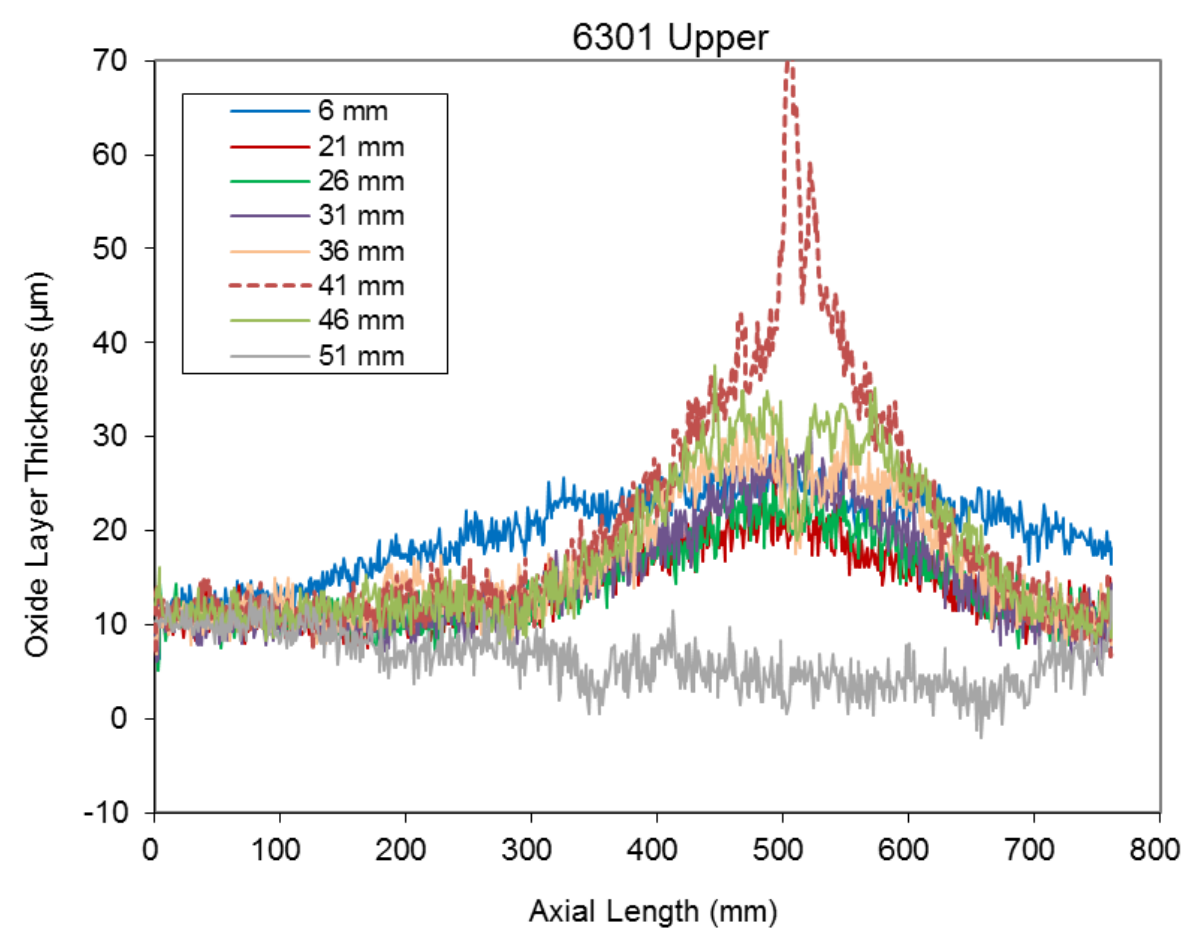

a) Upper side of fuel plate

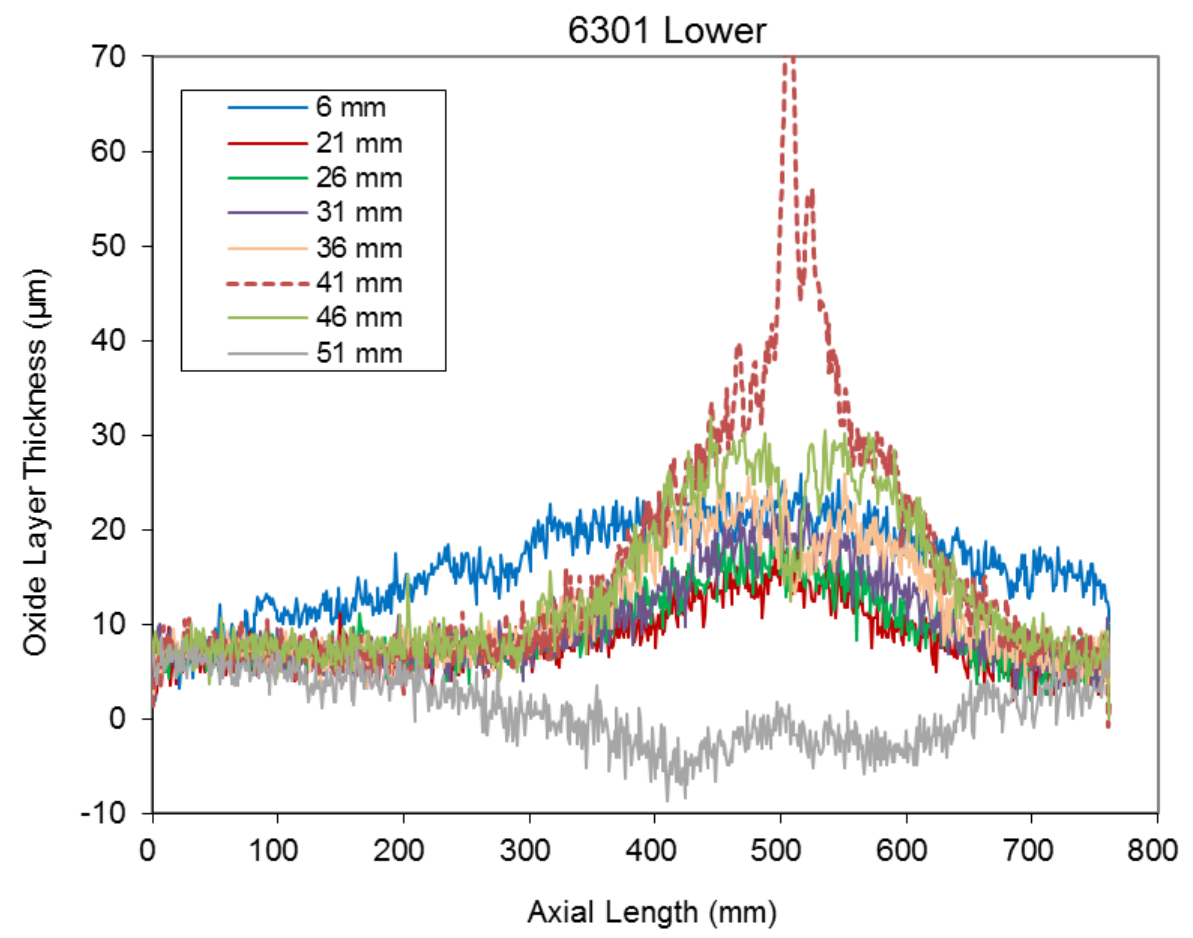

b) Lower side of fuel plate

Figure 6 Oxide layer thickness data for the fuel plate 6301 of the E-FUTURE experiment 


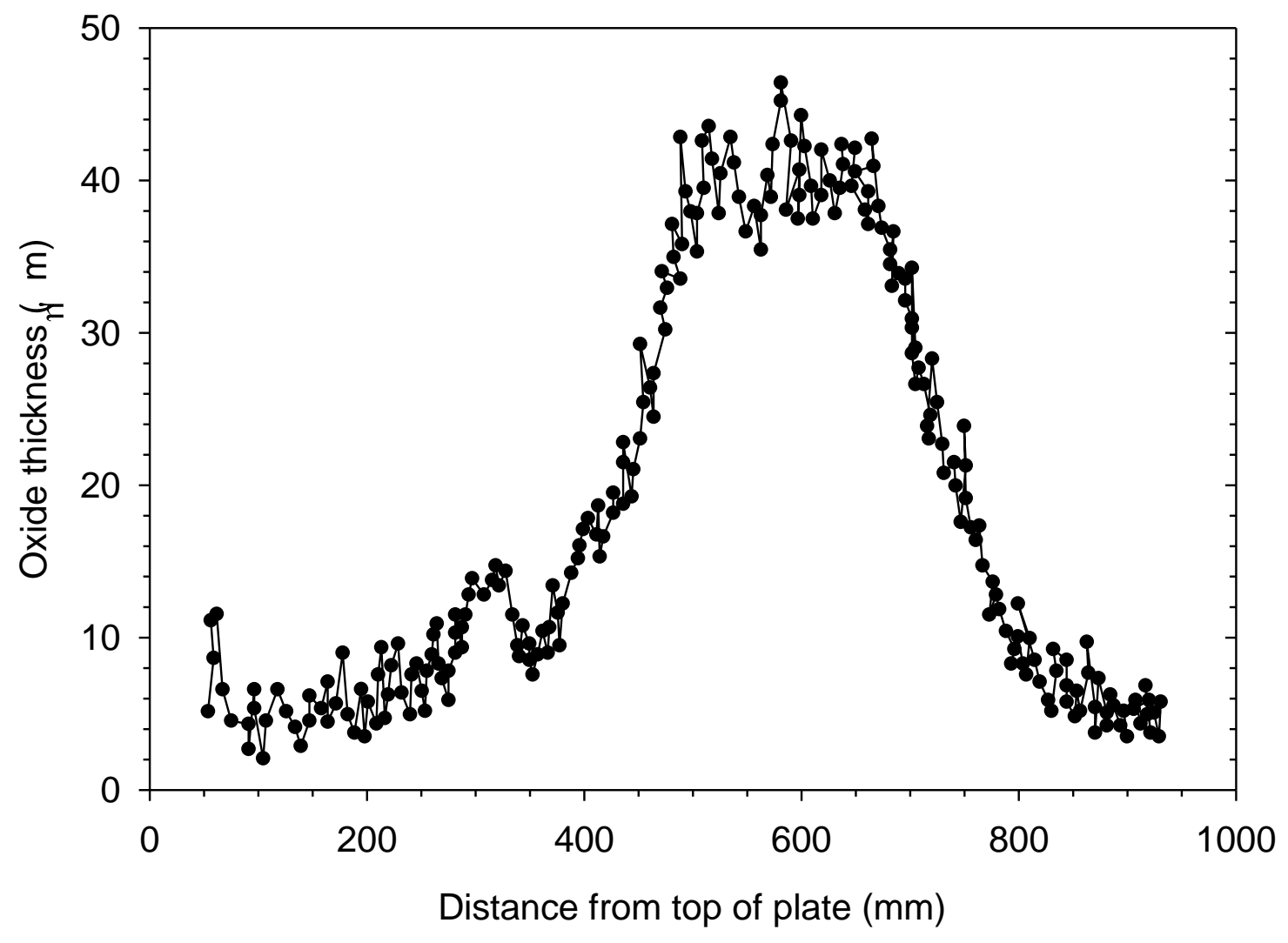

Figure 7 Oxide layer thickness data for the fuel plate 1221 of the SELENIUM experiment [3] 


\section{Section 4 Oxide Thickness Prediction Models}

\subsection{ANL Model}

The water-side oxide growth kinetics for Al cladding of research reactor fuel plates was described in a model proposed by Kim et al. [4]. In this report, the ANL model and Kim model are interchangeably used. The model comprises a series of equations empirically fit to measured data for AA 6061, predominantly at the ATR. This section is a summary of the model from Ref. $[4]$.

The rate equation for oxide growth was expressed by a power law:

$$
\frac{d x}{d t}=k x^{-p}
$$

where $\mathrm{x}, \mathrm{t}, \mathrm{k}$, and $\mathrm{p}$ are the oxide thickness, time, reaction constant and rate-law power, respectively. The integration of Eq. (2) gives the following general form of the kinetics equation:

$$
x=\left[x_{0}^{p+1}+(p+1) k \Delta t\right]^{\frac{1}{p+1}}
$$

where $\mathrm{x}_{0}$ is the film thickness at time zero in $\mu \mathrm{m}, \mathrm{p}$ is the rate law power, $\mathrm{k}$ is the rate function and $\Delta \mathrm{t}$ is the time step.

It is generally known that the oxide growth increase with increased oxide solubility [8]. The rate law power $\mathrm{p}$ is dependent on oxide dissolution in the water, so it is given by a function of coolant $\mathrm{pH}$ and temperature. The rate law power $\mathrm{p}$ is given by:

$$
\mathrm{p}=0.12+9.22 \exp \left(-\frac{\mathrm{C}_{\mathrm{s}}}{6.82 \times 10^{-9}}\right)
$$

and the oxide solubility, $\mathrm{C}_{\mathrm{s}}$ is expressed by:

$$
\mathrm{C}_{\mathrm{s}}=\exp \left[-\left(-13.79-\frac{1211.16}{\mathrm{~T}_{\mathrm{x} / \mathrm{w}}}\right)\left(0.041 \mathrm{H}^{2}-0.41 \mathrm{H}-0.07\right)\right]
$$

where $\mathrm{T}_{\mathrm{x} / \mathrm{w}}$ is the temperature at the oxide-water interface and $\mathrm{H}$ is $\mathrm{pH}$ of the coolant. The applicable temperature range is $25 \sim 300{ }^{\circ} \mathrm{C}$ and $\mathrm{pH}$ not greater than 7.0. 
The rate function $\mathrm{k}$ is expressed by an empirical formula:

$$
\mathrm{k}=3.9 \times 10^{5} \exp \left(\frac{-6071}{T_{x / w}+A B \frac{q x}{k_{T}}}\right)
$$

where $T_{x / w}$ is the oxide-water interface temperature in $\mathrm{K}, \mathrm{q}$ is the surface heat flux in $\mathrm{MW} / \mathrm{m}^{2}, \mathrm{x}$ in $\mu \mathrm{m}, k_{T}$ is the thermal conductivity of the oxide in $\mathrm{W} / \mathrm{m}-\mathrm{K}, \mathrm{A}$ is the augmentation factor, and $\mathrm{B}$ is the correction constant, as described below.

$\mathrm{A}$ is added to the equation as a multiplier to take into account the effect of coolant velocity. The augmentation factor increases as the coolant velocity increases because of the water ingress through the defective oxide. A is correlated with the coolant velocity using the following sigmoidal function:

$$
\mathrm{A}=0.43+\frac{3.21}{1+\exp \left(-\frac{\mathrm{v}_{\mathrm{c}}-13.39}{3.60}\right)}
$$

where $\mathrm{v}_{\mathrm{c}}$ is the coolant velocity in $\mathrm{m} / \mathrm{s}$. The applicable range of coolant velocity for this correlation is $3 \sim 28 \mathrm{~m} / \mathrm{s}$.

A correction constant, B, is needed to account for the reduction in the 'oxide thickness' caused by oxidant migration. In Ref.[4], the best fit was B $=0.37$ for AA 6061 and the ATR data.

The oxide thermal conductivity decreases as the oxide thickens. The oxide thermal conductivity was formulated as a function of the oxide thickness as follows:

$$
\begin{aligned}
& k_{T}=2.25, \quad \text { for } \mathrm{x} \leq 25, \\
& k_{T}=2.25-0.016(\mathrm{x}-25), \quad \text { for } 25 \leq \mathrm{x} \leq 100
\end{aligned}
$$

where $k_{T}$ is in $\mathrm{W} / \mathrm{m}-\mathrm{K}$ and $\mathrm{x}$ in $\mu \mathrm{m}$, defined by Eq. (3).

\subsection{Griess Model}

The Griess correlation was developed based upon out-of-pile data at Oak Ridge National Laboratory (ORNL) to evaluate the corrosion of the aluminum cladding in the High Flux Isotope 
Reactor (HFIR) and the Advanced Test Reactor (ATR) conditions. From the analysis of the test results, Griess derived the following correlation [7].

$$
x= \begin{cases}11,252 \exp \left(-\frac{4,600}{T}\right) t^{0.778}, & \text { for } \mathrm{pH}=5.0 \\ 30,480 \exp \left(-\frac{4,600}{T}\right) t^{0.778}, & \text { for } 5.7 \leq \mathrm{pH} \leq 7.0\end{cases}
$$

where $\mathrm{x}$ is the oxide layer thickness in $\mu \mathrm{m}, \mathrm{t}$ is the time in $\mathrm{h}$, and $\mathrm{T}$ is the cladding surface temperature in $\mathrm{K}$. The unique difference of the Griess model from other models is the ignorance of the effect of heat flux.

\subsection{KAERI-modified Griess Model}

The Griess correlation over-predicts when the heat flux is less than $3.18 \mathrm{MW} / \mathrm{m}^{2}$ [7]. At KAERI, the effect of heat flux was measured and a correction factor $\left(\mathrm{f}_{\mathrm{q}}\right)$ to modify the Griess model was obtained [9]. The KAERI-modified Griess model takes the following form:

$$
x= \begin{cases}11,252 \exp \left(-\frac{4,600}{T}\right) t^{0.778} f_{q}, & \text { for } \mathrm{pH}=5.0 \\ 30,480 \exp \left(-\frac{4,600}{T}\right) t^{0.778} f_{q}, & \text { for } 5.7 \leq \mathrm{pH} \leq 7.0\end{cases}
$$

In Eq. (11), the correction factor is expressed by

$$
f_{q}=\left\{\begin{array}{l}
-0.20836+0.18915 q, \text { for } 2.16 \mathrm{MW} / \mathrm{m}^{2}<q \\
0.2, \text { for } q<2.16 \mathrm{MW} / \mathrm{m}^{2}
\end{array}\right.
$$

where $\mathrm{q}$ is the heat flux in $\mathrm{MW} / \mathrm{m}^{2}$. 


\section{Section 5 Cladding Temperature Prediction}

\subsection{Power Distribution}

Power distribution data for the E-FUTURE test were available from Ref.[5]. The axial power distributions along the axial line measured $41 \mathrm{~mm}$ from the peak power side (see Figure 3 ) in the U7MC 4111, 4202 and 6301 fuel plates are presented in Tables 3 - 5, and Figures 9 - 11. As stated in Sect. 3.2, this line is slightly off from the peak power location. At BOC of the first irradiation cycle of the E-FUTURE plates, the maximum heat flux on the hottest experimental plate reached $\sim 470 \mathrm{~W} / \mathrm{cm}^{2}$. Mean burnup at the end of irradiation in plates was $\sim 48 \%$ (LEU equivalent), while the peak burnup was $\sim 71 \%$ (LEU equivalent).

Table 3 Axial heat flux distributions, q" $\left(\mathrm{W} / \mathrm{cm}^{2}\right)$, on the cooling surface of the E-FUTURE plate U7MC4111

\begin{tabular}{|c|c|c|c|c|c|c|}
\hline $\begin{array}{c}\text { Axial } \\
\text { position } \\
\text { from top } \\
(\mathrm{mm})\end{array}$ & \multicolumn{2}{|c|}{ Cycle 03/2010 } & \multicolumn{2}{c|}{ Cycle 04/2010 } & \multicolumn{2}{c|}{ Cycle 05/2010 } \\
\cline { 2 - 7 } & BOC - Day7 & Day7 - EOC & BOC - Day6 & Day7 - EOC & BOC - Day10 & Day10 - EOC \\
\hline 0 & 80 & 75 & 66 & 67 & 90 & 87 \\
\hline 45 & 95 & 96 & 88 & 85 & 111 & 103 \\
\hline 90 & 120 & 120 & 112 & 107 & 143 & 141 \\
\hline 134 & 147 & 152 & 123 & 136 & 161 & 164 \\
\hline 179 & 191 & 179 & 148 & 158 & 193 & 187 \\
\hline 224 & 210 & 208 & 182 & 175 & 230 & 216 \\
\hline 269 & 247 & 238 & 197 & 206 & 279 & 240 \\
\hline 314 & 295 & 285 & 254 & 229 & 299 & 270 \\
\hline 359 & 345 & 335 & 262 & 260 & 302 & 280 \\
\hline 403 & 387 & 364 & 296 & 286 & 305 & 276 \\
\hline 448 & 424 & 400 & 313 & 304 & 305 & 281 \\
\hline 493 & 429 & 412 & 322 & 315 & 303 & 277 \\
\hline 538 & 430 & 408 & 322 & 315 & 290 & 267 \\
\hline 583 & 403 & 392 & 330 & 304 & 274 & 264 \\
\hline 628 & 370 & 355 & 297 & 280 & 261 & 261 \\
\hline 672 & 333 & 313 & 266 & 261 & 249 & 237 \\
\hline 717 & 274 & 271 & 228 & 220 & 215 & 220 \\
\hline 762 & 235 & 228 & 189 & 196 & 183 & 187 \\
\hline
\end{tabular}




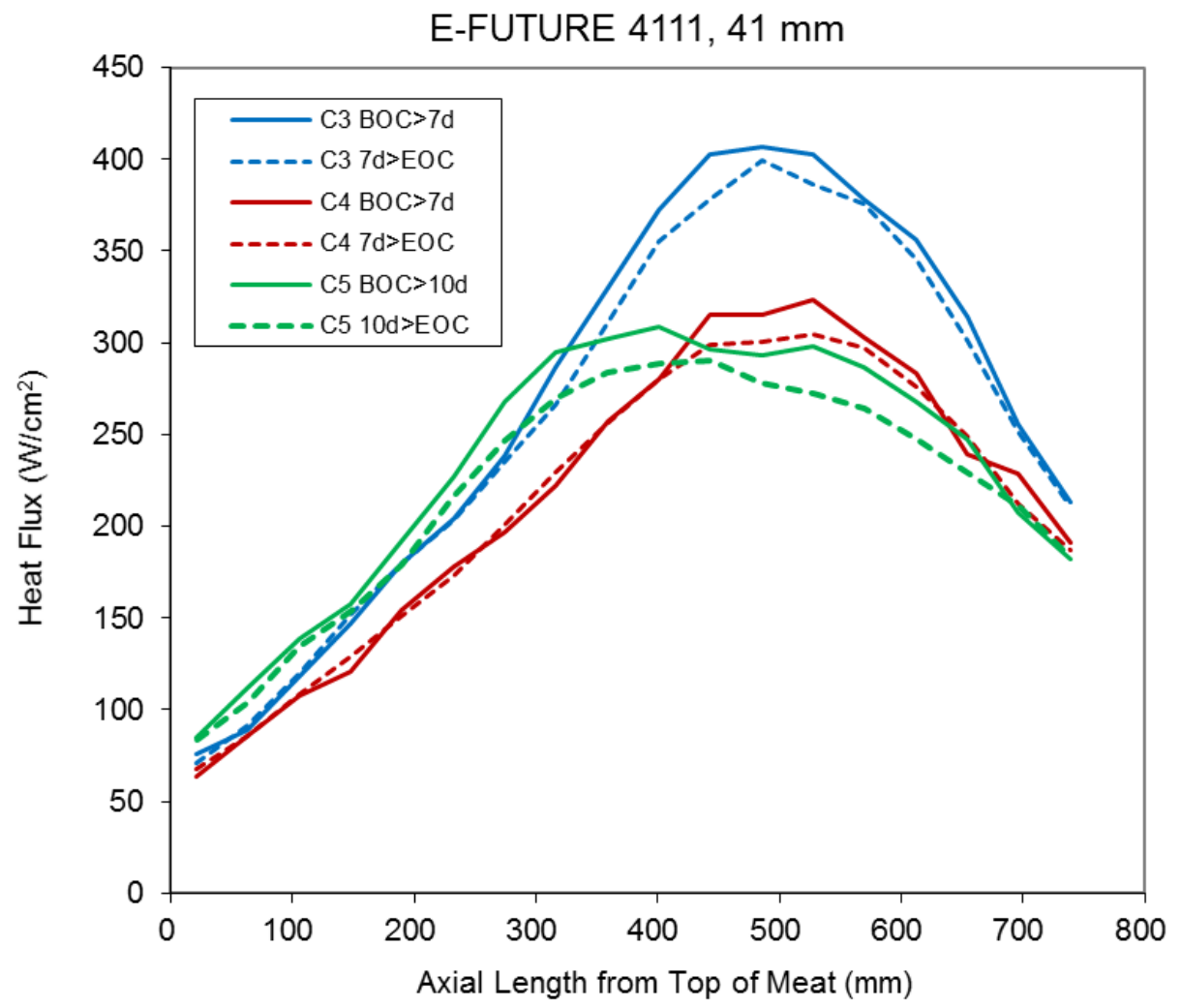

Figure 8 Axial power distribution of the fuel plate 4111 of the E-FUTURE experiment 
Table 4 Axial heat flux distributions, q" $\left(\mathrm{W} / \mathrm{cm}^{2}\right)$, on the cooling surface of the E-FUTURE plate U7MC4202

\begin{tabular}{|c|c|c|c|c|c|c|}
\hline $\begin{array}{c}\text { Axial } \\
\text { position } \\
\text { from top } \\
(\mathrm{mm})\end{array}$ & \multicolumn{2}{|c|}{ Cycle 03/2010 } & \multicolumn{2}{c|}{ Cycle 04/2010 } & \multicolumn{2}{c|}{ Cycle 05/2010 } \\
\cline { 2 - 7 } & BOC - Day7 & Day7 - EOC & BOC - Day7 & Day7 - EOC & BOC - Day10 & Day10 - EOC \\
\hline 0 & 75 & 79 & 64 & 68 & 86 & 83 \\
\hline 45 & 93 & 97 & 89 & 83 & 105 & 106 \\
\hline 90 & 118 & 120 & 112 & 106 & 133 & 133 \\
\hline 134 & 151 & 143 & 116 & 132 & 172 & 162 \\
\hline 179 & 178 & 181 & 160 & 154 & 204 & 187 \\
\hline 224 & 208 & 207 & 179 & 177 & 222 & 220 \\
\hline 269 & 248 & 242 & 198 & 200 & 268 & 235 \\
\hline 314 & 283 & 276 & 212 & 222 & 281 & 267 \\
\hline 359 & 325 & 314 & 257 & 253 & 299 & 274 \\
\hline 403 & 366 & 343 & 277 & 276 & 301 & 275 \\
\hline 448 & 392 & 370 & 312 & 297 & 306 & 272 \\
\hline 493 & 394 & 393 & 313 & 293 & 292 & 269 \\
\hline 538 & 396 & 382 & 319 & 296 & 288 & 267 \\
\hline 583 & 374 & 367 & 296 & 289 & 276 & 259 \\
\hline 628 & 346 & 337 & 306 & 281 & 251 & 255 \\
\hline 672 & 300 & 301 & 230 & 247 & 239 & 231 \\
\hline 717 & 257 & 257 & 231 & 210 & 195 & 202 \\
\hline 762 & 216 & 213 & 182 & 187 & 177 & 186 \\
\hline
\end{tabular}




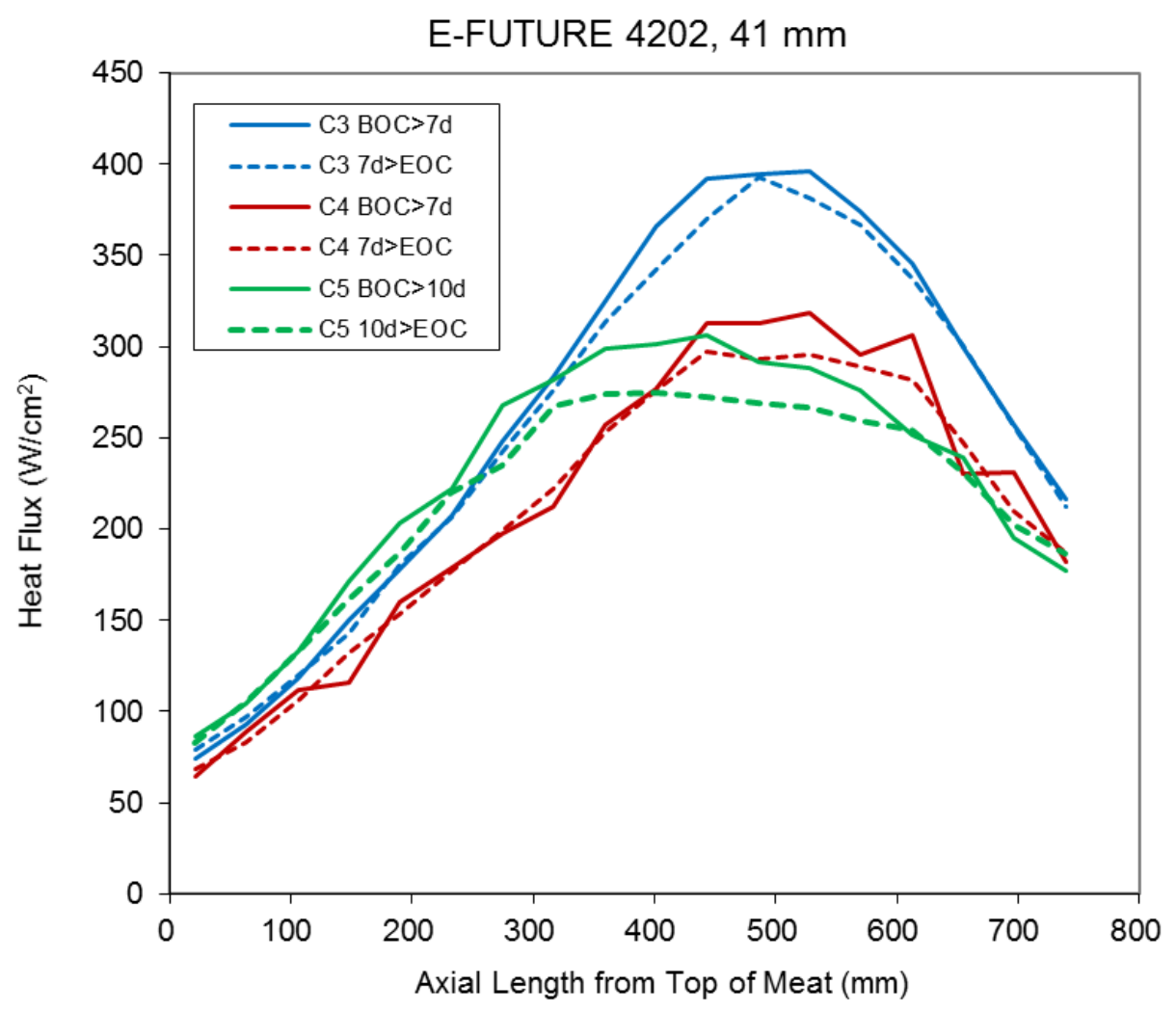

Figure 9 Axial power distribution of the fuel plate 4202 of the E-FUTURE experiment 
Table 5 Axial heat flux distributions, q" $\left(\mathrm{W} / \mathrm{cm}^{2}\right)$, on the cooling surface of the E-FUTURE plate U7MC6301

\begin{tabular}{|c|c|c|c|c|c|c|}
\hline $\begin{array}{c}\text { Axial } \\
\text { position } \\
\text { from top } \\
(\mathrm{mm})\end{array}$ & \multicolumn{2}{|c|}{ Cycle 03/2010 } & \multicolumn{2}{c|}{ Cycle 04/2010 } & \multicolumn{2}{c|}{ Cycle 05/2010 } \\
\cline { 2 - 7 } & BOC - Day7 & Day7 - EOC & BOC - Day7 & Day7 - EOC & BOC - Day10 & Day10 - EOC \\
\hline 0 & 72 & 68 & 60 & 63 & 77 & 80 \\
\hline 45 & 88 & 85 & 72 & 80 & 102 & 103 \\
\hline 90 & 111 & 111 & 98 & 97 & 125 & 120 \\
\hline 134 & 139 & 136 & 124 & 121 & 152 & 153 \\
\hline 179 & 165 & 161 & 146 & 140 & 186 & 173 \\
\hline 224 & 191 & 187 & 160 & 158 & 231 & 212 \\
\hline 269 & 225 & 210 & 194 & 186 & 255 & 242 \\
\hline 314 & 270 & 263 & 202 & 214 & 286 & 266 \\
\hline 359 & 323 & 301 & 276 & 239 & 298 & 277 \\
\hline 403 & 370 & 340 & 279 & 272 & 311 & 280 \\
\hline 448 & 403 & 370 & 311 & 295 & 296 & 278 \\
\hline 493 & 419 & 388 & 325 & 299 & 308 & 280 \\
\hline 538 & 411 & 385 & 327 & 306 & 287 & 273 \\
\hline 583 & 396 & 360 & 306 & 292 & 276 & 268 \\
\hline 628 & 359 & 338 & 312 & 276 & 254 & 252 \\
\hline 672 & 314 & 301 & 233 & 249 & 245 & 236 \\
\hline 717 & 267 & 256 & 229 & 216 & 201 & 210 \\
\hline 762 & 223 & 216 & 177 & 181 & 178 & 179 \\
\hline
\end{tabular}




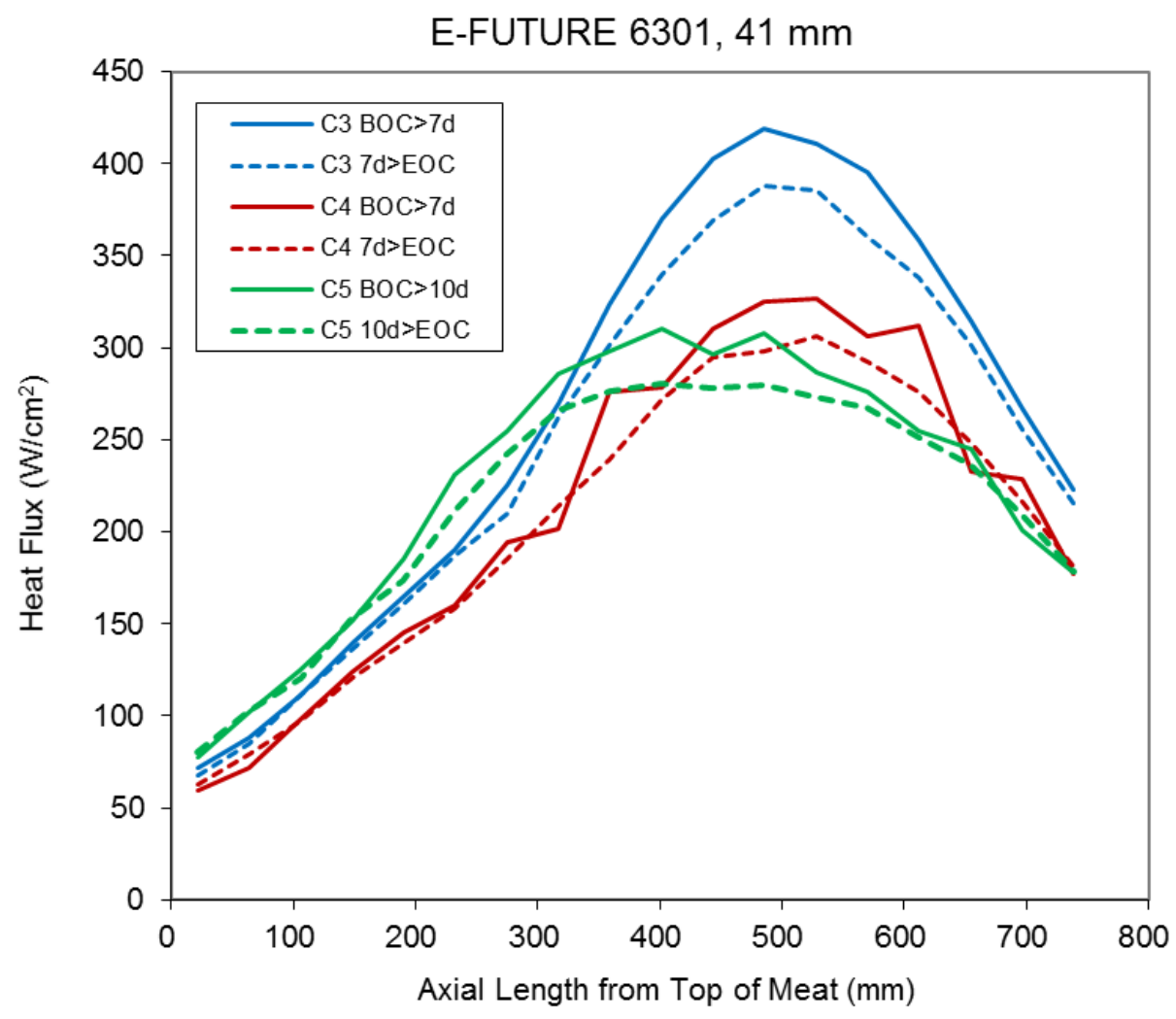

Figure 10 Axial power distribution of the fuel plate 6301 of the E-FUTURE experiment 
Power distribution data for the SELENIUM test were available from [6]. The cycle-by-cycle axial power distribution along the axial line measured $41 \mathrm{~mm}$ from the peak power side (see Figure 3) for the U7MD1221 fuel plate of SELENIUM test is given in Table 6 and Figure 12. The maximum power at BOC of the first cycle was close to $470 \mathrm{~W} / \mathrm{m}^{2}$. The plate average and local peak burnups were $48 \%$ (LEU equivalent) and slightly lower than $70 \%$ (LEU equivalent), respectively.

Table 6 Axial heat flux distributions, $\mathrm{q}^{\prime \prime}\left(\mathrm{W} / \mathrm{cm}^{2}\right)$, on the cooling surface of the SELENIUM plate U7MD1221

\begin{tabular}{|c|c|c|c|c|c|c|c|c|c|}
\hline $\begin{array}{c}\text { Axial } \\
\text { position } \\
\text { from } \\
\text { top } \\
(\mathrm{mm})\end{array}$ & \multicolumn{3}{|c|}{ Cycle 02/2012 } & \multicolumn{3}{c|}{ Cycle 03/2012 } & \multicolumn{3}{c|}{ Cycle 04/2012 } \\
\cline { 2 - 11 } & BOC & Day6 & EOC & BOC & Day6 & EOC & BOC & Day6 & EOC \\
\hline 0 & 72 & 69 & 99 & 101 & 86 & 125 & 82 & 79 & 123 \\
\hline 45 & 90 & 79 & 122 & 124 & 113 & 161 & 94 & 93 & 158 \\
\hline 90 & 107 & 117 & 163 & 168 & 140 & 198 & 126 & 122 & 183 \\
\hline 134 & 145 & 137 & 213 & 200 & 159 & 242 & 150 & 140 & 219 \\
\hline 179 & 169 & 165 & 246 & 254 & 198 & 280 & 167 & 164 & 238 \\
\hline 224 & 218 & 200 & 286 & 286 & 221 & 301 & 190 & 178 & 248 \\
\hline 269 & 263 & 231 & 308 & 336 & 246 & 319 & 227 & 207 & 241 \\
\hline 314 & 308 & 271 & 329 & 358 & 283 & 332 & 262 & 222 & 241 \\
\hline 359 & 344 & 301 & 340 & 371 & 315 & 328 & 272 & 259 & 230 \\
\hline 403 & 381 & 357 & 342 & 366 & 352 & 320 & 272 & 265 & 215 \\
\hline 448 & 402 & 372 & 348 & 374 & 373 & 303 & 286 & 263 & 209 \\
\hline 493 & 407 & 375 & 343 & 366 & 370 & 316 & 281 & 261 & 204 \\
\hline 538 & 393 & 359 & 325 & 360 & 359 & 304 & 282 & 270 & 197 \\
\hline 583 & 393 & 337 & 307 & 331 & 343 & 300 & 275 & 274 & 195 \\
\hline 628 & 352 & 320 & 287 & 309 & 321 & 285 & 256 & 258 & 198 \\
\hline 672 & 313 & 279 & 246 & 263 & 294 & 261 & 243 & 235 & 184 \\
\hline 717 & 252 & 228 & 217 & 215 & 245 & 229 & 213 & 213 & 175 \\
\hline 762 & 217 & 197 & 181 & 188 & 210 & 207 & 189 & 177 & 148 \\
\hline
\end{tabular}




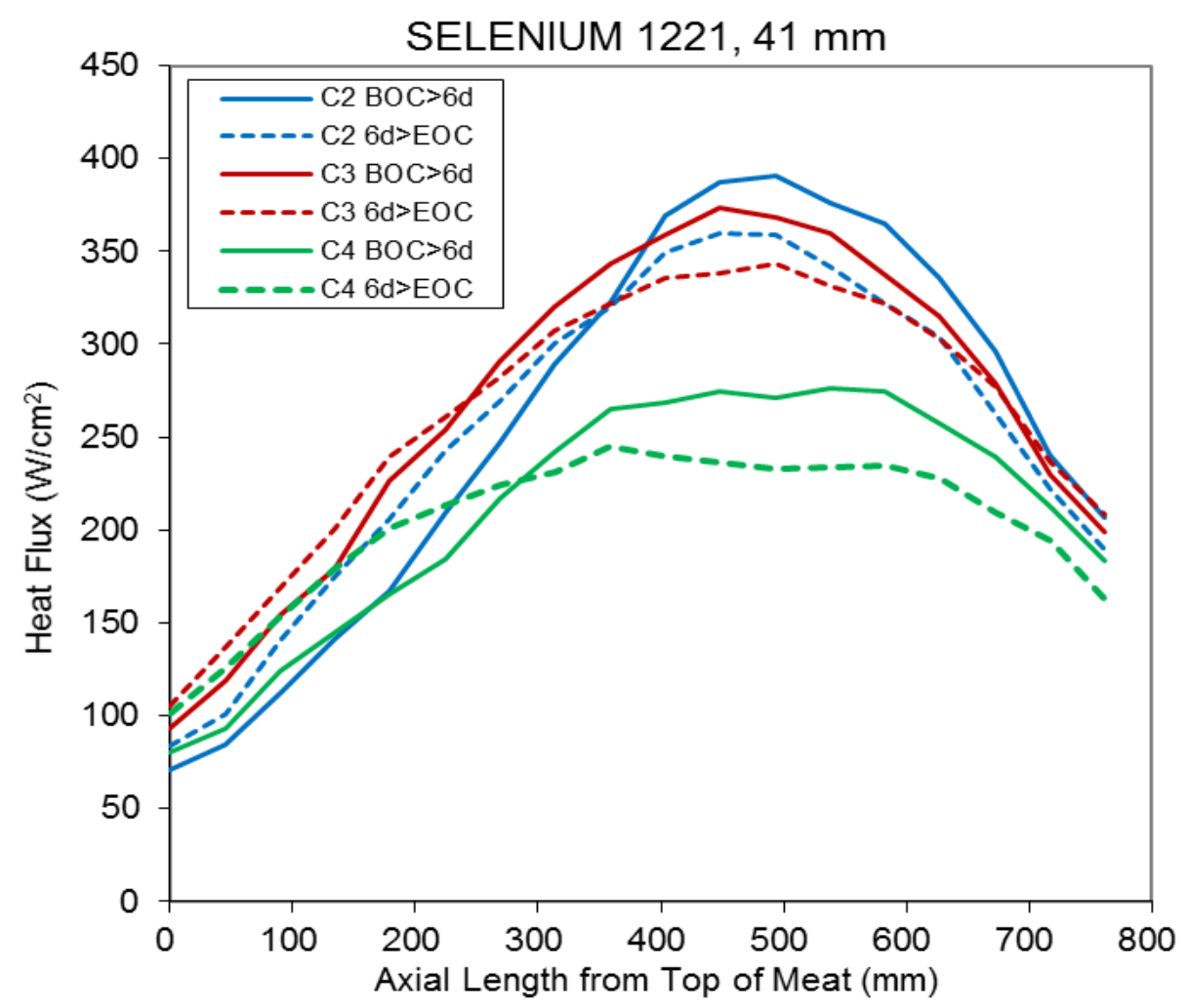

Figure 11 Axial power distribution of the fuel plate 1221 of the SELENIUM experiment 


\subsection{Correlations for Heat Transfer at Cladding Surface}

All of the experiments examined in this study had fluid velocity in the turbulent regime. Convection is, therefore, the dominant mode of heat transfer. Applying Newton's law of cooling, the cladding surface temperature is expressed by

$$
T_{w}=T_{b}+\frac{q}{h a}
$$

where $T_{b}$ is the bulk fluid temperature in $\mathrm{K}, q$ is the thermal power in $\mathrm{W}, h$ is the heat transfer coefficient in $\mathrm{W} /\left(\mathrm{m}^{2}-\mathrm{K}\right)$ and $a$ is the heated surface area in $\mathrm{m}^{2}$. All values can be explicitly inputted in Eq.(13) to calculate the surface temperature for a particular set of appropriate boundary conditions. Four correlations are most frequently used to calculate heat transfer coefficient in plate type geometry. This group includes the Dittus-Boelter correlation [10], the Sieder-Tate correlation [11], the Colburn correlation [12], and KAERI correlation [13] as listed below.

The Dittus-Boelter correlation is

$$
N u_{D B}=\frac{h D_{e}}{k}=0.023 R e_{b}^{0.8} P r_{b}^{0.4}
$$

where $\mathrm{Nu}, \mathrm{Re}$ and $\mathrm{Pr}$ are the Nusselt, Reynolds and Prandtl numbers evaluated at the bulk coolant temperature $\left(T_{b}\right), D_{e}$ is the hydraulic diameter in $\mathrm{m}$, and $k$ is the coolant thermal conductivity in $\mathrm{W} /(\mathrm{m} \mathrm{K})$.

The Sieder-Tate correlation is

$$
N u_{S T}=0.027 \operatorname{Re}_{b}^{0.8} \operatorname{Pr}_{b}^{1 / 3}\left(\frac{\mu_{b}}{\mu_{w}}\right)^{0.14}
$$

where $\mu_{b}$ and $\mu_{w}$ are the dynamic fluid viscosities in N-s $/ \mathrm{m}^{2}$ evaluated at the bulk coolant and cladding surface temperatures.

The Colburn correlation is

$$
N u_{C B}=0.023 R e_{f}^{0.8} P r_{f}^{0.3}
$$

where subscript $f$ means the film temperature. The film temperature is the arithmetic mean of the bulk fluid and cladding surface temperatures.

The KAERI correlation is 


$$
N u_{K A}=0.0058 R e_{b}^{0.9383} P r_{b}^{0.4}
$$

The Dittus-Boelter correlation is recommended specifically for a situation in which the difference between cladding surface and fluid temperatures is small. On the other hand, the Sieder and Tate correlation is suitable for a condition that has a large temperature difference between cladding surface and fluid temperatures because it is capable of explicitly incorporate the viscosities of the fluid at bulk fluid and cladding surface temperatures. The Colburn correlation is similar to the Dittus-Boelter correlation while it is different in that it considers the fluid properties at the film temperature, $T_{f}$. The KAERI correlation was recently developed based on experimental data measured for a rectangular channel, simulating the coolant channel of a plate type fuel.

\subsection{Cladding Surface Temperature}

The test plates were irradiated over three reactor cycles. The axial power (or heat flux) distributions available from core physics calculations were used to calculate plate surface temperatures and coolant temperatures as shown in Figure 8 - Figure 11.

In order to account for the changes in heat flux during a cycle, the total irradiation time was divided into time intervals consistent with those used in the physics calculation. The local power during a time interval was converted to local heat flux to calculate surface temperature. The plate surface temperatures along the line passing through the peak oxide thickness location, which was $41 \mathrm{~mm}$ off from the higher power edge of the plate, were calculated.

The four models discussed in sect. 5.2 were employed to calculate heat transfer coefficients. In order to compare the heat transfer correlations, the calculated Nusselt number and surface temperature along the plate length of the E-FUTURE 6301 plate are plotted in Figure 14.

The Dittus-Boelter correlation gave the highest cladding surface temperature. This result may be attributed to the model's inability to account for the difference in fluid viscosity at the cladding surface compared to the bulk coolant [14]. The difference in the maximum cladding surface temperature at axial length of $\sim 500 \mathrm{~mm}$ between the predictions by the Dittus-Boelter and KAERI correlations was $\sim 30{ }^{\circ} \mathrm{C}$. The axial surface temperature was calculated using a program developed at KAERI (Thermal Hydraulic Margin Calculator for Plate-type Fueled Reactor Core for Windows) [15]. 


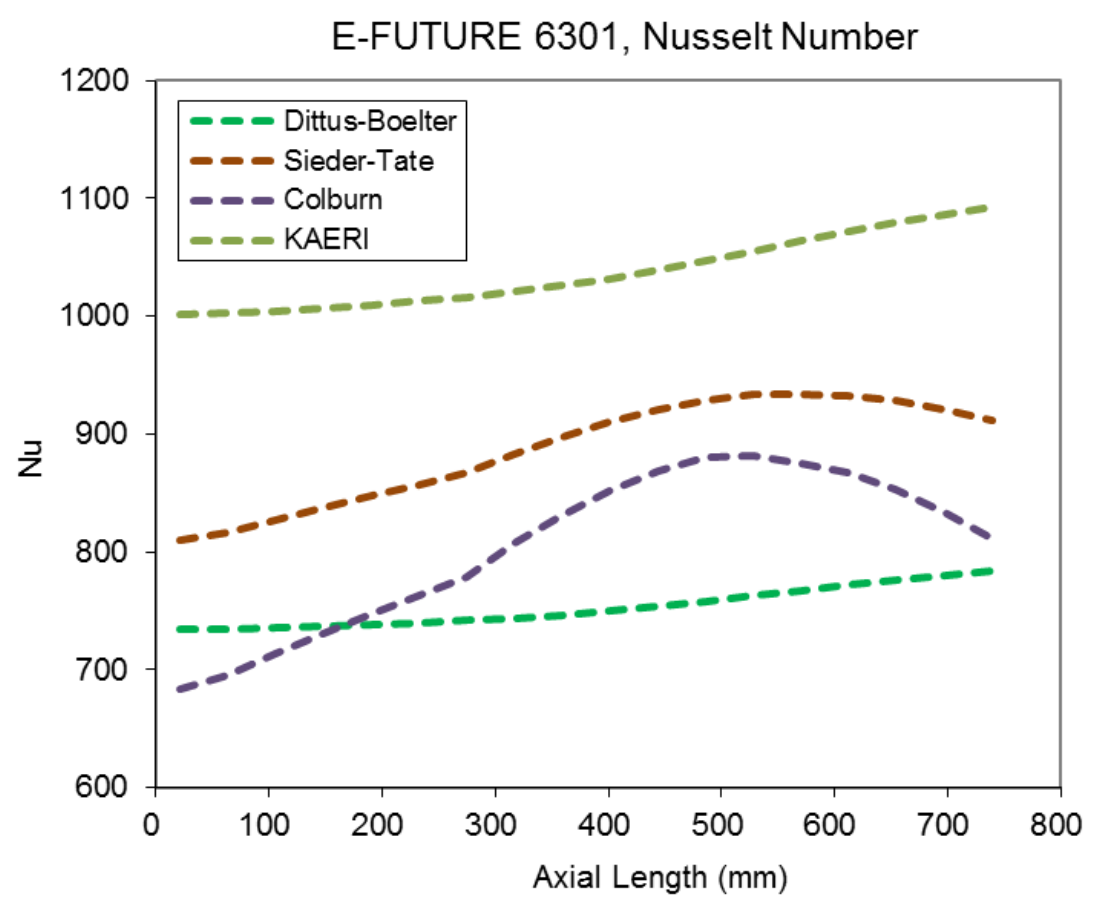

a) Nusselt number

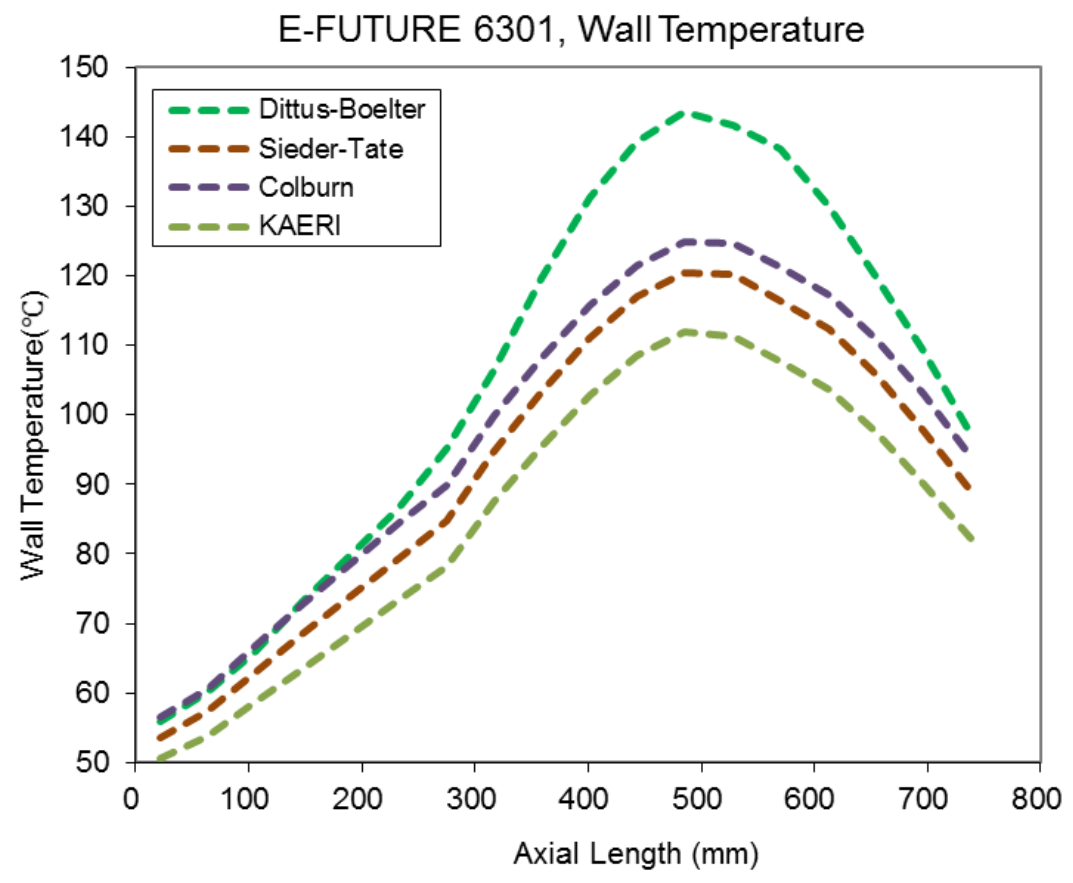

b) Cladding surface temperature

Figure 12 Comparisons of Nusselt number and cladding surface temperature between heat transfer correlations for the E-FUTURE 6301 plate 


\section{Section 6 Oxide Prediction and Model Revision}

\subsection{Model Comparison and Effect of Heat Transfer Coefficient}

The three oxide prediction models described in sect. 4, i.e., the Kim model, the original Griess correlation and the modified Griess correlation were employed to calculate oxide thickness to investigate which correlation is most accurate for the test conditions at BR2.

Comparisons between the oxide prediction models and measured data for each heat transfer correlation are given in Figure 15 - Figure 16. The experimental data of the figures are those obtained by averaging over the length of $10 \mathrm{~mm}$ from the oxide thickness data measured and reported with a $1-\mathrm{mm}$ interval. The measured oxide data were reported for 10 parallel lines along the plate axial length 5-mm apart from each other as shown in Figure 4 - Figure 6. Among these data, the data for the line $41 \mathrm{~mm}$ from the cold edge of the plate was selected because this line runs through the peak oxide thickness region near $500 \mathrm{~mm}$ from the top of the fuel meat.

As can be seen in the figures, the calculated oxide thickness varies substantially depending on the applied heat transfer correlation. In general, the Griess model predicts the highest of all heat transfer correlations, and over-predicted the experimental data. The oxide predictions by the Kim model coupled with the Dittus Boelter correlation diverged at the peak power location. Except for the E-FUTURE 4111 with the Dittus-Boelter correlation and Colburn correlation, the KAERI-modified Griess model predicted the lowest oxide thickness of the oxide growth correlations with all heat transfer correlations.

When coupled with the Colburn correlation or the Sieder-Tate correlation, the Kim model was consistent with the measured data. 


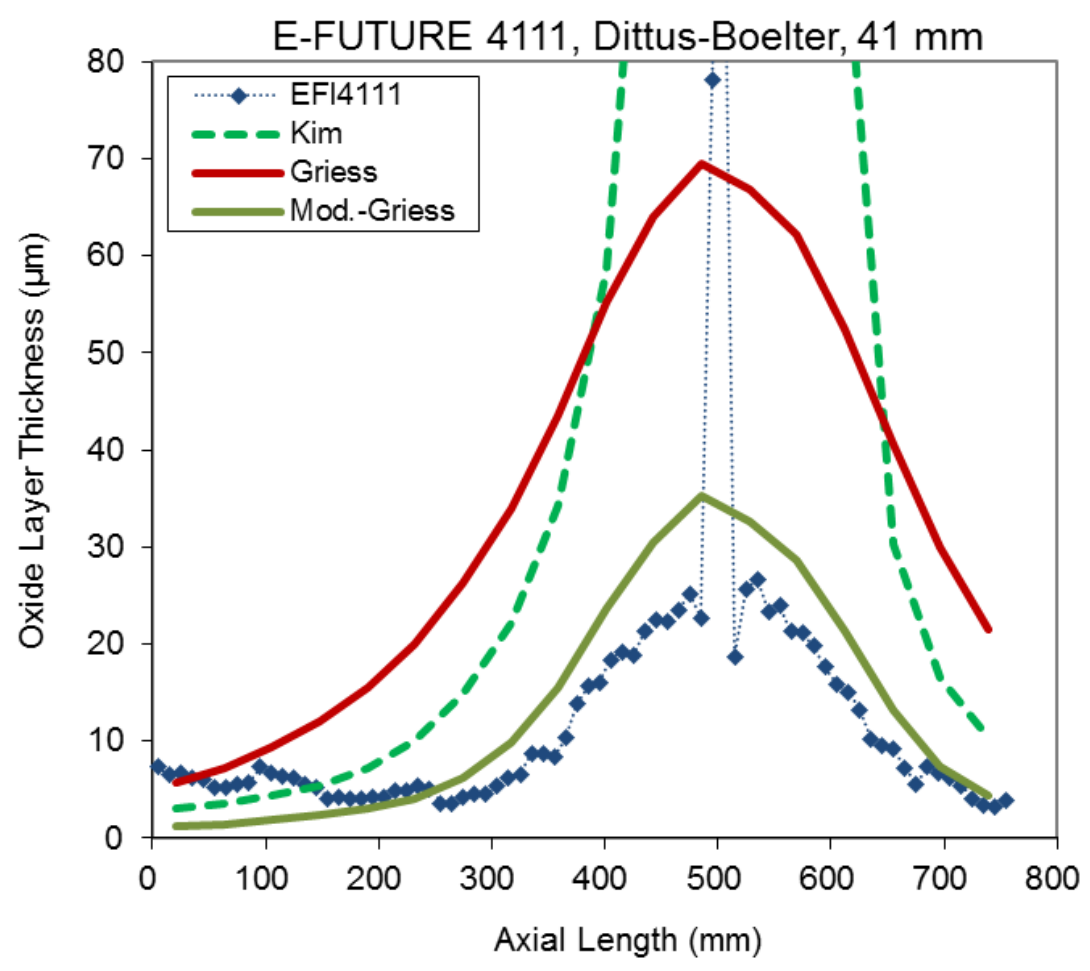

a) Heat transfer coefficient by Dittus-Boelter correlation

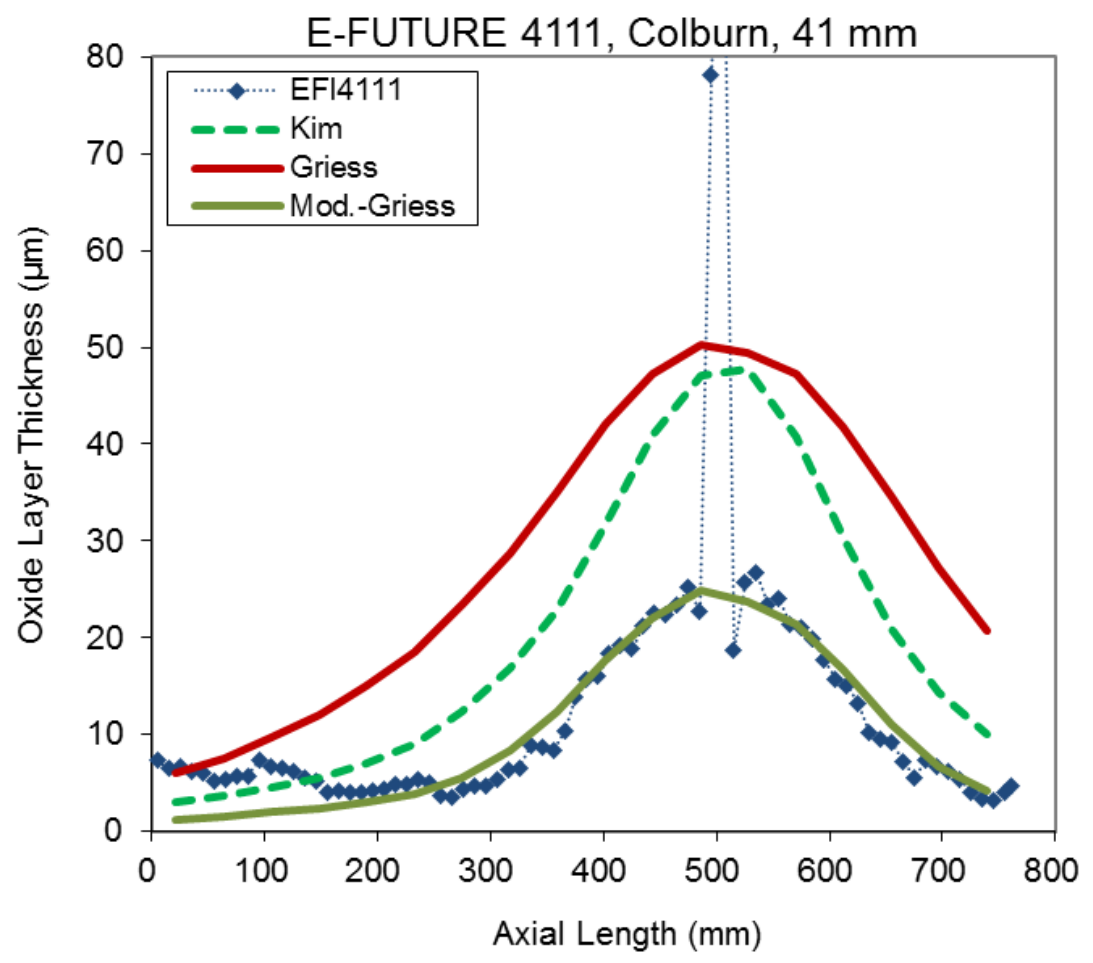

b) Heat transfer coefficient by Colburn correlation

Figure 13 Comparison of oxide thickness model predictions with measured data for fuel plate 4111 of the E-FUTURE experiment 


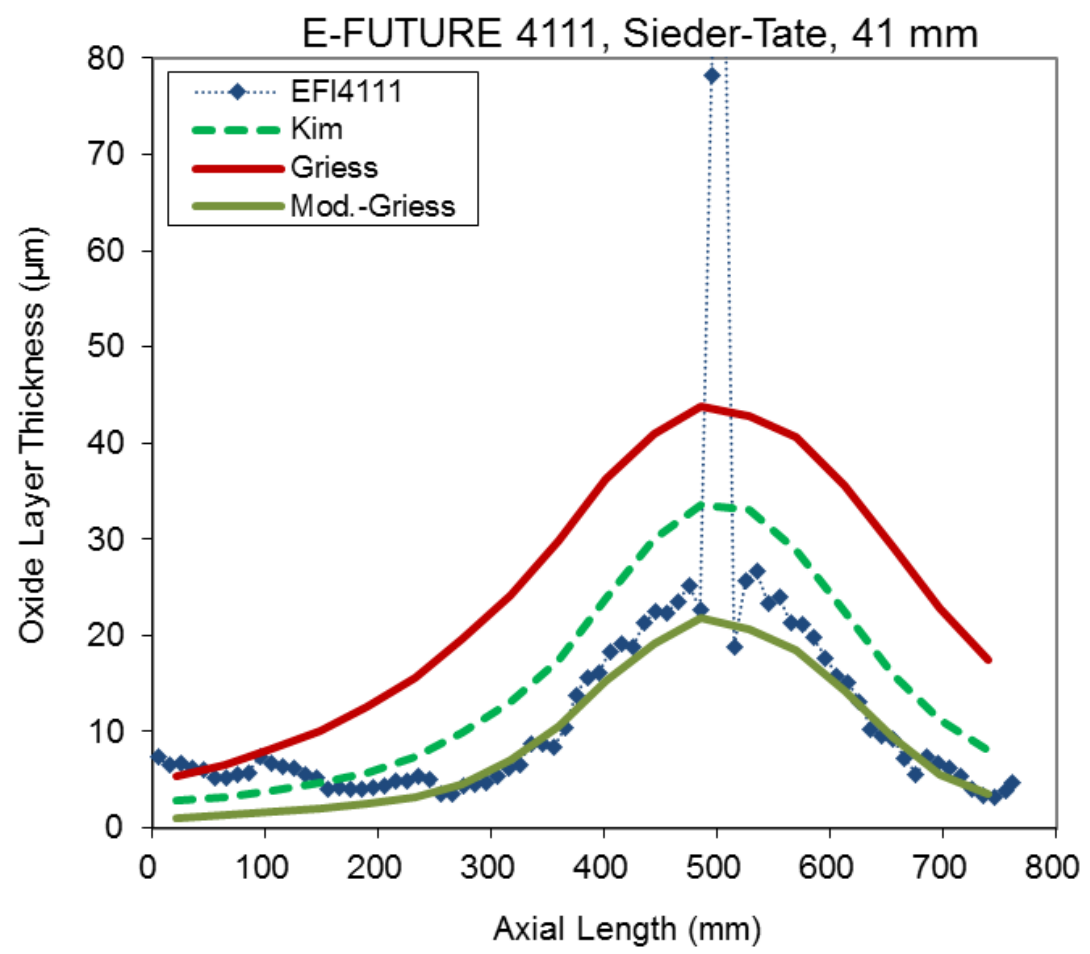

c) Heat transfer coefficient by Sieder-Tate correlation

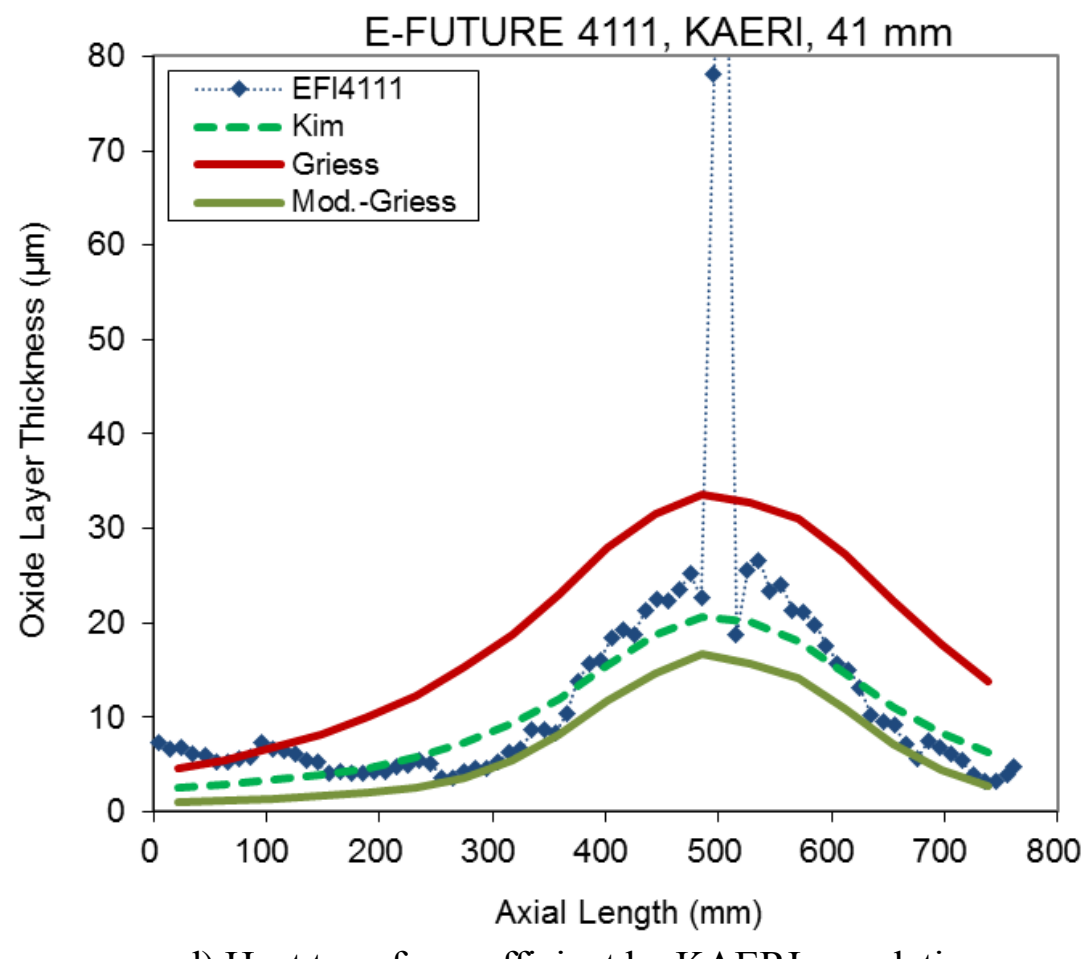

d) Heat transfer coefficient by KAERI correlation

Figure 15 Comparison of oxide thickness model predictions with measured data for fuel plate 4111 of the E-FUTURE experiment (continued) 


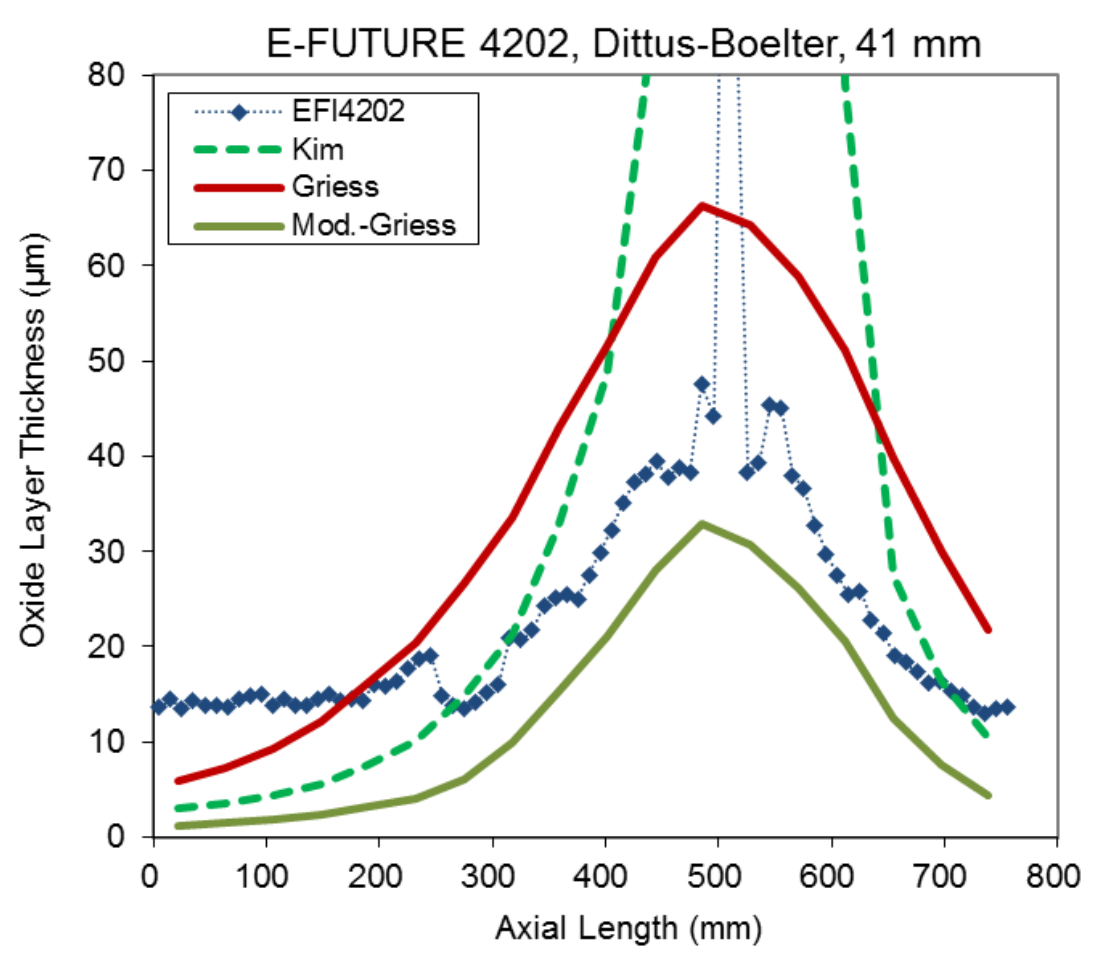

a) Heat transfer coefficient by Dittus-Boelter correlation

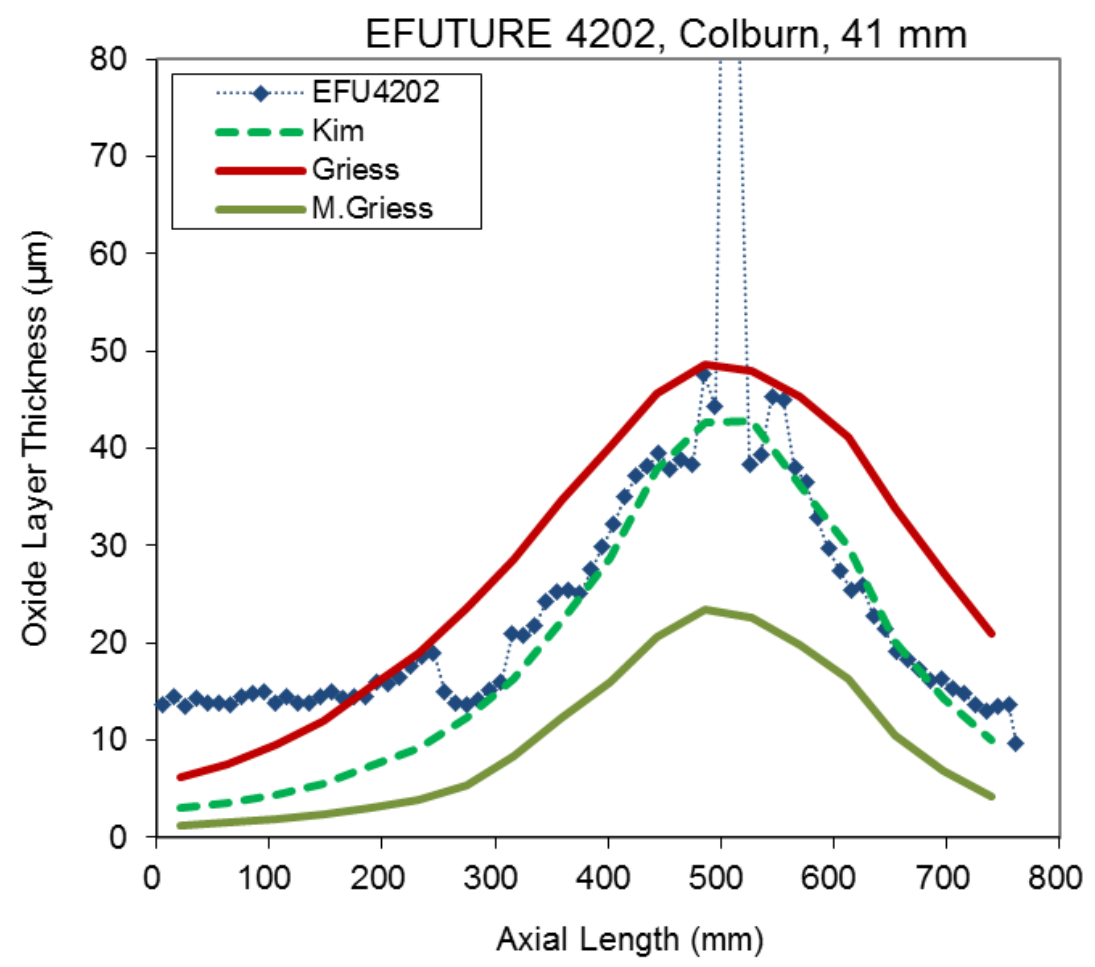

b) Heat transfer coefficient by Colburn correlation

Figure 14 Comparison of oxide thickness model predictions with measured data for fuel plate 4202 of the E-FUTURE experiment 


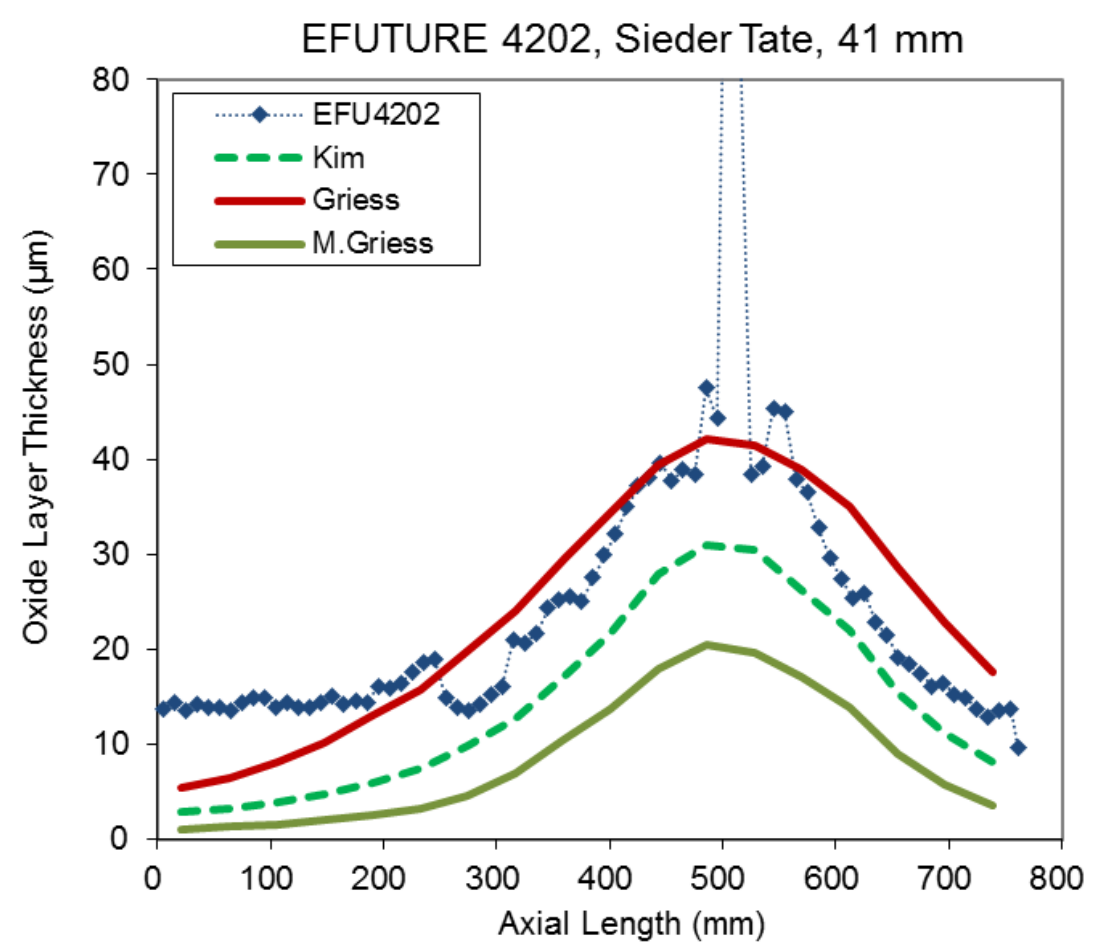

c) Heat transfer coefficient by Sieder-Tate correlation

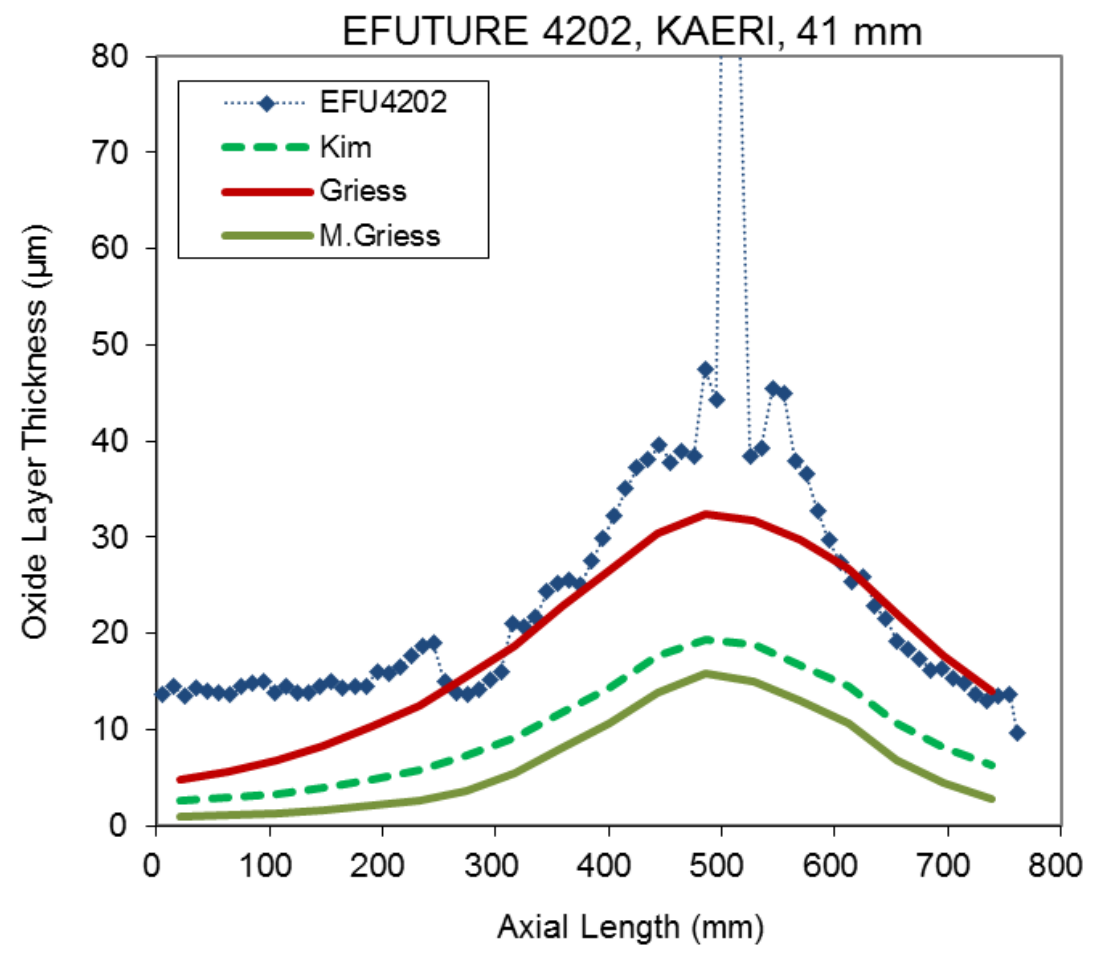

d) Heat transfer coefficient by KAERI correlation

Figure 16 Comparison of oxide thickness model predictions with measured data for fuel plate 4202 of the E-FUTURE experiment (continued) 


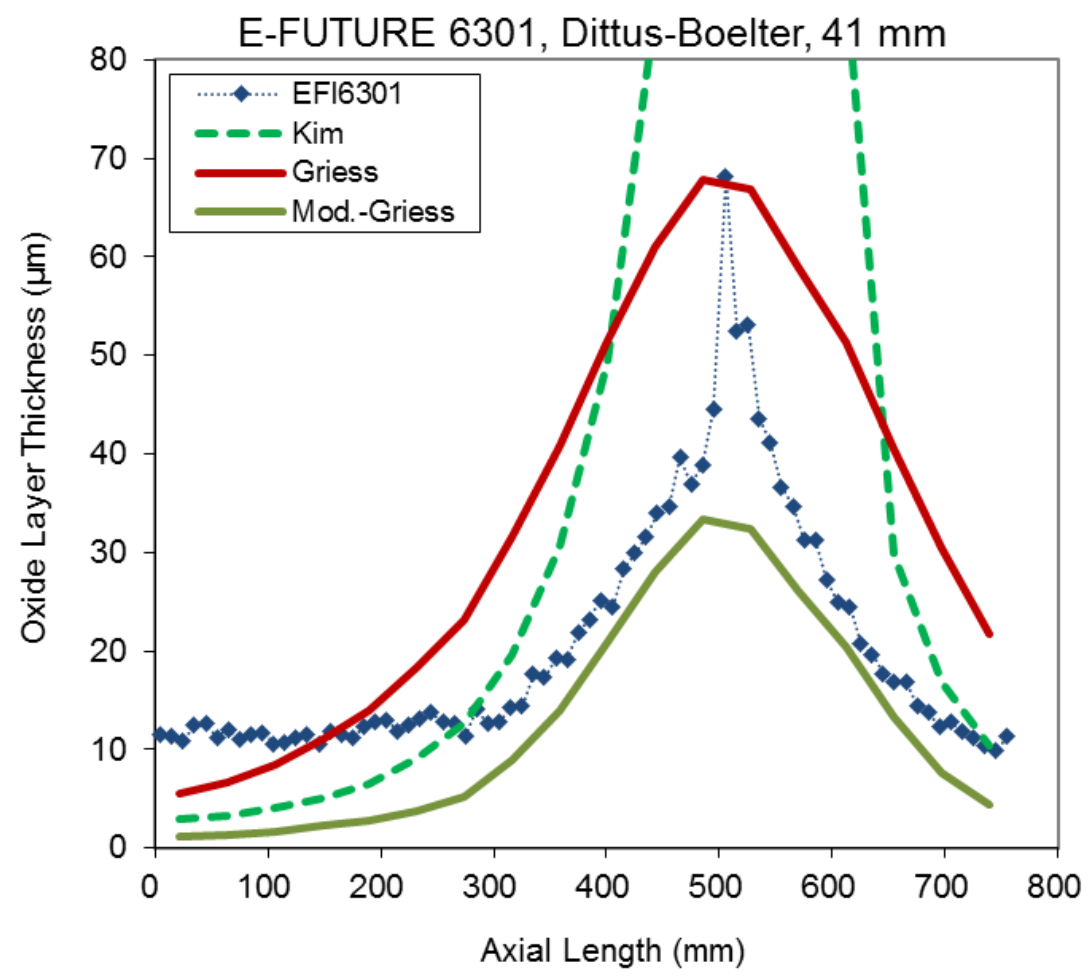

a) Heat transfer coefficient by Dittus-Boelter correlation

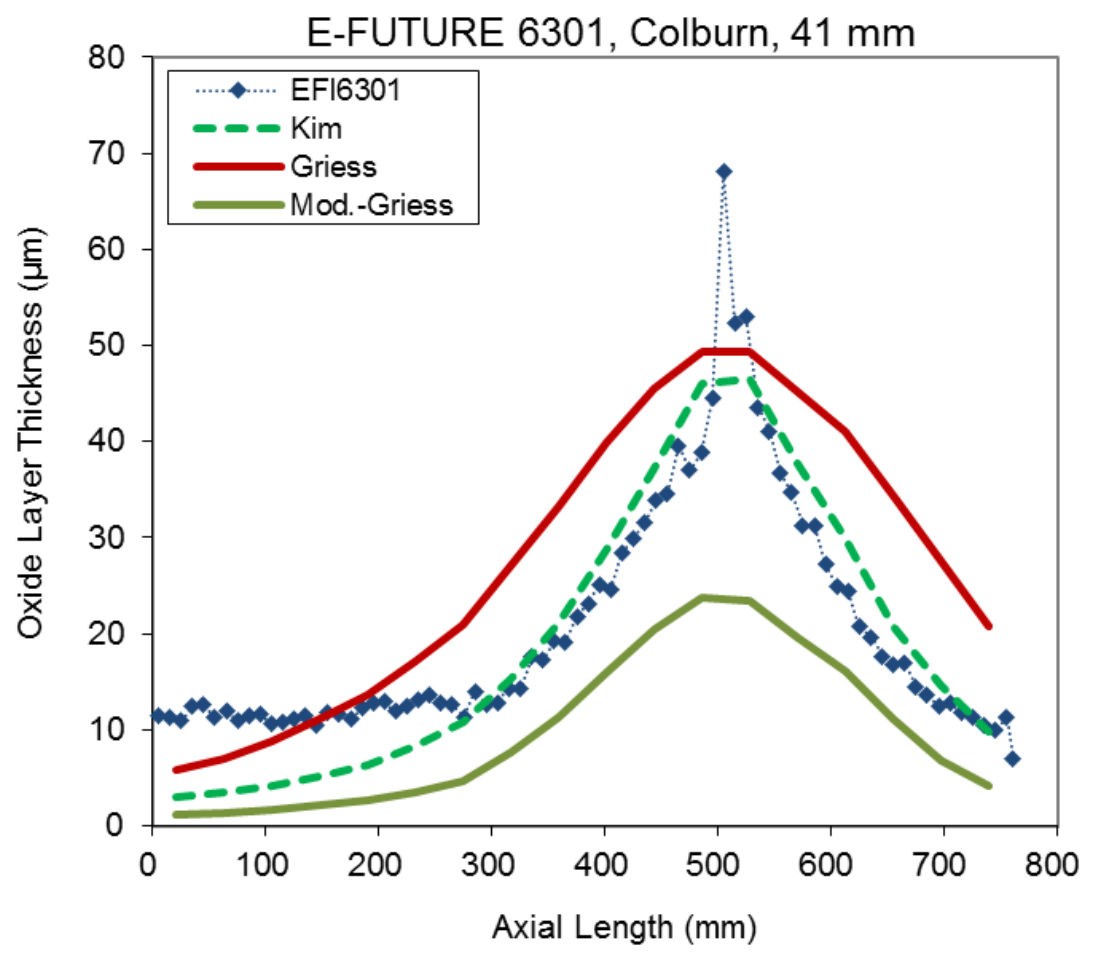

b) Heat transfer coefficient by Colburn correlation

Figure 15 Comparison of oxide thickness model predictions with measured data for fuel plate 6301 of the E-FUTURE experiment 


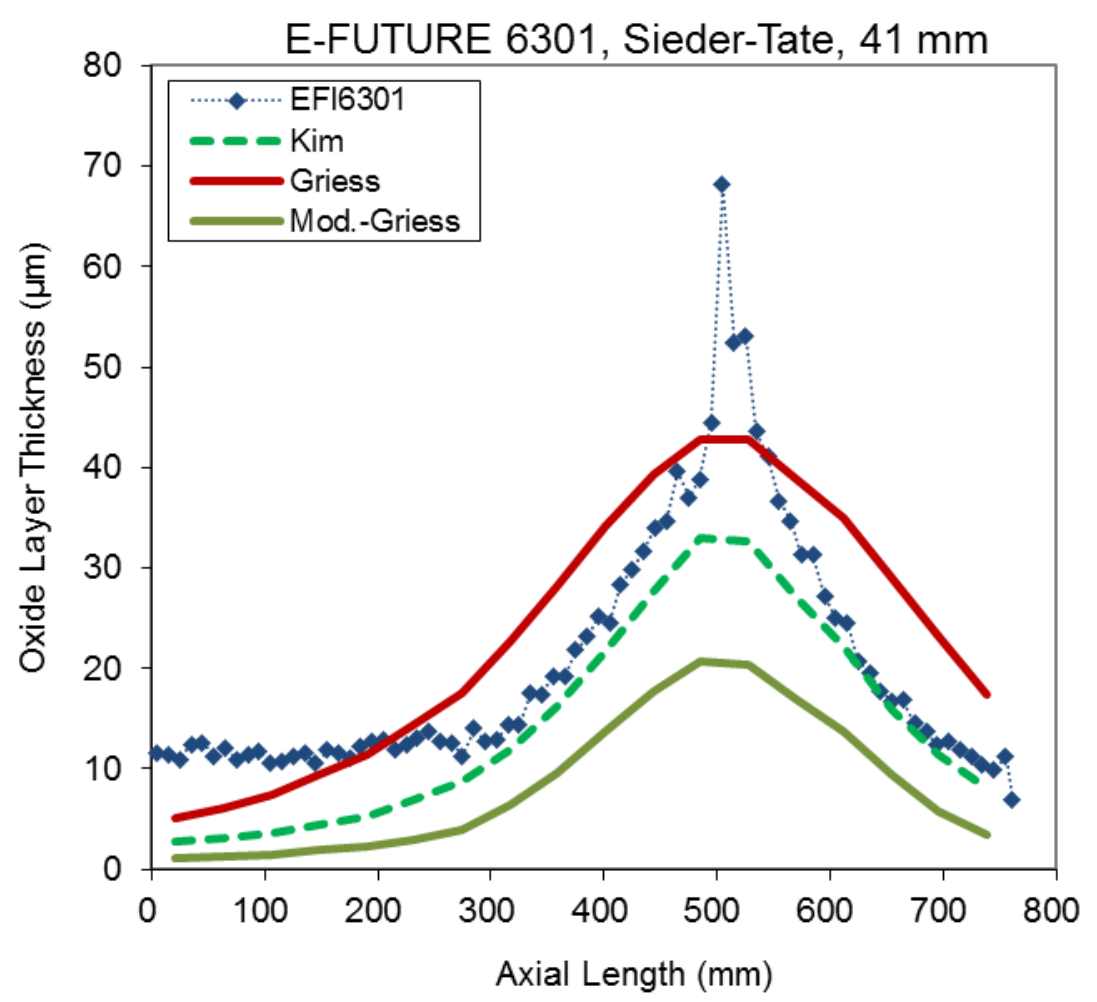

c) Heat transfer coefficient by Sieder-Tate correlation

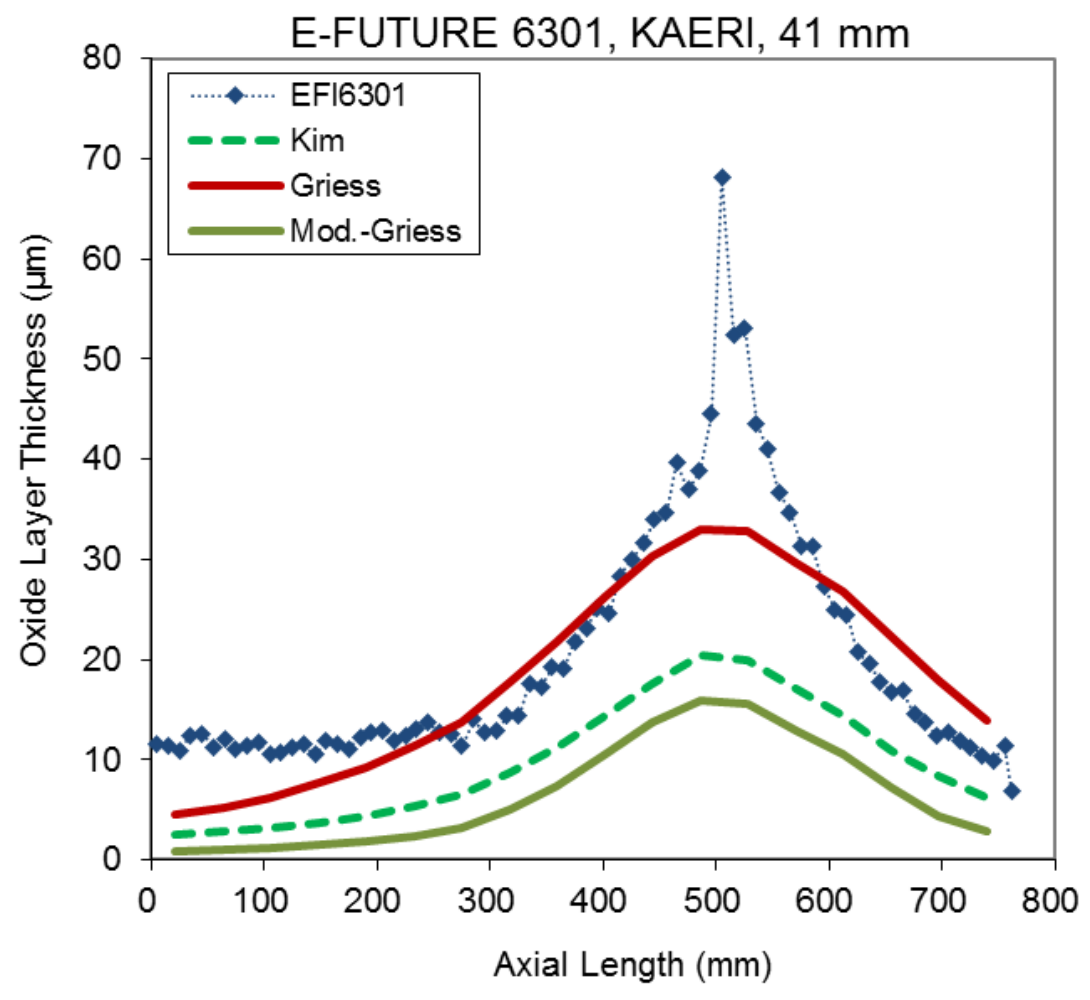

d) Heat transfer coefficient by KAERI correlation

Figure 17 Comparison of oxide thickness model predictions with measured data for fuel plate 6301 of the E-FUTURE experiment (continued) 


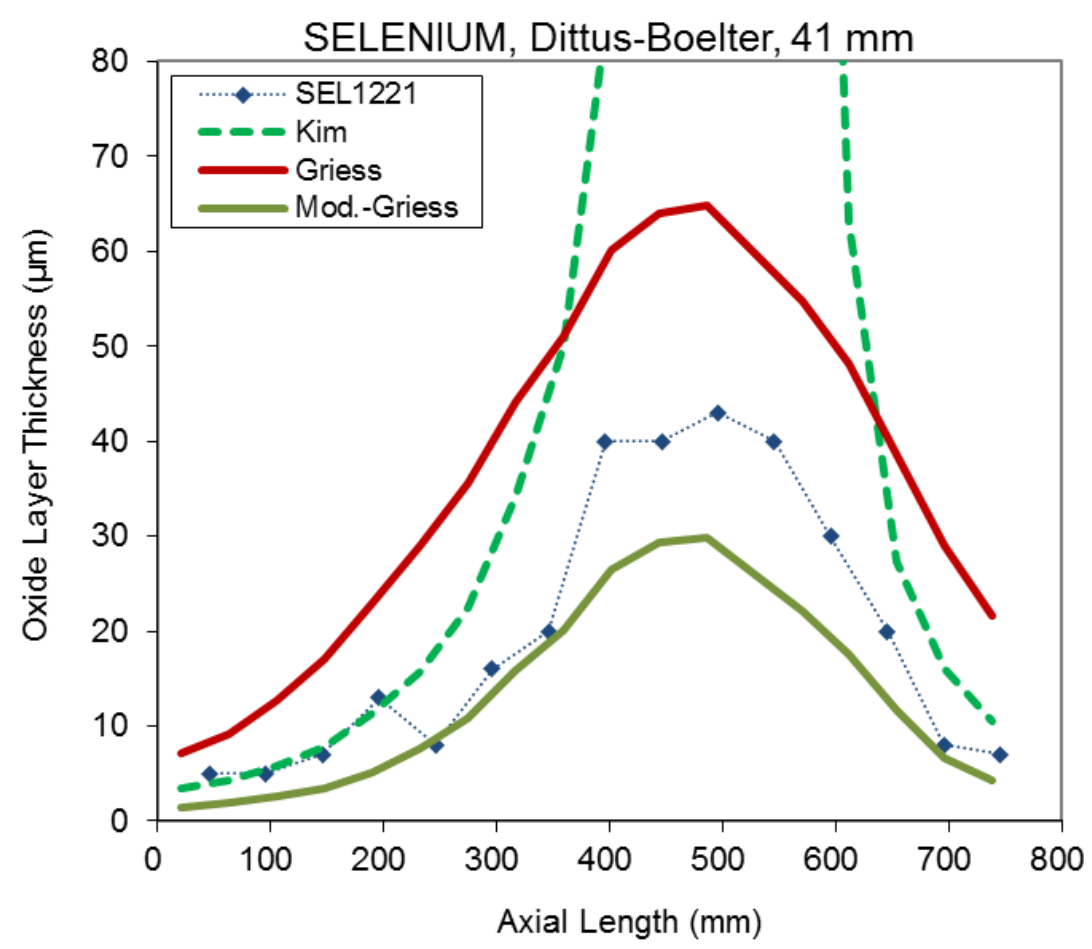

a) Heat transfer coefficient by Dittus-Boelter correlation

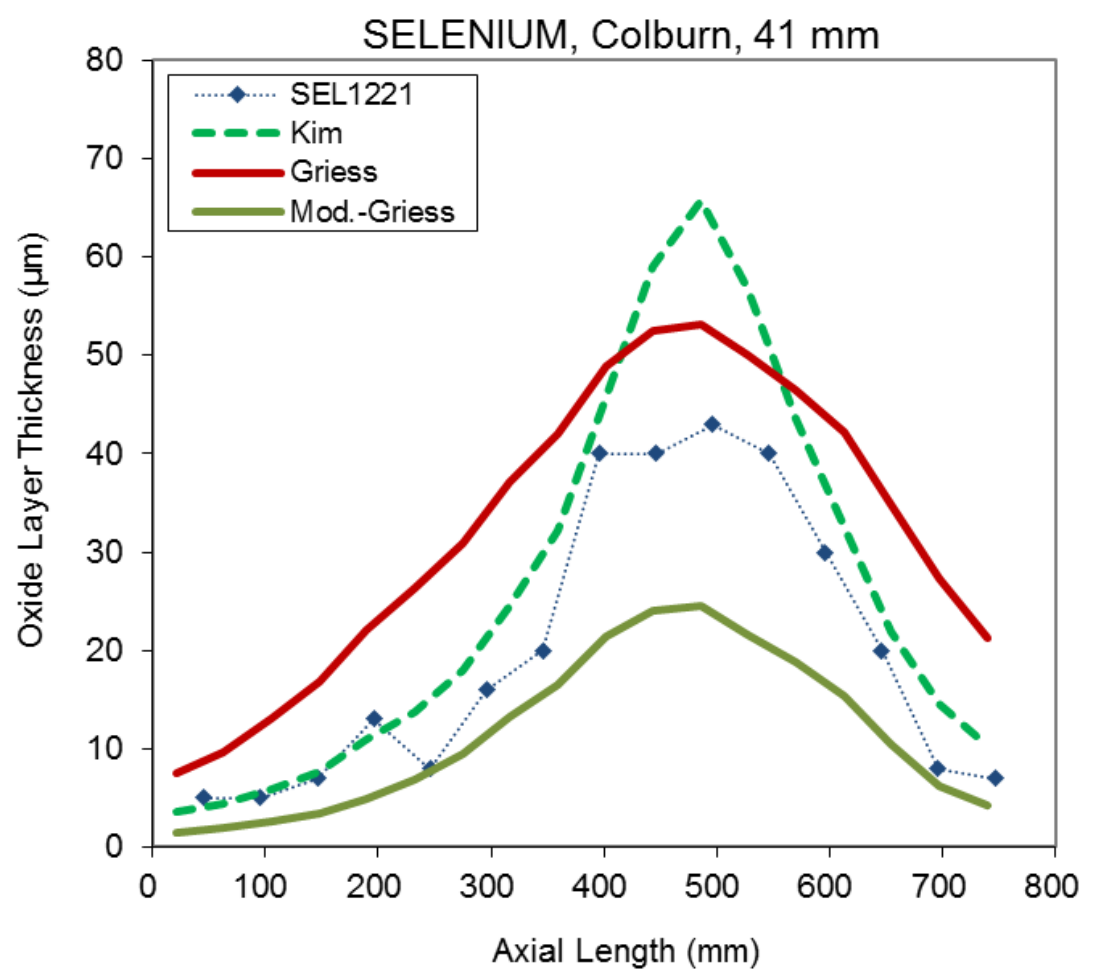

b) Heat transfer coefficient by Colburn correlation

Figure 16 Comparison of oxide thickness model predictions with measured data for fuel plate 1221 of the SELENIUM experiment 


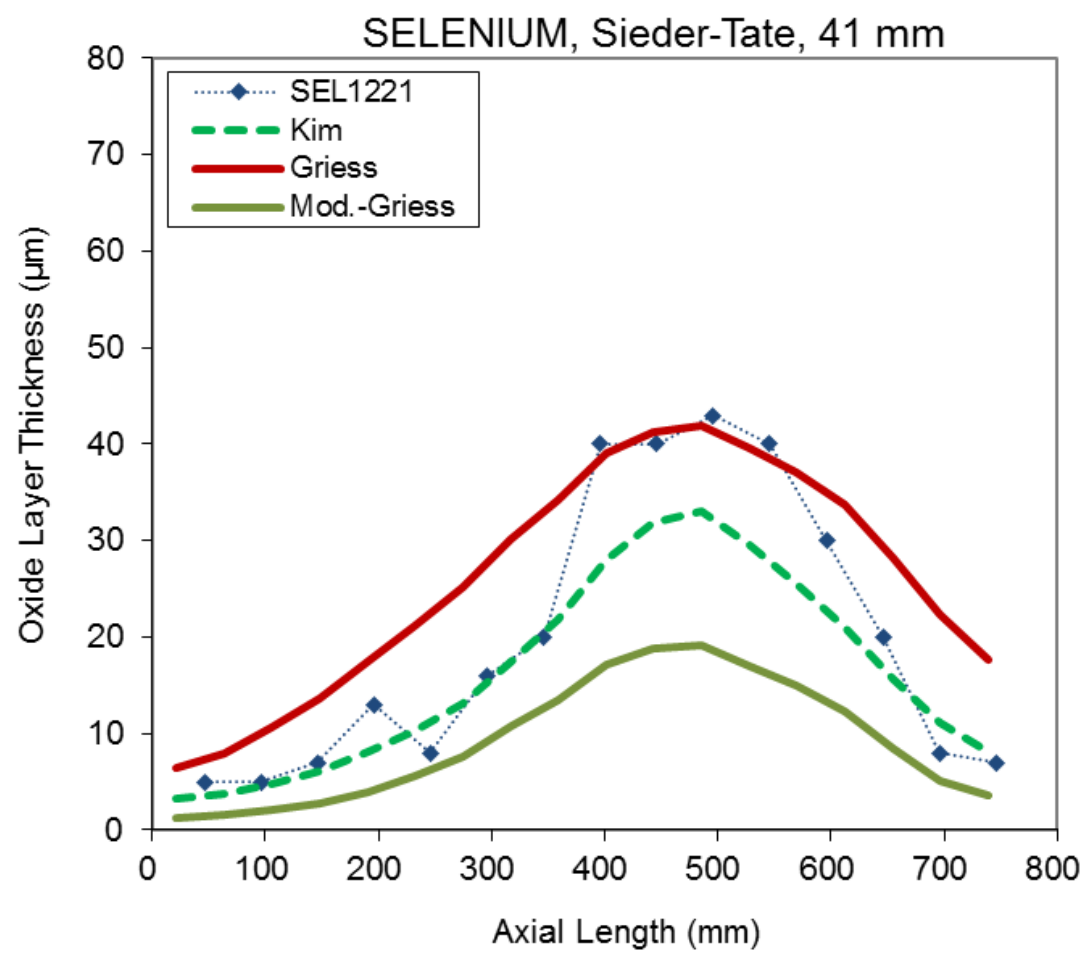

c) Heat transfer coefficient by Sieder-Tate correlation

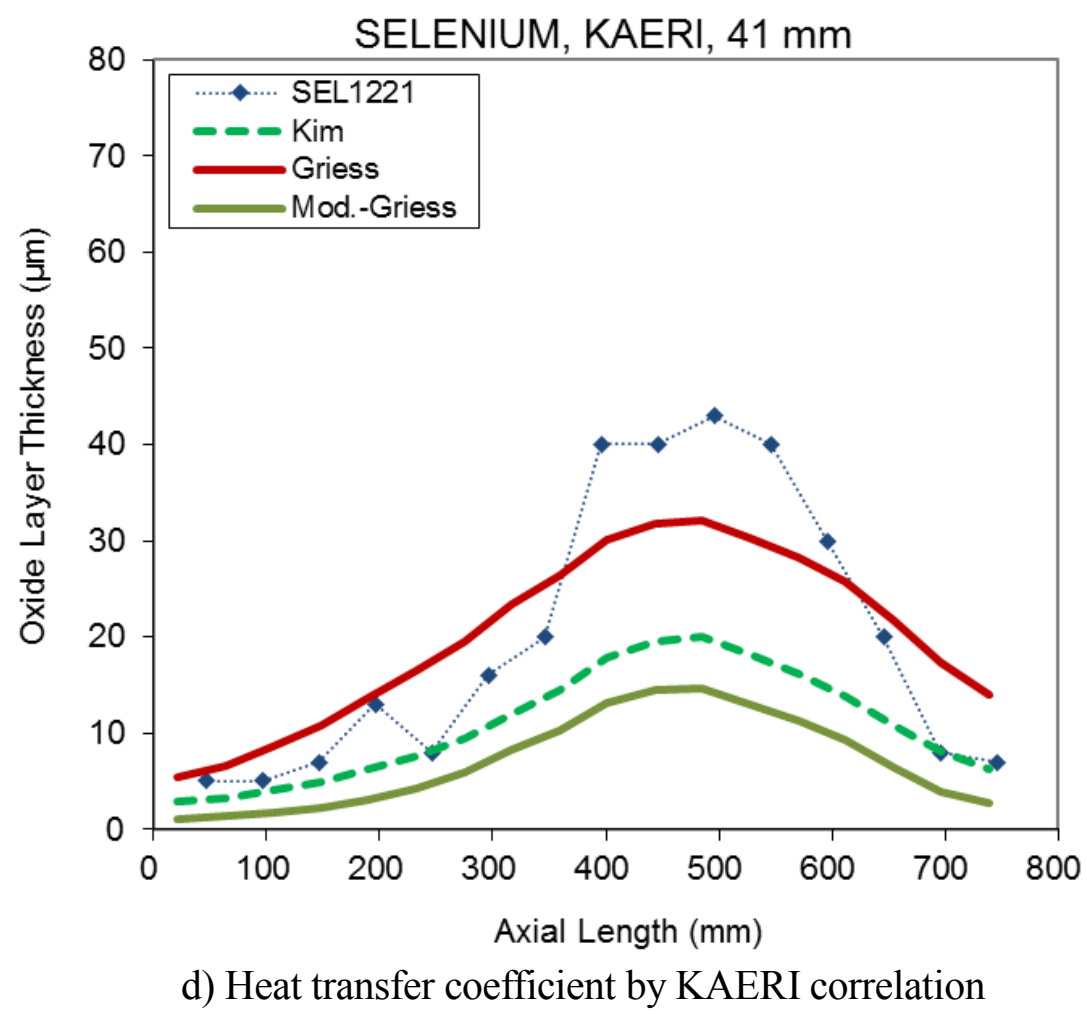

Figure 18 Comparison of oxide thickness model predictions with measured data for fuel plate 1221 of the SELENIUM experiment (continued) 


\subsection{Effect of Cladding Surface Temperature}

The cladding surface temperature was calculated using the four heat transfer coefficient correlations. The Kim model was applied for the E-FUTURE-4111, 4202, 6301, and SELENIUM experimental data to investigate the effect of cladding surface temperature on oxide prediction. The results are shown in Figure 19 - Figure 22.

When the correction constant B was set to 0.37 , the Dittus-Boelter correlation yielded a divergence in oxide thickness, whereas the Sieder-Tate and Colburn correlations gave reasonable results in general. This result shows that cladding surface temperature has a dominant effect on oxide growth, so the application of an accurate heat transfer correlation is critical for oxide thickness modeling. 


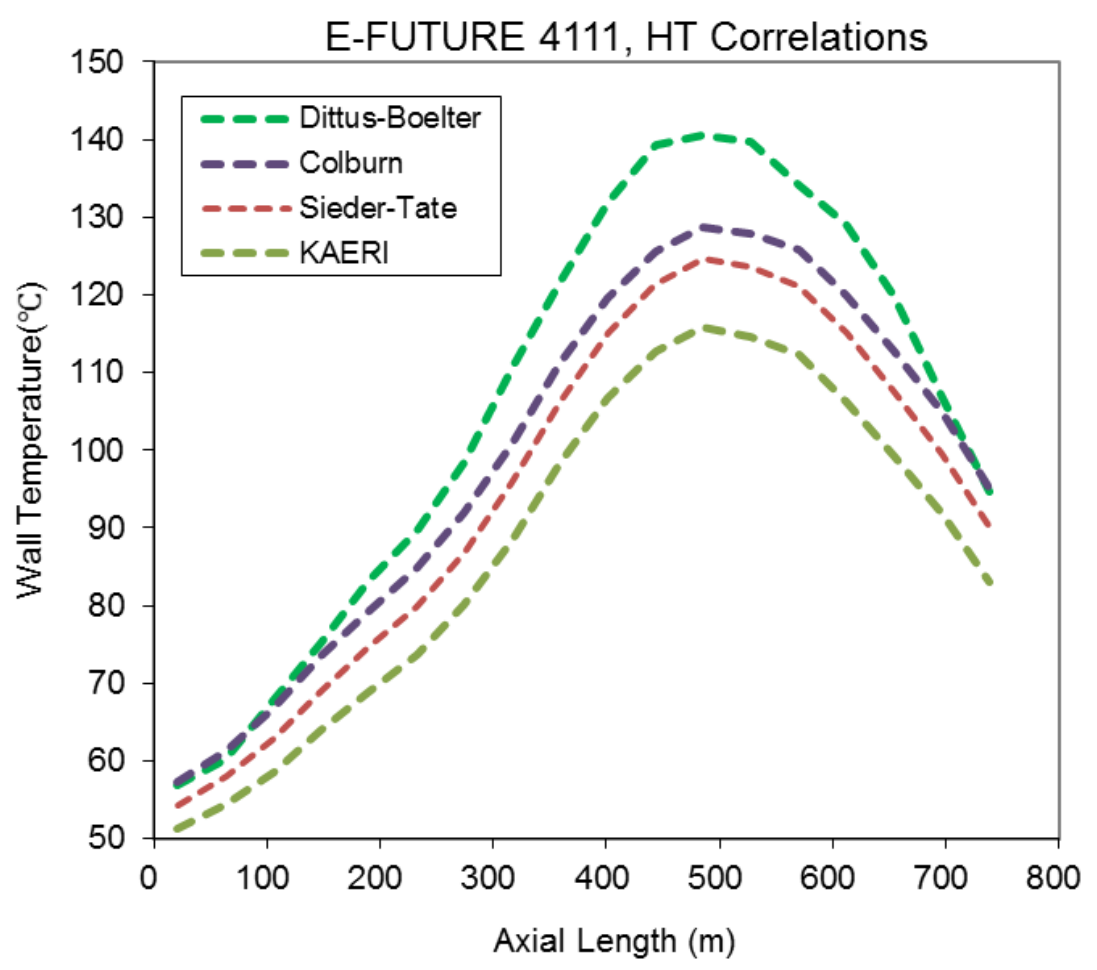

a) Cladding surface temperature

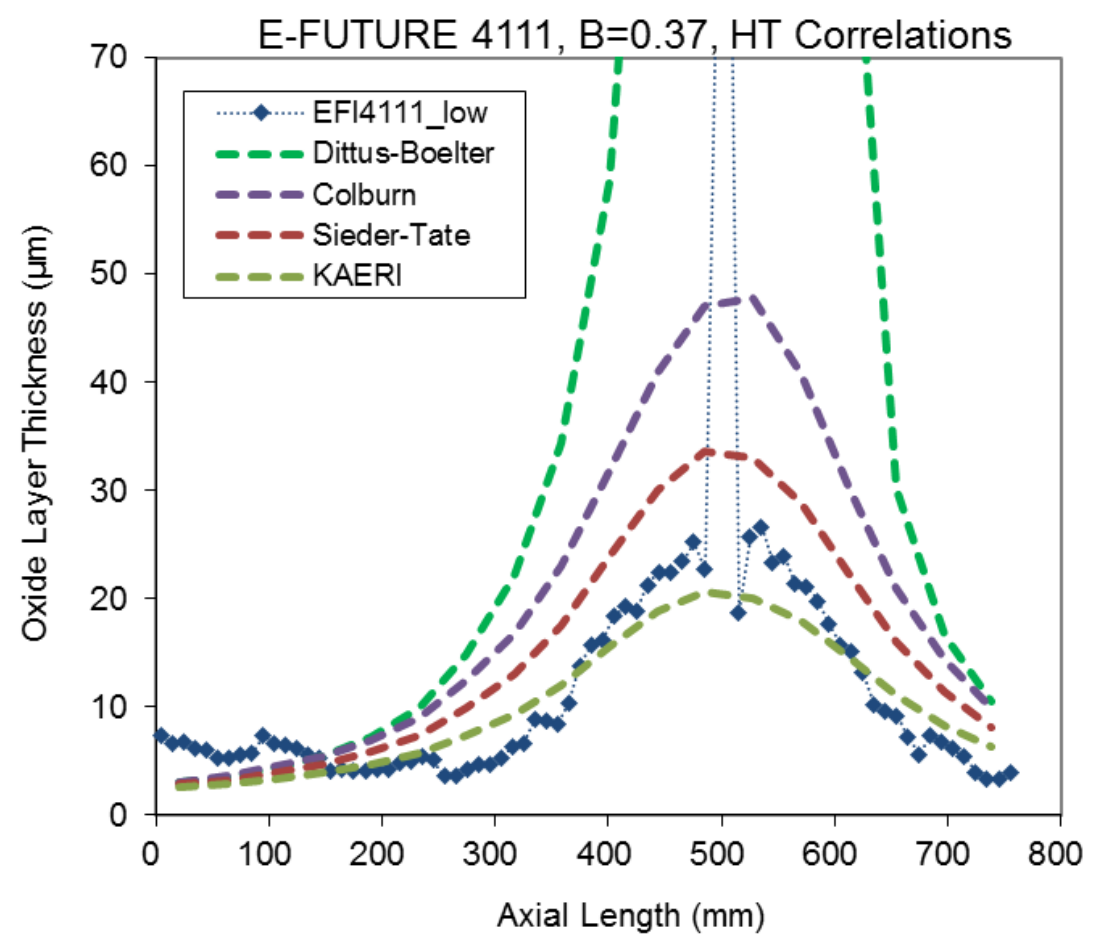

b) Oxide thickness prediction

Figure 17 Effect of cladding surface temperature on oxide thickness prediction in Kim model estimated for the fuel plate 4111 of the E-FUTURE experiment 


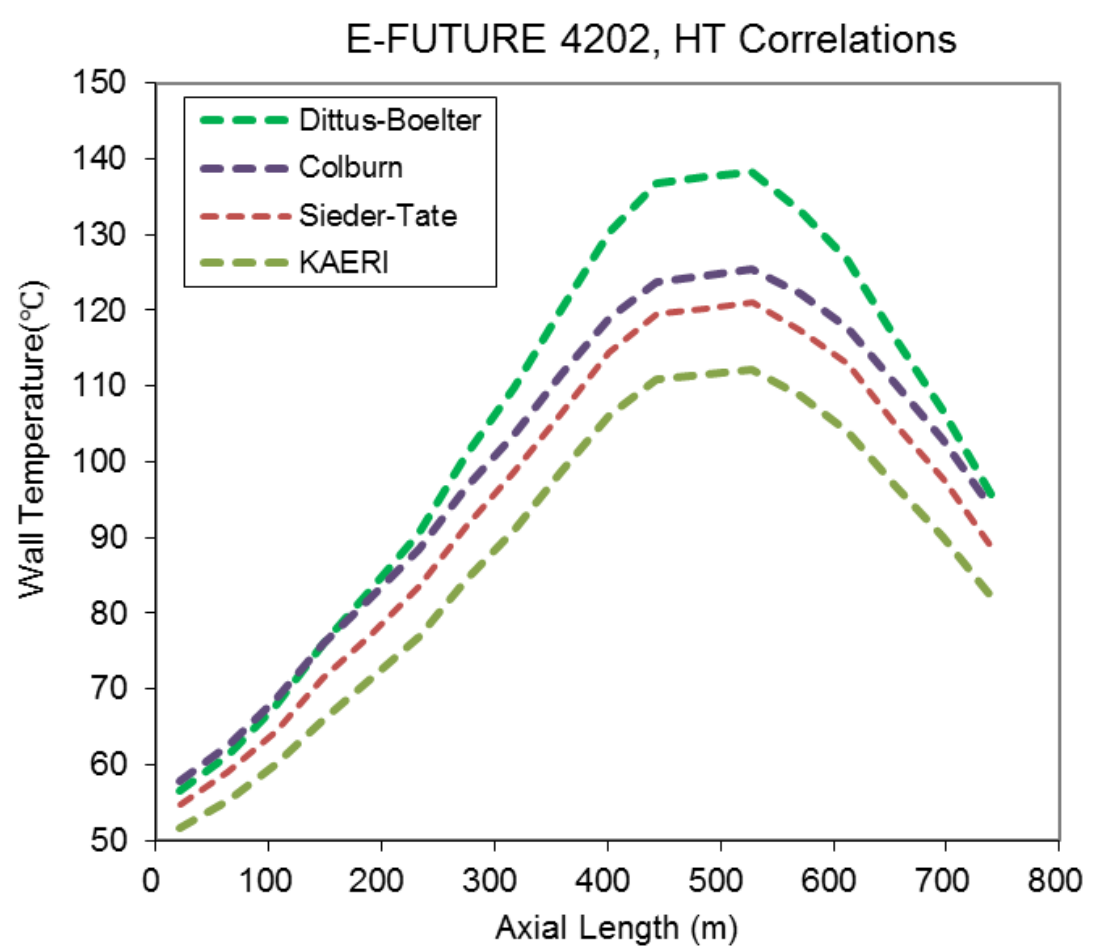

a) Cladding surface temperature

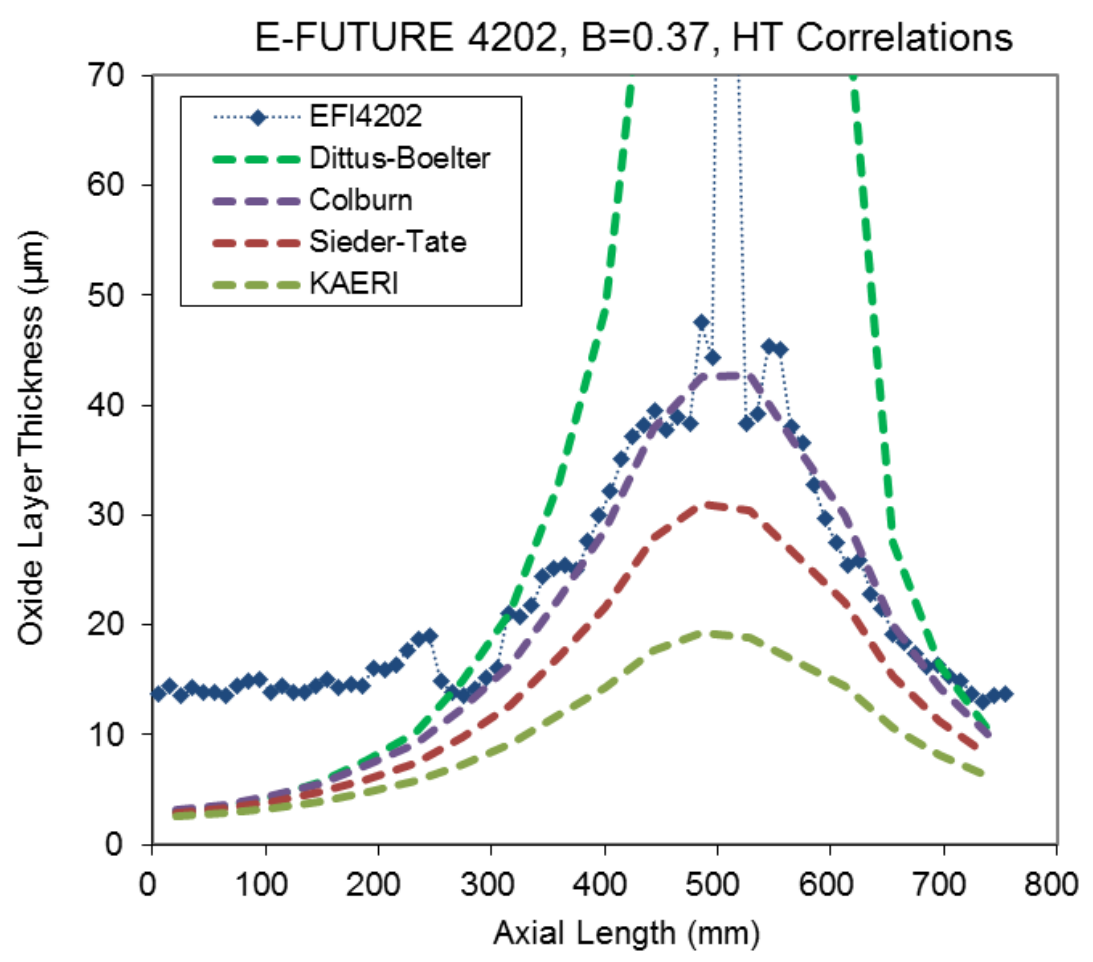

b) Oxide thickness prediction

Figure 18 Effect of cladding surface temperature on oxide thickness prediction in ANL Model estimated for the fuel plate 4202 of the E-FUTURE experiment 


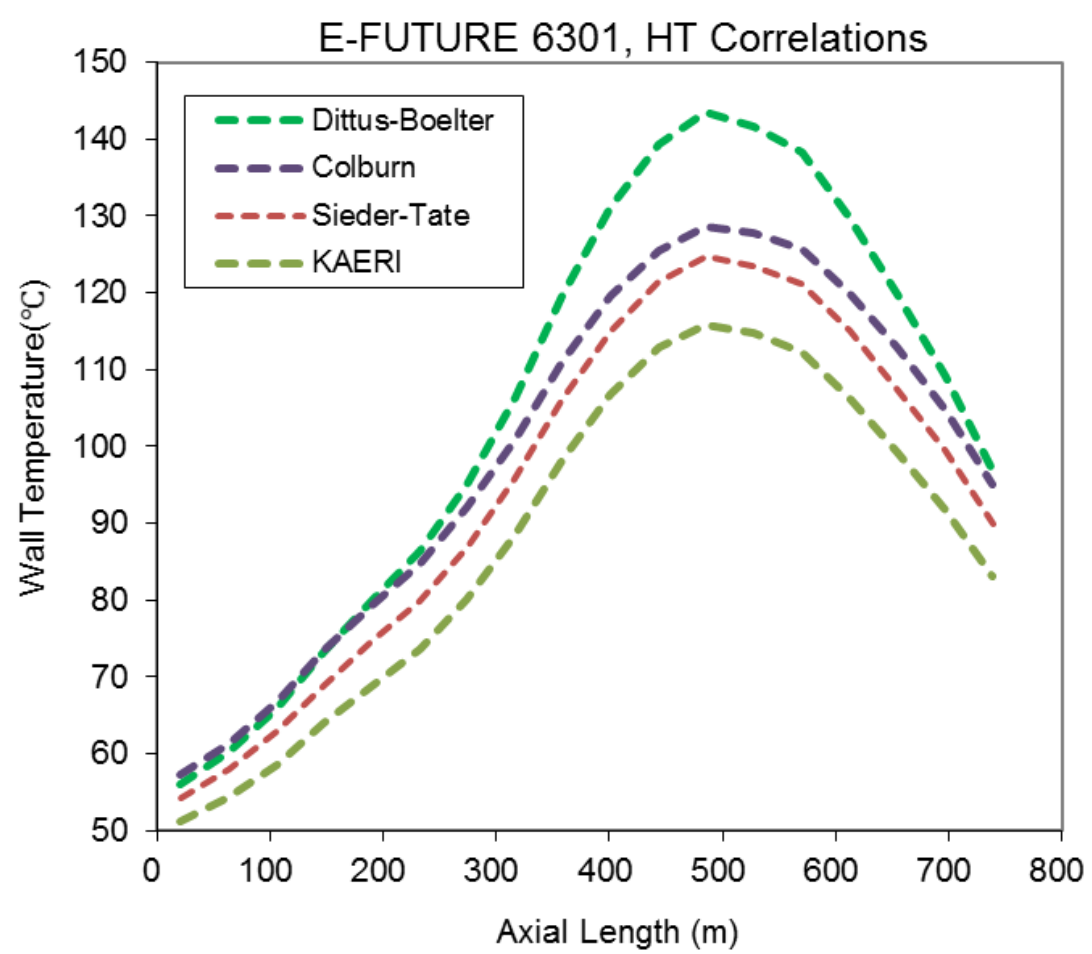

a) Cladding surface temperature

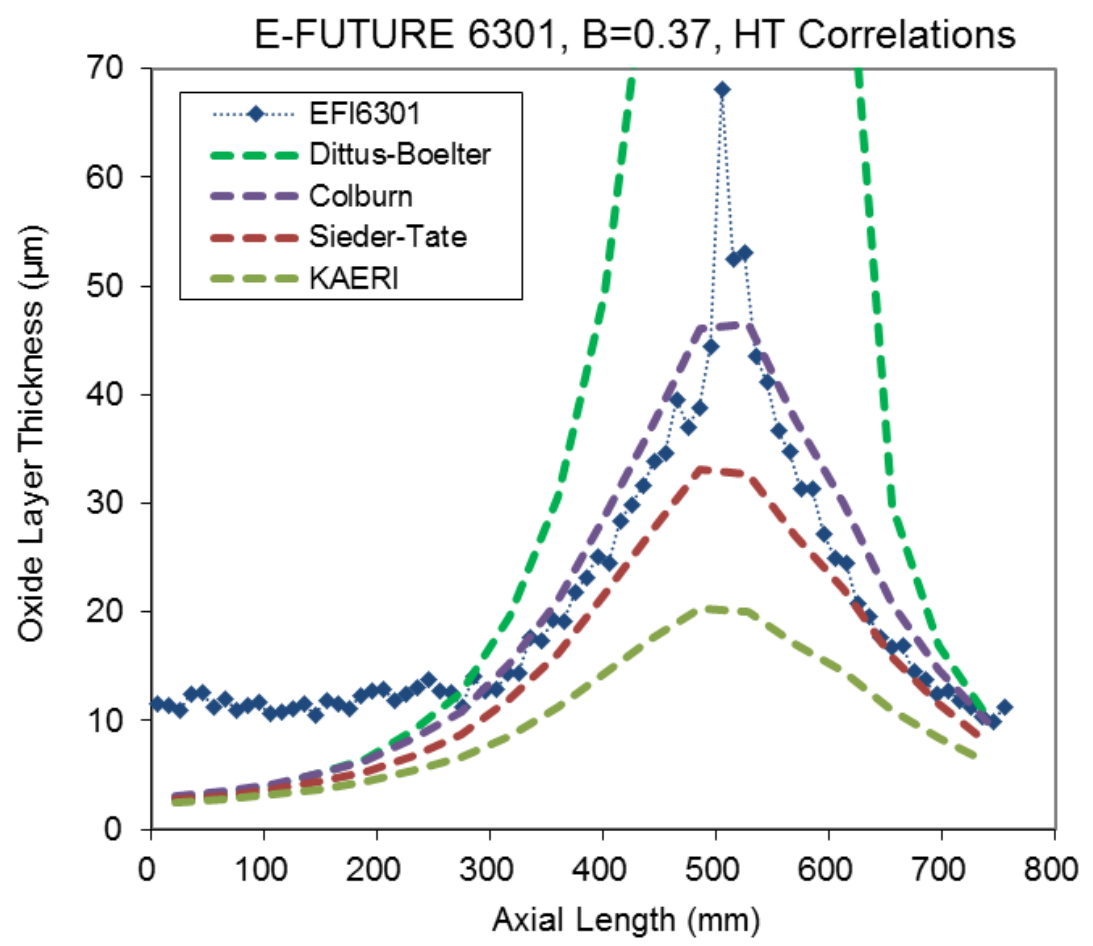

b) Oxide thickness prediction

Figure 19 Effect of cladding surface temperature on oxide thickness prediction in Kim model estimated for the fuel plate 6301 of the E-FUTURE experiment 


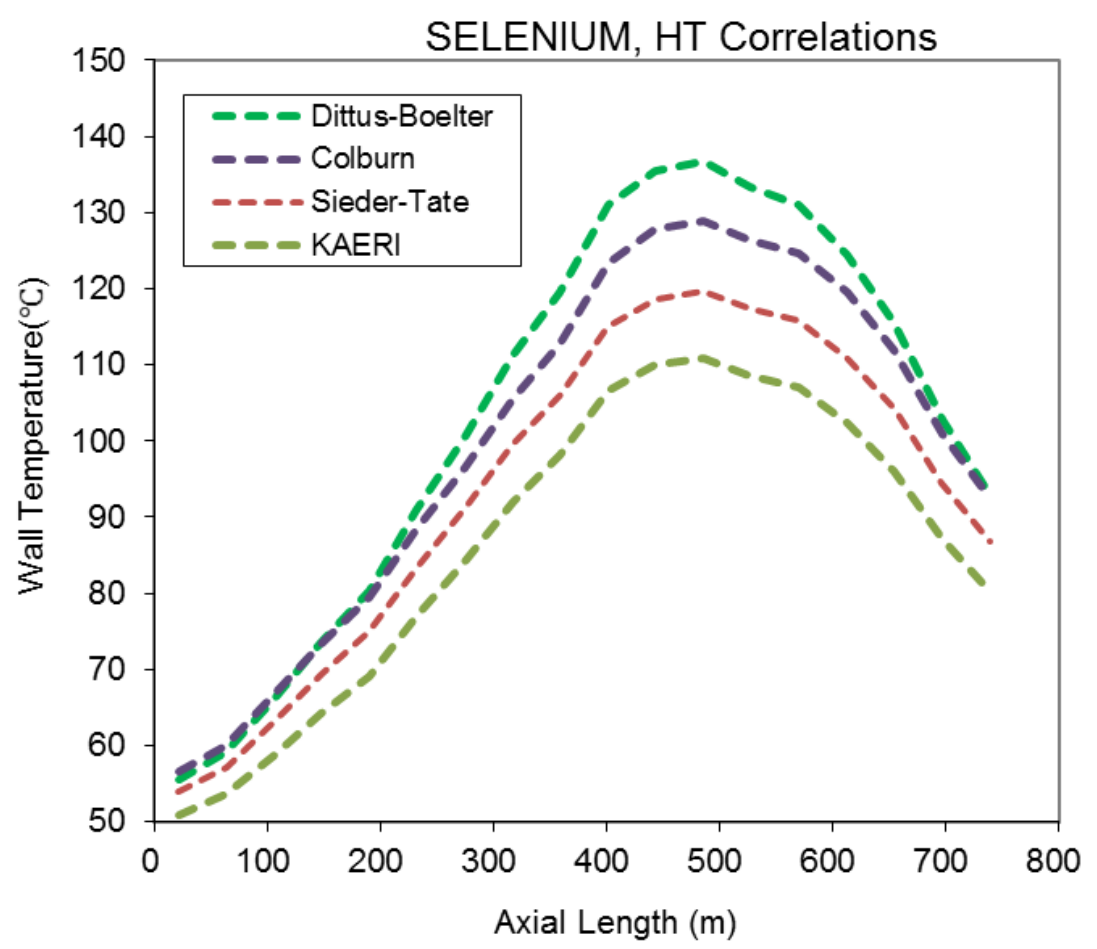

a) Cladding surface temperature

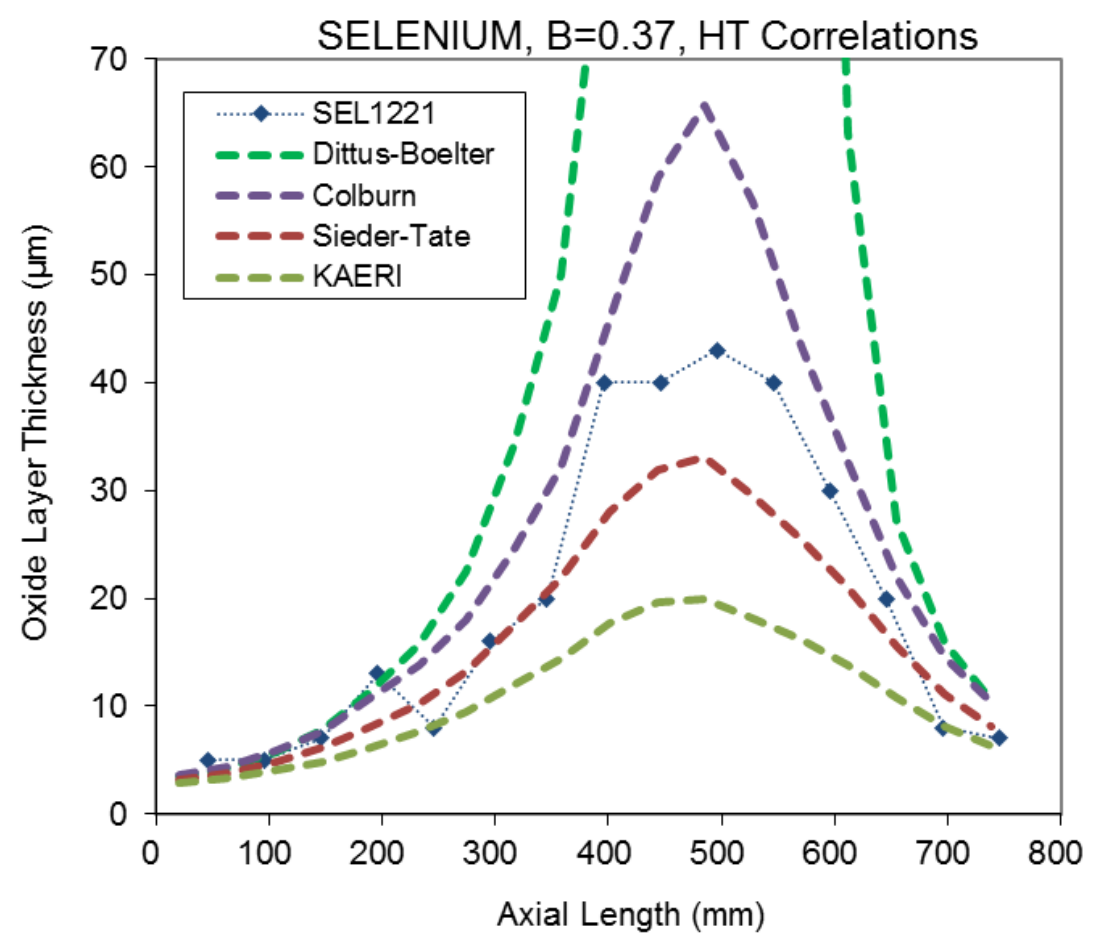

b) Oxide thickness prediction

Figure 20 Effect of cladding surface temperature on oxide thickness prediction in Kim model estimated for the fuel plate 1221 of the SELENIUM experiment 


\subsection{Parametric Study of Heat Transfer Coefficient}

Figure 15- Figure 18 compare the predicted oxide layer thicknesses with the measured for the EFUTURE and SELENIUM tests. As discussed earlier, the prediction by the original Griess correlation is considerably higher than the others, whereas those by the Kim and modified Griess models are in relatively good agreement with the experimental results.

A parametric study of the constant B in the Kim model was performed for the E-FUTURE 6301 plate, the results of which are shown in Figure 23. B must be set close to zero to match the experimental result when the heat transfer coefficient was calculated by the Dittus-Boelter correlation. However, reasonable predictions were made when B was set $0.32,0.47$, and 0.8 when coupled with the Colburn, the Sieder-Tate, and the KAERI correlations, respectively. From this study, it was found that the Kim model was sensitive to B because the heat flux, and accordingly the cladding surface temperature, in the study were high. 


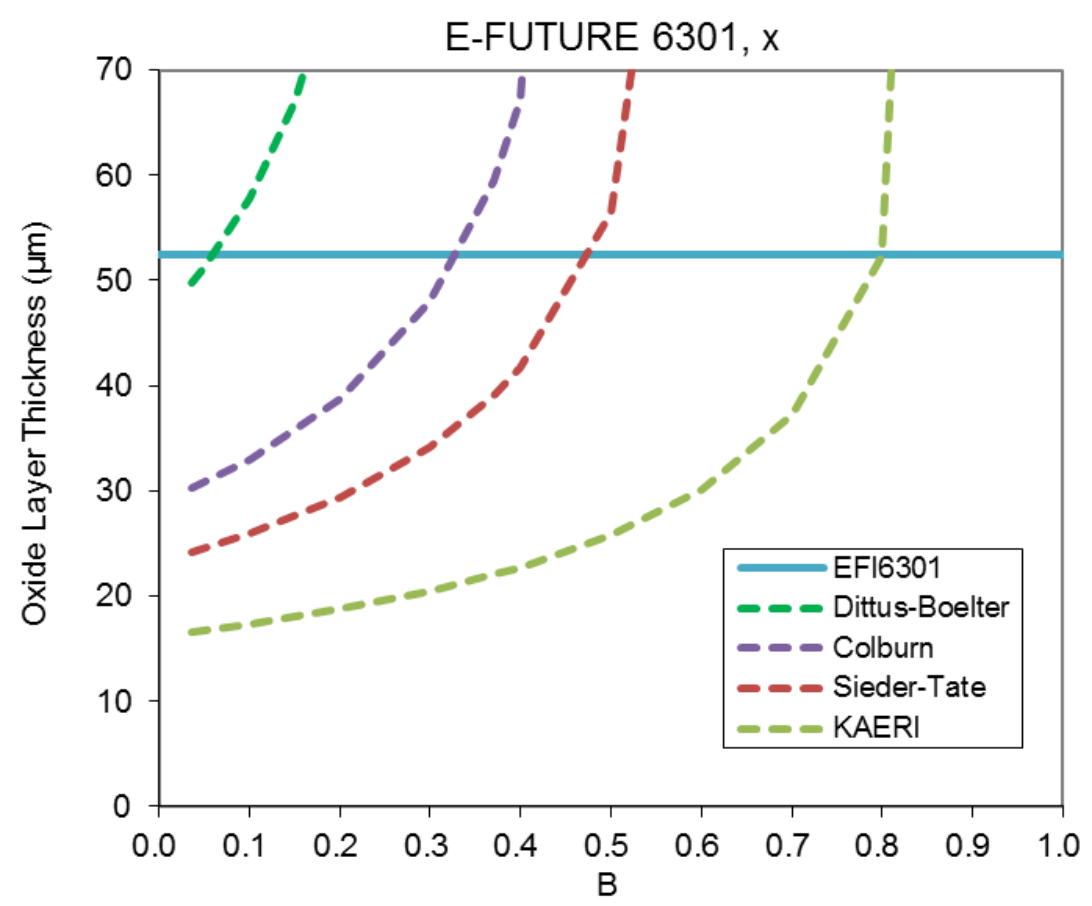

a) Oxide thickness vs B

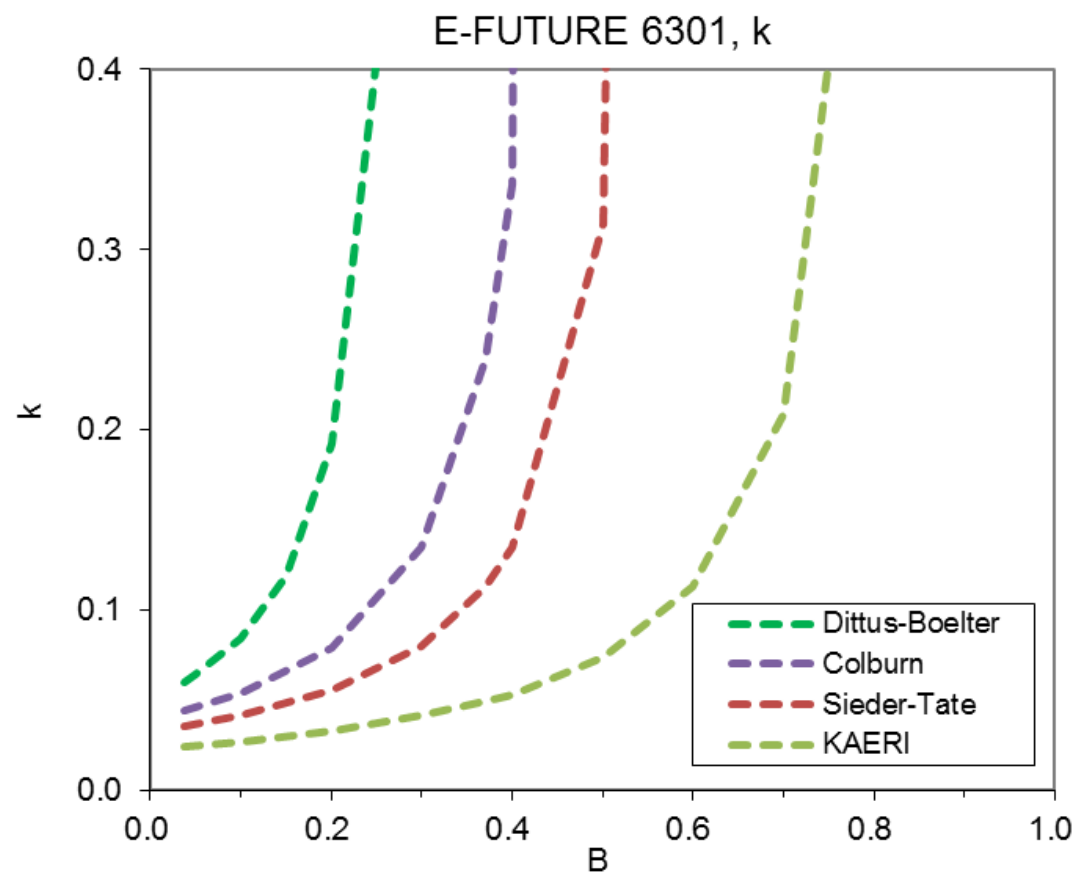

b) k vs B

Figure 21 Effect of B of the Kim model coupled with the heat transfer correlations on oxide thickness prediction for the fuel plate 6301 of the E-FUTURE experiment 


\subsection{Correction Constant B in the Kim Model}

The Kim model [4] as described in section 4.1 is applied as the oxide layer growth model. In Eq. (5) of the original model, based predominantly upon RERTR miniplate test results, a correction constant, B, accounting for the reduction in the oxide thickness for oxidant migration was originally recommended as 0.37 [4]. The purpose of this constant was to consider the quality of oxide forming in different coolant flow conditions in the model such as channel geometry or any unknown factors specific to the reactor, which cannot be dealt adequately with the coolant velocity term (A) alone. The BR2 full-size tests have about two times wider and longer coolantchannel cross section than the RERTR miniplate tests (Fig. 23), by which the coolant flow is probably much less turbulent in the BR2 tests. Under these conditions, the damage to the oxide will be less, so the reduction in the effective transport distance for the oxidant to travel to the metal-oxide interface, where oxidation occurs, becomes smaller. Consequently, the oxide growth becomes slower. A smaller B value should be used for this case.

As found in the proceeding section, the Kim model coupled with the Dittus-Boelter correlation resulted in over-predictions for all test plates. In cases where the Dittus-Boelter correlation is used, the constant B must also be revised to be applicable for BR2 tests. A refit was performed and a new value of 0.037 was found.

The oxide thicknesses calculated by the Kim model with $\mathrm{B}=0.037$ and the Dittus-Boelter correlation were compared with experimental data in Figure 23 - Figure 25 for the E-FUTURE plates and in Figure 26 for the SELENIUM plate. The lowered B value effectively removed the necessity of repeating the calculation at a time interval of 1 day, providing added convenience to the model prediction. The location where the peak oxide was measured approximately corresponds to the location with the peak power. Although the measured and predicted results are in fair agreement, discrepancies are also noticeable. In particular, the oxide thickness in the low power region from the top of the fuel meat to $\sim 300 \mathrm{~mm}$ from the top are under-predicted in plates 4202 and 6301 of the E-FUTURE test. Considering the similar conditions in heat flux, $\mathrm{pH}$ of coolant and coolant velocity because they were in the same basket, the cause for this discrepancy is unclear at this time. Additionally, the oxide thickness for plate E-FUTURE 4111

is substantially over-predicted, as discussed below. The reason for this anomalous result is unknown. 


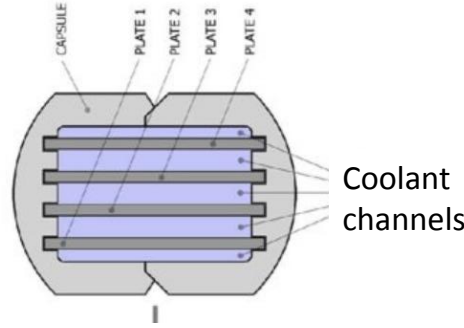

Coolant channel width $=2.2 \mathrm{~mm}$

RERTR mini-plate basket

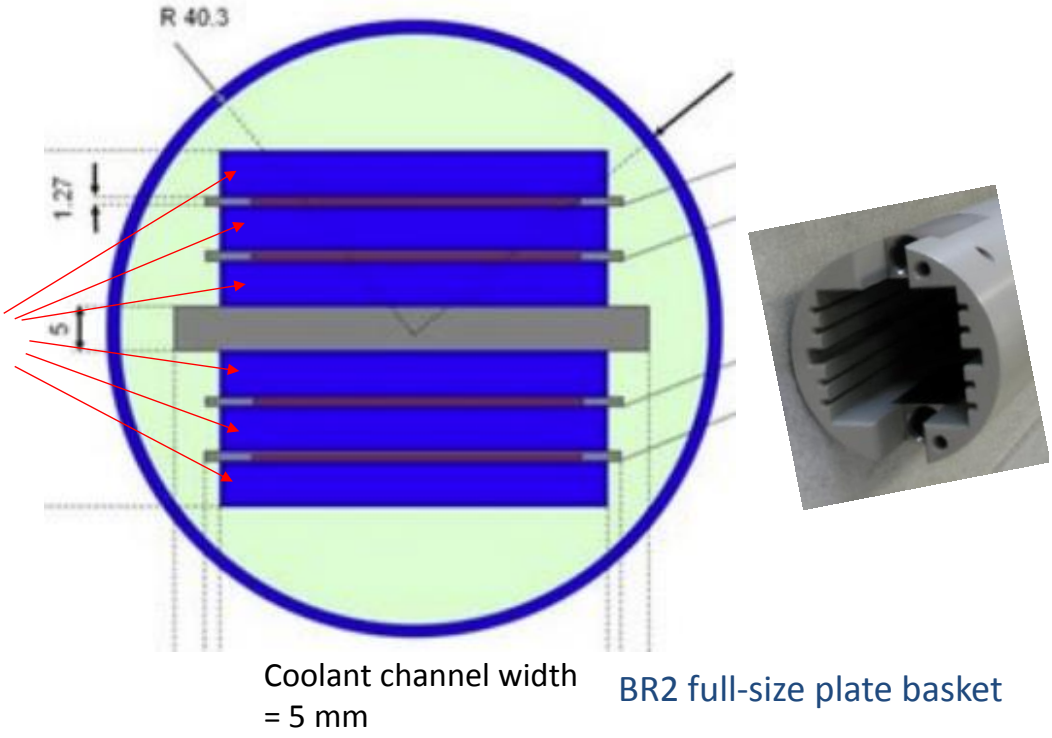

Coolant
$=5 \mathrm{~mm}$

Figure 22 Comparison of coolant channel cross sections between RERTR miniplate tests and BR2 tests 


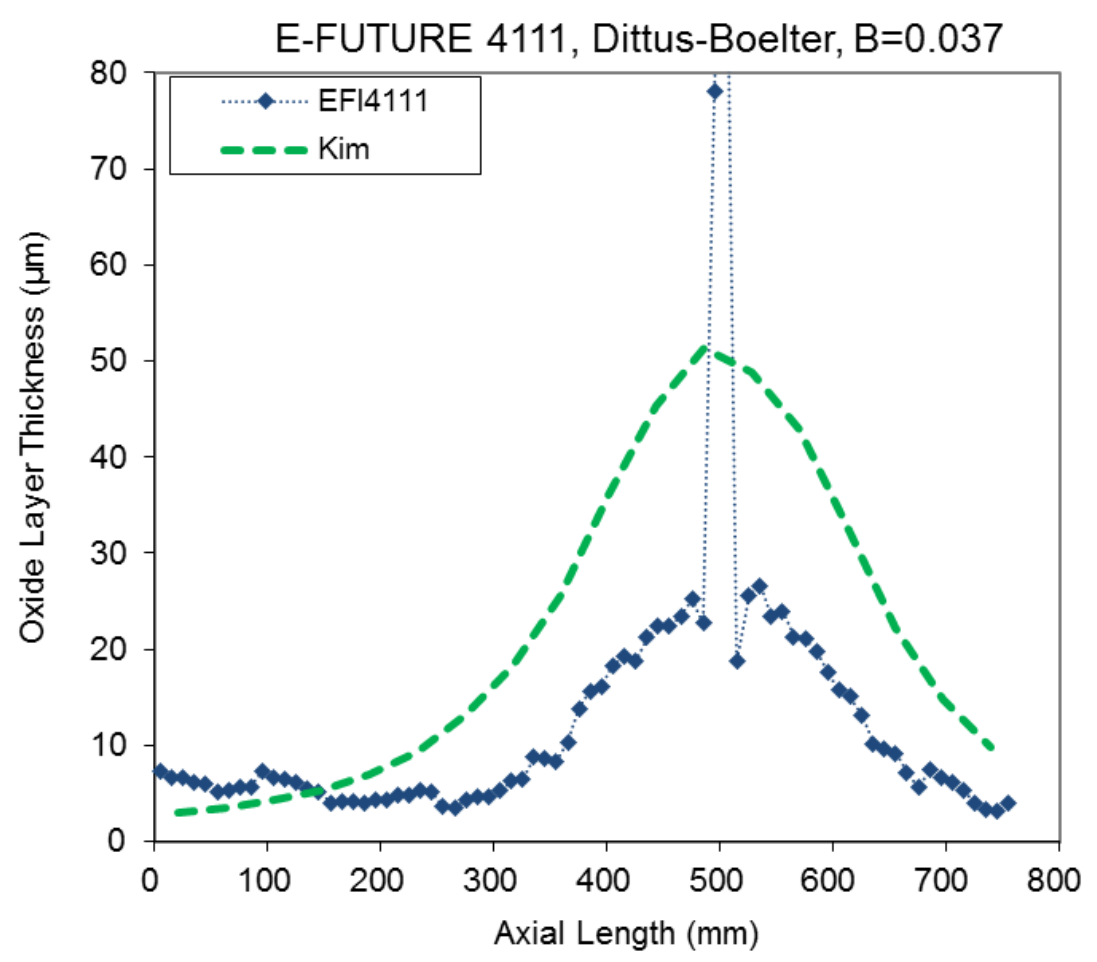

a) Axial oxide profile

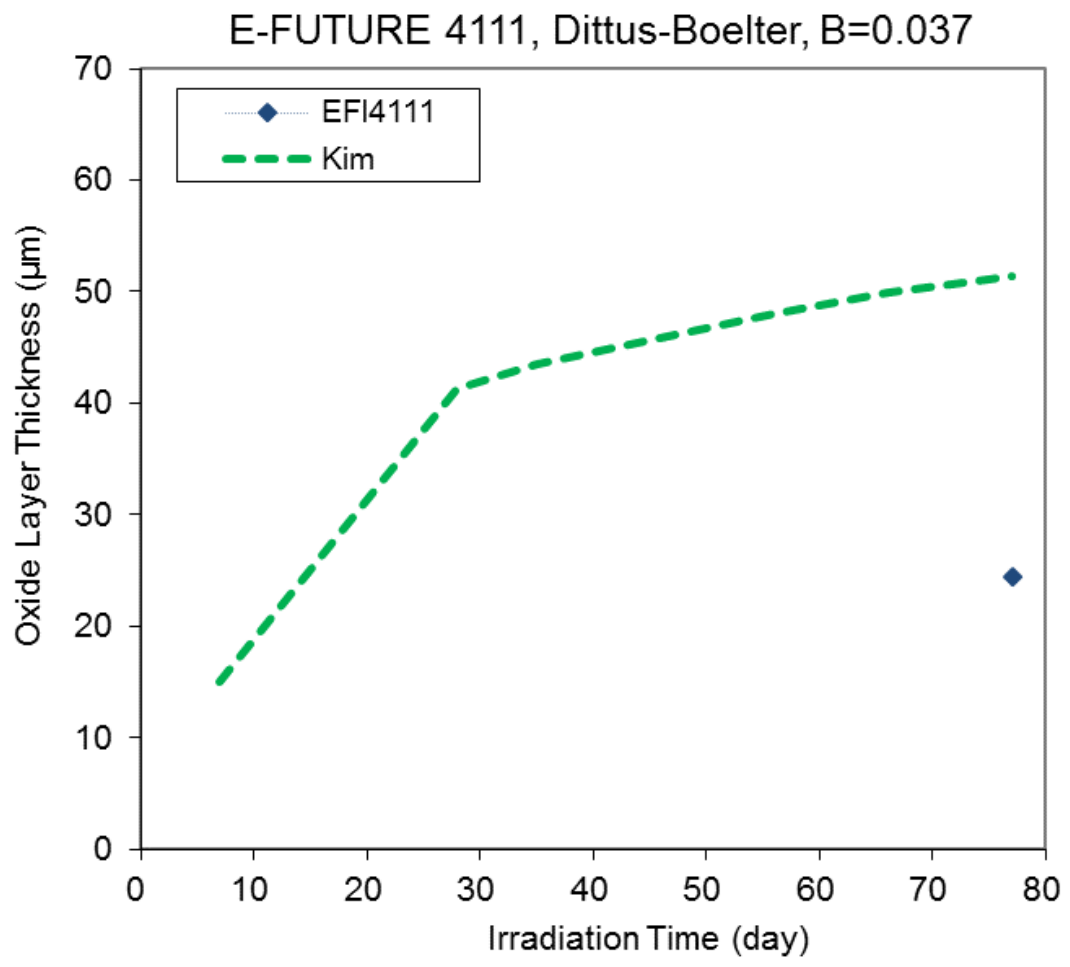

b) Prediction at peak power location

Figure 23 Comparison of the Kim model with $\mathrm{B}=0.037$ and the Dittus-Boelter correlation with measured data for the fuel plate 4111 of the E-FUTURE experiment 


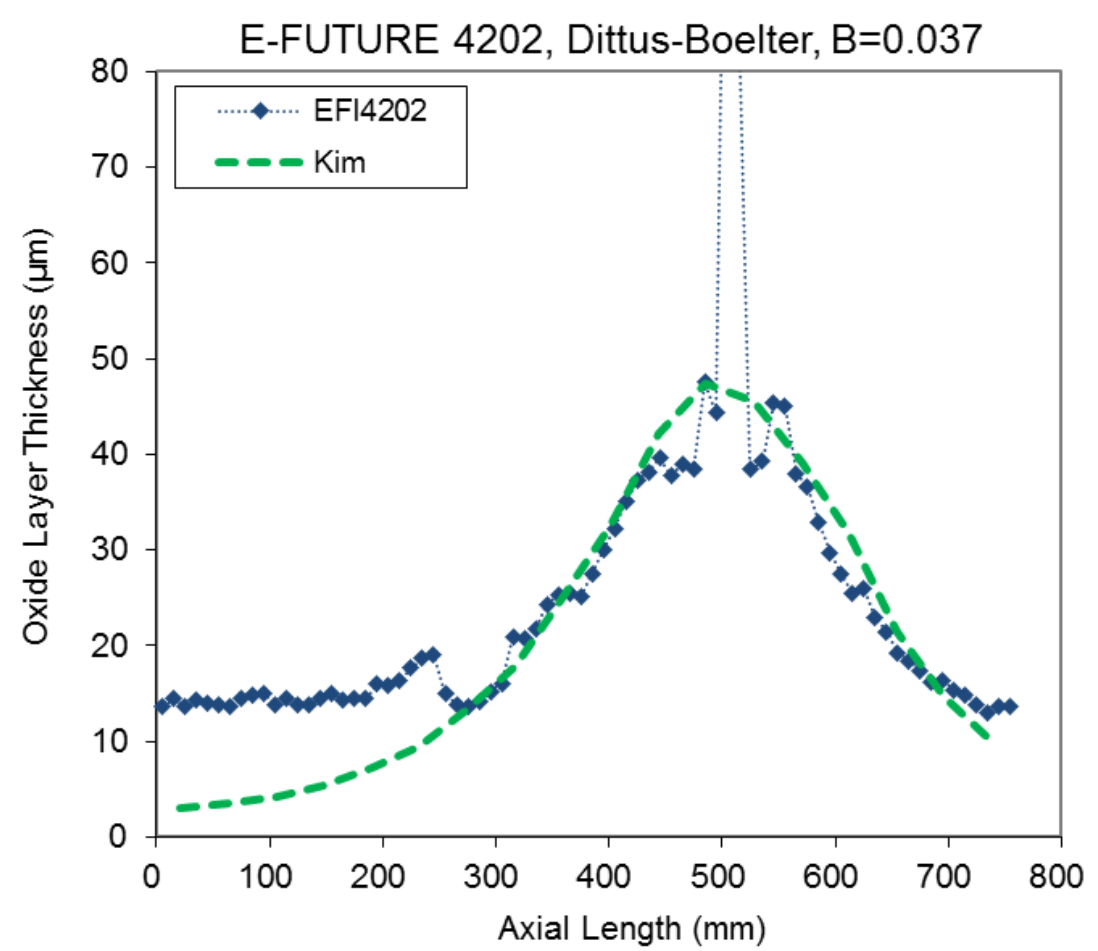

a) Axial oxide profile

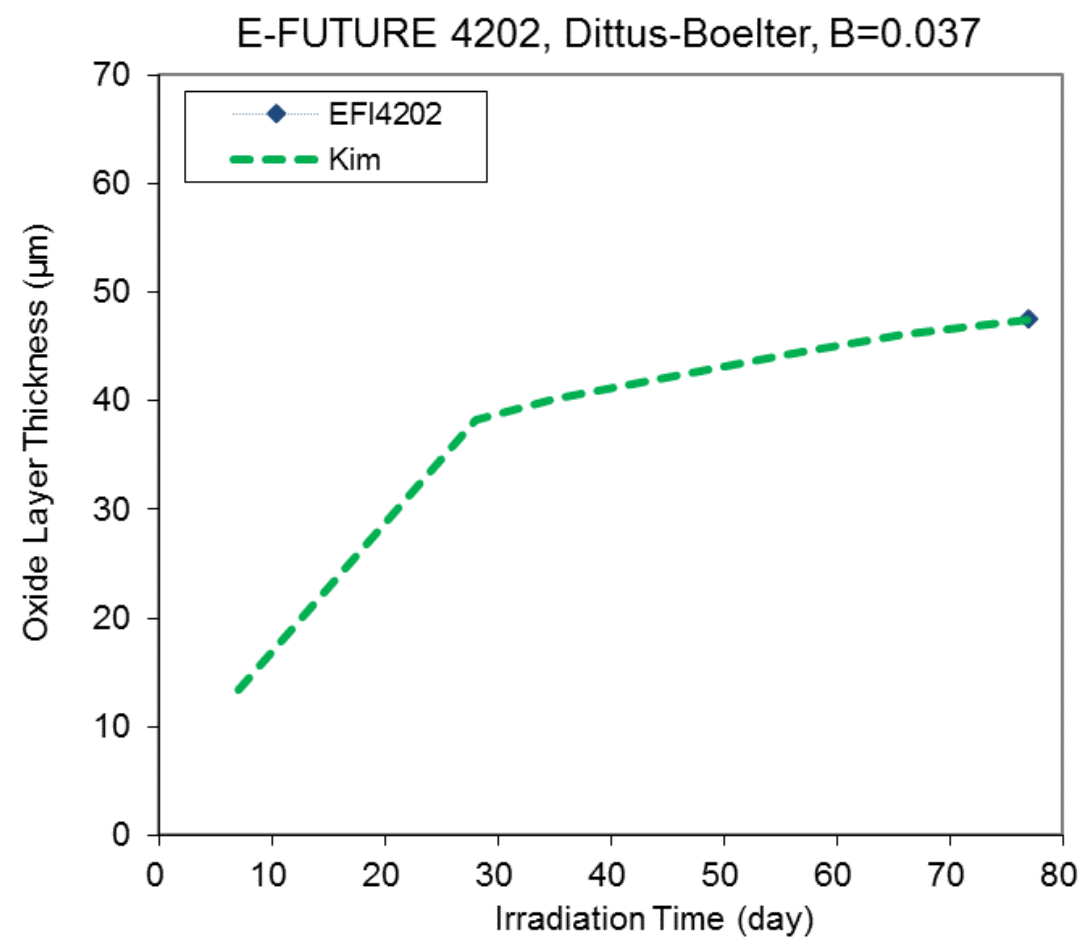

b) Prediction at peak power location

Figure 24 Comparison of the Kim model with $B=0.037$ and the Dittus-Boelter correlation with measured data for the fuel plate 4202 of the E-FUTURE experiment 


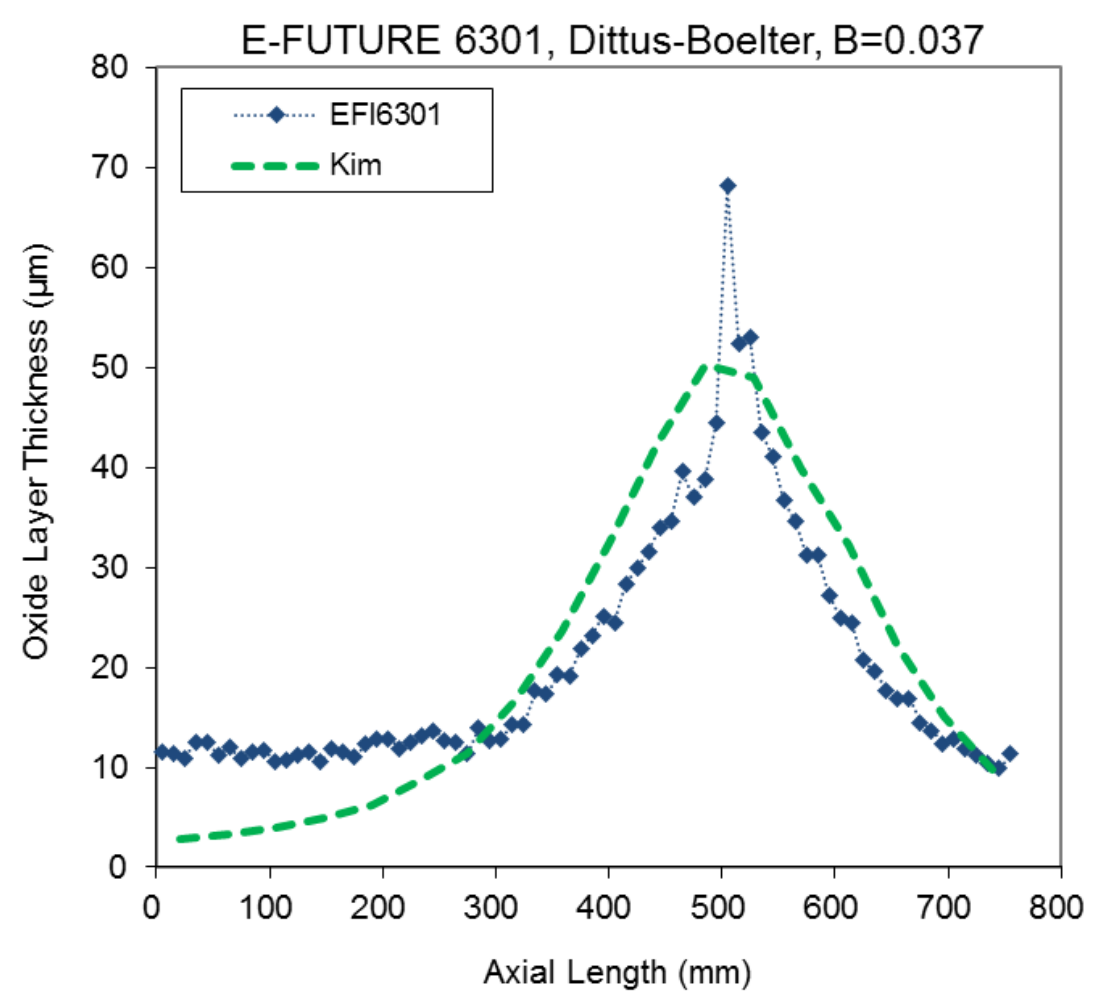

a) Axial oxide profile

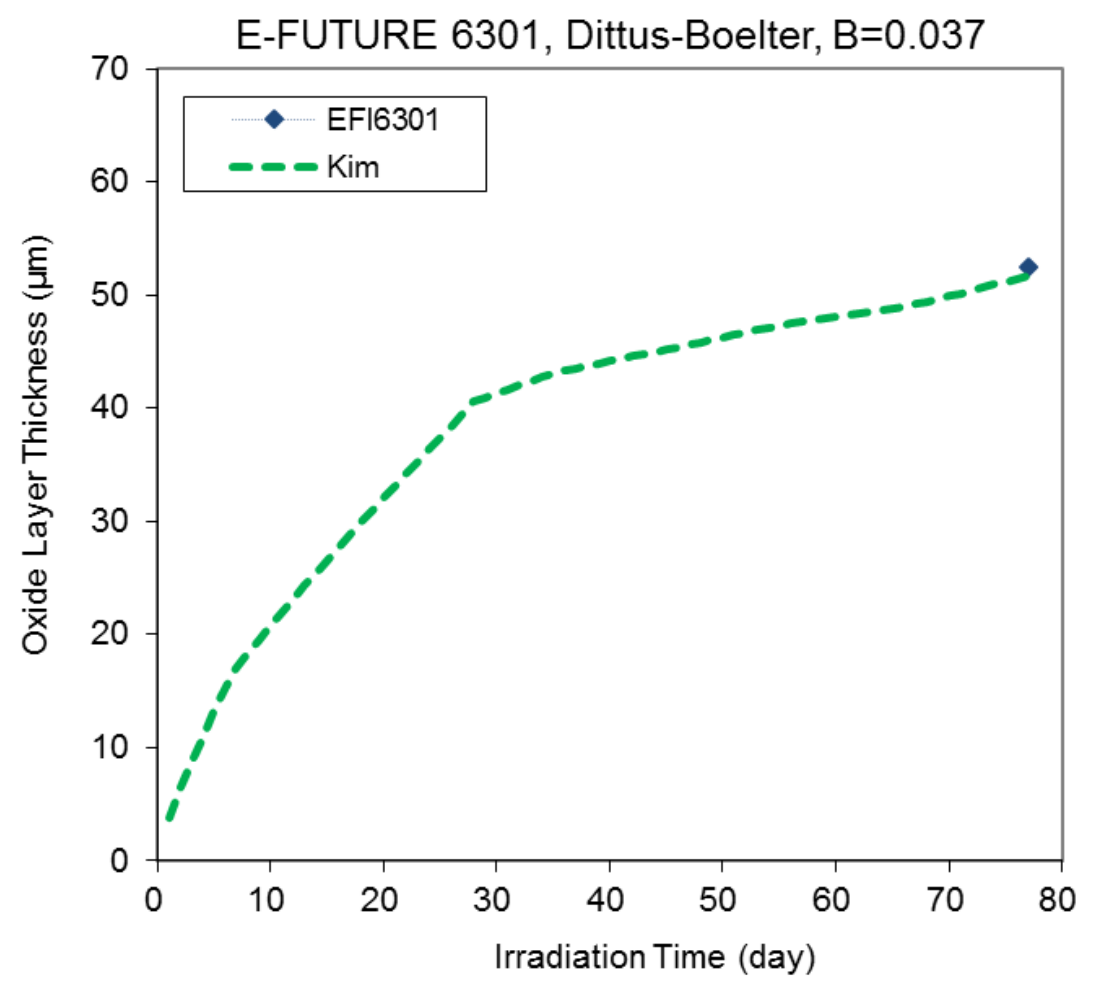

b) Prediction at peak power location

Figure 25 Comparison of the Kim model with $\mathrm{B}=0.037$ and the Dittus-Boelter correlation with measured data for the fuel plate 6301 of the E-FUTURE experiment 


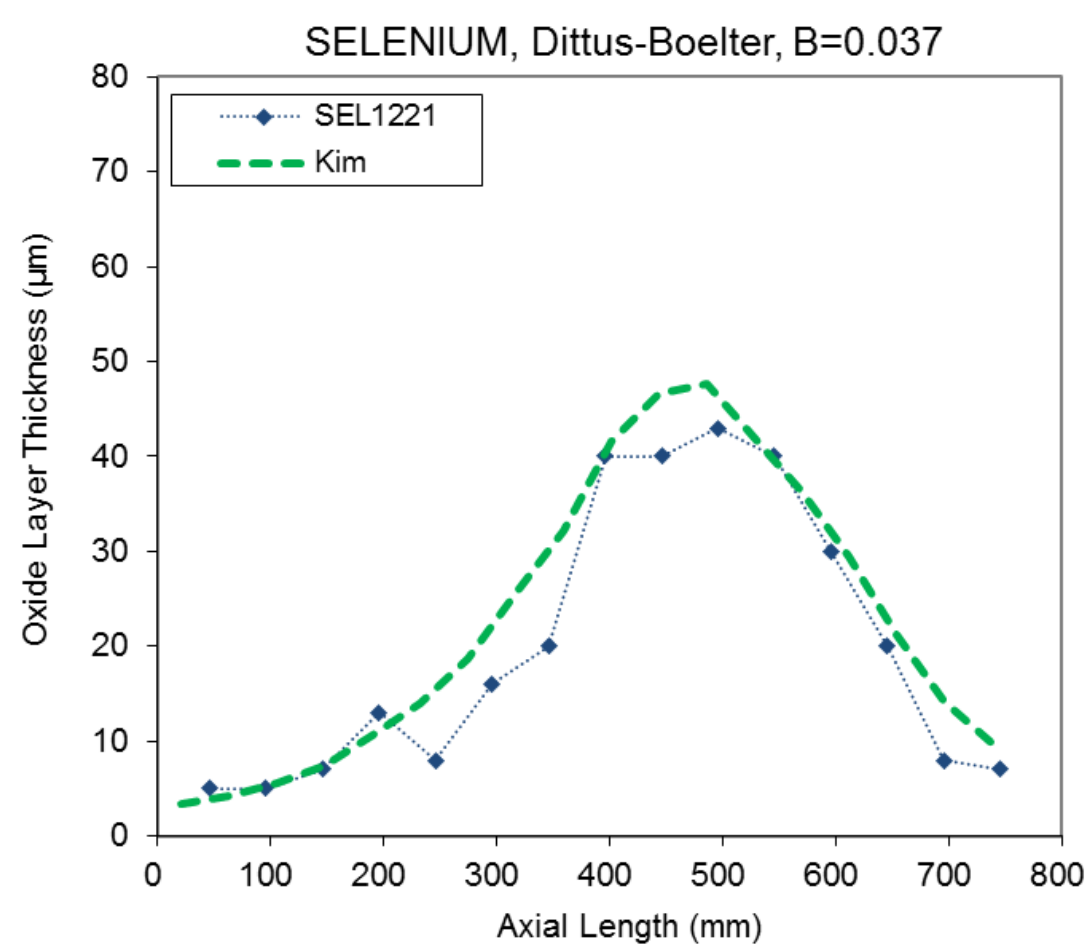

a) Axial oxide profile

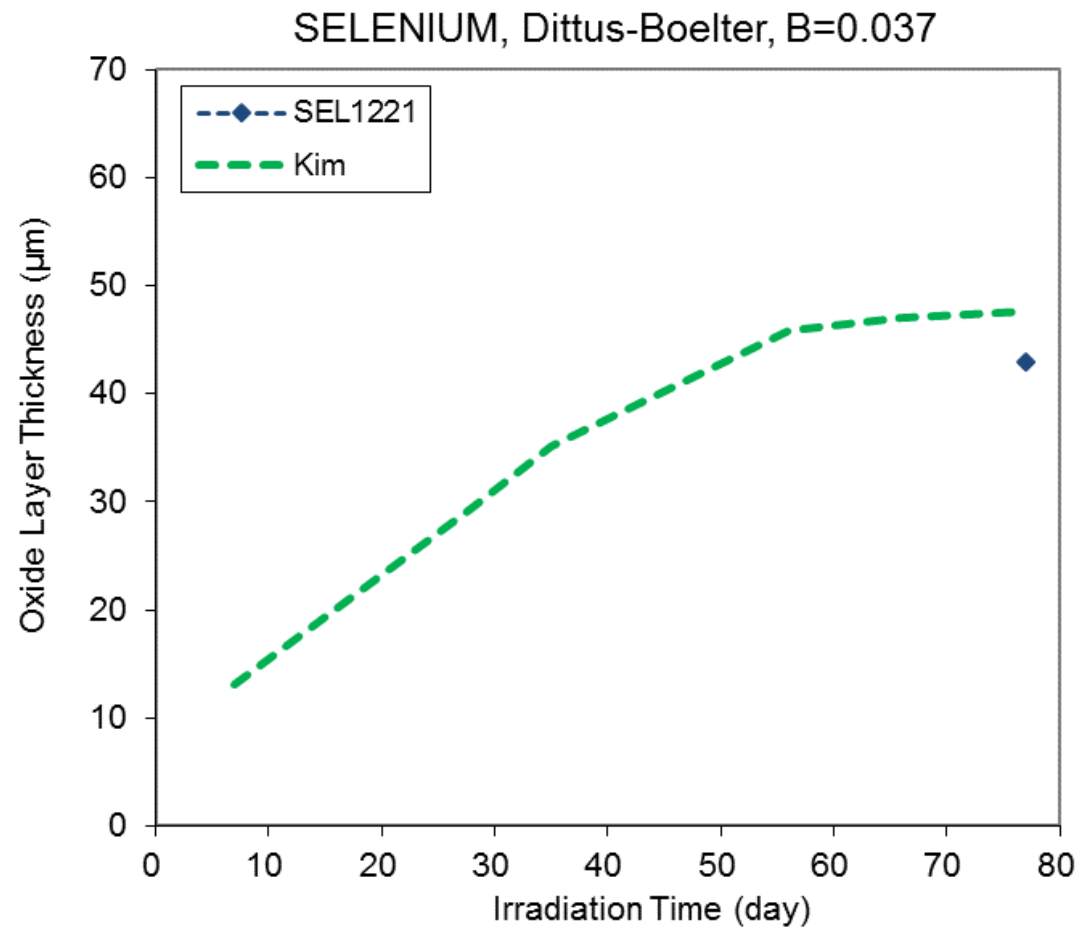

b) Prediction at peak power location

Figure 26 Comparison of the Kim model with $\mathrm{B}=0.037$ and the Dittus-Boelter correlation with measured data for the fuel plate 1221 of the SELENIUM experiment 


\subsection{Effect of Coolant Heat-up}

In the BR2 test basket, the coolant channels were heated either by two plates or by a single plate (see Fig. 1). Due to the loading pattern, plates 4111, 6301, and 4202 all have one side where the coolant channel is heated by two plates while the other side is only heated by one plate. $\backslash$. Therefore, each side of these plates might have a different heating condition in the coolant channels. To mitigate this possibility of difference in heating between plate sides, the BR2 test design has significantly wide channel gaps in the basket (see Figure 22).

However, it is worthwhile investigating whether there is indeed no difference by comparing oxide between sides of the plates. Figure 29 shows the comparison. The two-plate heating channel sides of plate 4111 (lower side) and 4202 (upper side) show slightly thicker oxide than the one-plate heating channel sides. The two-plate heating channel side of plate 6301 (upper side) shows clearly thicker oxide. From this result, it can be said that there is indeed some difference, considerable in some instances (plate 6301). The possible cause is thought to be the higher cladding surface temperature due to higher heating. This observation suggests that the measured data includes uncertainty, the effect of which is not considered in any model predictions. 


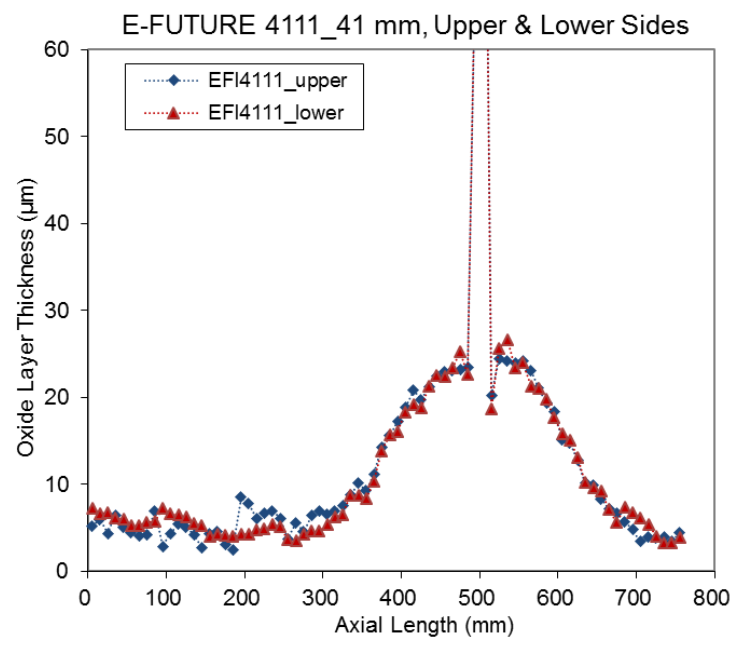

a) E-FUTURE 4111

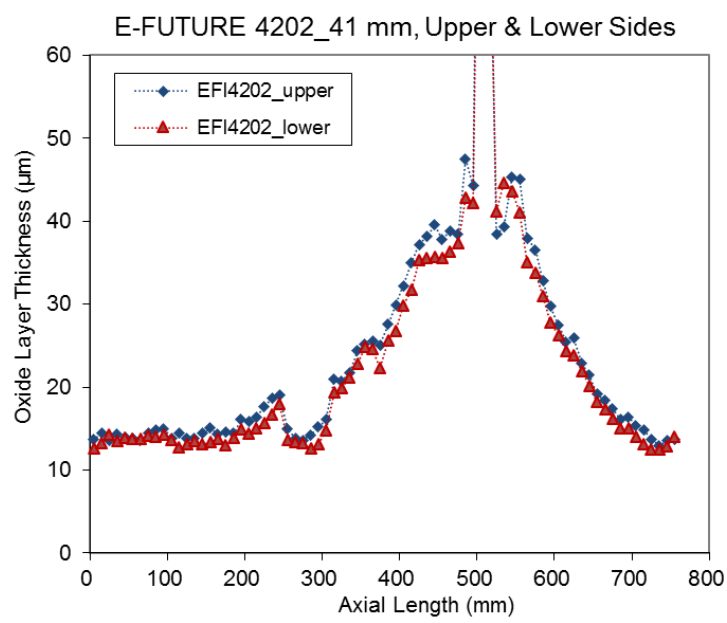

b) E-FUTURE 4202

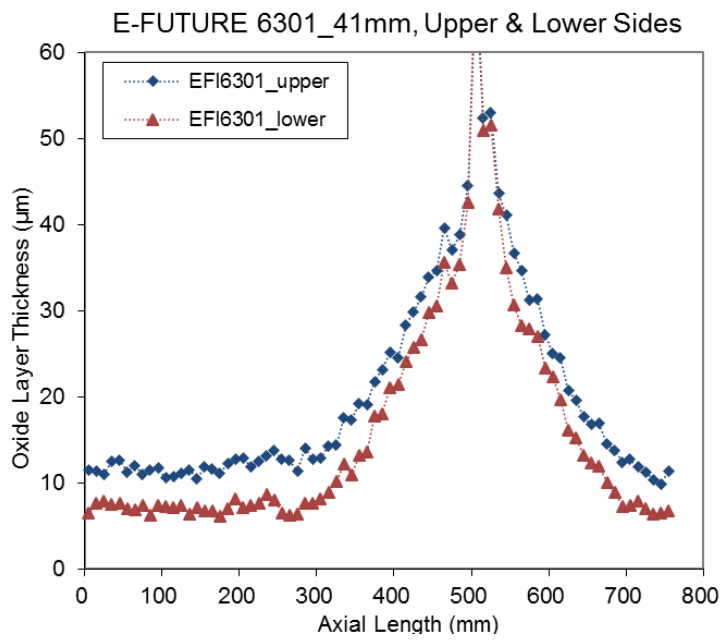

c) E-FUTURE 6301

Figure 27 Comparison between the measured oxide thicknesses along the heated plate sides in the E-FUTURE experiment 


\subsection{Effect of Cladding Type}

Because the plate cladding materials of the BR2 test plates were AG3NE (close to AA5754) and AlFeNi Al-alloys, different from AA6061 the Kim model was based upon, one might expect an impact on the oxide growth (see the nominal compositions compared between these three alloys in Table 7).

In order to investigate the effect of cladding type on oxide growth, the E-FUTURE test results with different cladding types were compared, as shown in Figure 28. The E-FUTURE 4111 plate made with AlFeNi Al-alloy had, in general, lower oxide thickness than those of the E-FUTURE 4202 and 6301 plates made with AG3NET Al-alloy.

Because the E-FUTURE plates have virtually the same power, burnup and coolant conditions, AlFeNi cladding appears to be slightly advantageous over AG3NET. This result is an outlier compared to the findings in the literature [4],[17],[18]. The possible reason may be attributed to the higher temperatures for the present test than those in the literature. Like a magnifying glass, the high temperature test magnifies the difference that was not discernable in the low temperature tests. However, it is these authors' belief that this effect is less important, at the most a secondary effect, than that of coolant conditions on oxide thickness. Therefore, in this report a detailed discussion on the impact of cladding type on oxide growth is not included. The uncertainties in $\mathrm{pH}$, coolant velocity, and reactor power are likely larger than the effect of cladding type.

Table 7 Compositions (wt.\%) of aluminum cladding alloys [16]

\begin{tabular}{|c|c|c|c|c|c|c|c|c|c|c|c|c|}
\hline \multirow[t]{2}{*}{ Alloy } & \multirow[t]{2}{*}{$\mathrm{Si}$} & \multirow[t]{2}{*}{$\mathrm{Fe}$} & \multirow[t]{2}{*}{$\mathrm{Cu}$} & \multirow[t]{2}{*}{$\mathrm{Mn}$} & \multirow[t]{2}{*}{$\mathrm{Mg}$} & \multirow[t]{2}{*}{$\mathrm{Cr}$} & \multirow[t]{2}{*}{$\mathrm{Ni}$} & \multirow[t]{2}{*}{$\mathrm{Zn}$} & \multirow[t]{2}{*}{$\mathrm{Zr}$} & \multirow[t]{2}{*}{$\mathrm{Ti}$} & \multicolumn{2}{|c|}{$\begin{array}{c}\text { Other } \\
\text { unspecified } \\
(\max )\end{array}$} \\
\hline & & & & & & & & & & & each & total \\
\hline $\mathrm{AlFeNi}$ & $\begin{array}{c}0.3 \\
\text { Max }\end{array}$ & $\begin{array}{c}0.8- \\
1.2\end{array}$ & $\begin{array}{c}0.008 \\
\max \end{array}$ & $\begin{array}{c}0.2- \\
0.6\end{array}$ & $\begin{array}{c}0.8- \\
1.2\end{array}$ & $\begin{array}{c}0.2- \\
0.5\end{array}$ & $\begin{array}{c}0.8- \\
1.2\end{array}$ & $\begin{array}{l}0.03 \\
\max \end{array}$ & $\begin{array}{c}0.06- \\
0.14\end{array}$ & $\begin{array}{c}0.02- \\
0.08\end{array}$ & 0.03 & 0.5 \\
\hline Ag3NET & $\begin{array}{c}0.3 \\
\max \end{array}$ & $\begin{array}{l}0.2- \\
0.40\end{array}$ & $\begin{array}{c}0.008 \\
\max \end{array}$ & $\begin{array}{c}0.7 \\
\max \end{array}$ & $\begin{array}{c}2.5- \\
3.0\end{array}$ & $\begin{array}{c}0.3 \\
\max \end{array}$ & - & $\begin{array}{l}0.03 \\
\max \end{array}$ & - & $\begin{array}{l}0.02 \\
\max \end{array}$ & 0.03 & 0.15 \\
\hline AA6061 & $\begin{array}{c}0.4- \\
0.8\end{array}$ & $\begin{array}{l}0.70 \\
\max \end{array}$ & $\begin{array}{c}0.15- \\
0.40\end{array}$ & $\begin{array}{l}0.15 \\
\max \end{array}$ & $\begin{array}{c}0.8- \\
1.2\end{array}$ & $\begin{array}{c}0.04- \\
0.35\end{array}$ & - & $\begin{array}{l}0.25 \\
\max \end{array}$ & - & $\begin{array}{l}0.15 \\
\max \end{array}$ & 0.05 & 0.15 \\
\hline
\end{tabular}




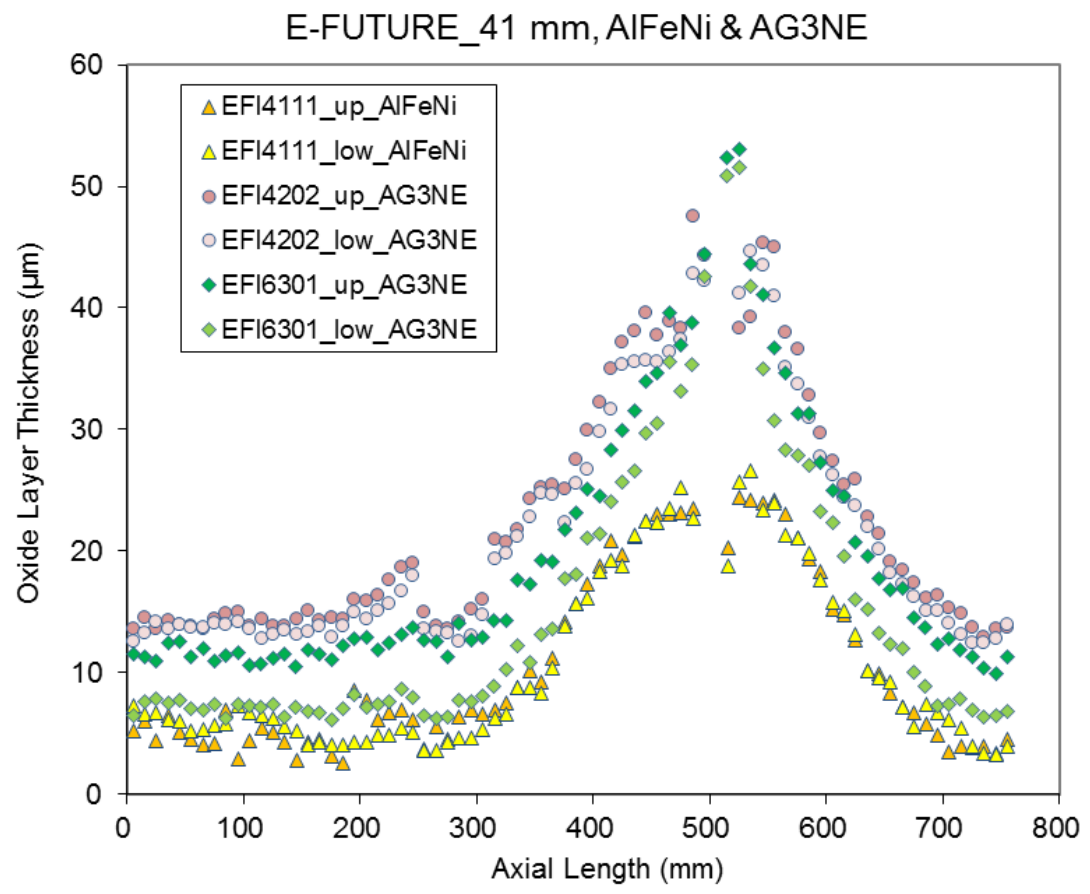

Figure 28 Comparison between the measured oxide thicknesses along the cladding materials in the E-FUTURE experiment 


\section{Section 7 Conclusions}

In an effort to qualify high-density UMo/Al dispersion fuel applicable for EUHPRR, the EFUTURE and SELENIUM tests were conducted at bounding power conditions for EUHPRR. In this report, cladding oxide thickness data measured from the E-FUTURE and SELENIUM tests were used to examine the frequently used oxide prediction models available in the literature and the popular correlations for heat transfer at cladding surface.

The oxide prediction models including the Griess model, KAERI-modified Griess model and Kim model were studied in conjunction with the most frequently employed heat transfer correlations including the Dittus-Boelter correlation, the Colburn corrrelation, the Sieder-Tate correlation, and KAERI-developed plate channel correlation. The Griess model generally overpredicts for all heat transfer correlations. The Kim model, coupled with the Colburn correlation or the Sieder-Tate correlation, gave most consistent results with the measured oxide data. However, the Kim model was found inapplicable to the EUHPRR test conditions at peak power locations if it is coupled with the Dittus-Boelter correlation because the Dittus-Boelter correlation resulted in high cladding temperatures.

For the Colburn correlation, the best predictions for all test plates were found when the correction constant $\mathrm{B}$ in the Kim model was set at $\mathrm{B}=0.32$. For the Sieder-Tate correlation, the same can be said when $B=0.47$. These two values are close to the originally published value $\mathrm{B}=0.37$. If the Dittus-Boelter correlation was used, the constant $\mathrm{B}$ needed to be set an order of magnitude lower $(\mathrm{B}=0.037)$ to best predict the measured data. The new value for $\mathrm{B}$ was thought to be necessary because the coolant channel geometry for the measured data was different from that the typical ones the original model was based upon.

A slight difference in oxide growth was observed between the two-plate heating channel and the single-plate heating channel in the test basket. The former is thought to provide higher cladding surface temperature than the latter. However, this effect is not considered in the model prediction as it has only a minor effect on oxide growth.

The original models was developed on data obtained for AA6061 whereas the EUHPRR including the BR2 tests use AG3NE or AlFeNi. The difference in cladding alloy type was not considered in the formulation. The examination of the E-FUTURE test plates revealed that a noticeable difference, albeit small, exists between AG3NE and AlFeNi. AlFeNi appears to result in a slightly thinner oxide layer. However, it was thought that this difference only became significant because the high power test enhanced the oxide growth. For lower power test cases, however, the difference in alloy type was believed to have only a secondary effect, hard to differentiate from other uncertainties. 


\section{Acknowledgments}

This report contains data gathered at SCK-CEN, available in the open literature. The authors are grateful to A. Leenaers, S. Van den Berghe and V. Kuzminov of SCK-CEN for the data. This work was supported by the U.S. Department of Energy, National Nuclear Security Administration (NNSA), Office of Material Management and Minimization (NA-23) Reactor Conversion Program under Contract No. DE-AC-02-06CH11357 between UChicago Argonne, LLC and the US Department of Energy. 


\section{References}

[1] F. Frery et al., "LEONIDAS UMo Dispersion Fuel Qualification Program: Progress and Prospects," Proceedings of the 32nd International Meeting on Reduced Enrichment for Research and Test Reactors, Lisbon, Portugal, October 10-14, 2010.

[2] S. Van den Berghe, Y. Parthoens, F. Charollais, Y. S. Kim, A. Leenaers, E. Koonen, V. Kuzminov, P. Lemoine, C. Jarousse, H. Guyon, D. Wachs, D. Keiser Jr, A. Robinson, J. Stevens, G. Hofman, "Swelling of U(Mo)-Al(Si) dispersion fuel under irradiation - Nondestructive analyses of the LEONIDAS E-FUTURE plates," Journal of Nuclear Materials, Vol.430, 246-258, 2012.

[3] S. Van den Berghe, Y. Parthoens, G. Cornelis, A. Leenaers, E. Koonen, V. Kuzminov, C. Detavernier, "Swelling of U(Mo) dispersion fuel under irradiation - Non-destructive analyses of the SELENIUM plates," Journal of Nuclear Materials, Vol.442, 60-68, 2013.

[4] Y.S. Kim, G.L Hofman, A.B. Robinson, J.L. Snelgrove, N. Hanan, "Oxidation of aluminum alloy cladding for research and test reactor fuel," Journal of Nuclear Materials, Vol.378, 220-228, 2008.

[5] V. Kuzminov, E. Koonen, "Qualification irradiation of new high density UMo LEU fuel plates and operating conditions during irradiation at the BR2 high flux materials testing reactor," Proceedings of the International Conference on Research Reactor Fuel Management (RRFM), Rome, Italy, 2011.

[6] V. Kuzminov, "SELENIUM Test Irradiation. Evaluation of Irradiation Conditions for Two UMo LEU 'SELENIUM' Fuel Plates during the BR2 Cycles 02/2012 - 04/2012," Report, SCK·CEN-R-5639. Revision 1, SCK·CEN, January 2013.

[7] J.C. Griess, H.C. Savage, J.L. English, "Effect of heat flux on the corrosion of aluminum by water. Part IV. Tests relative to the Advanced Test Reactor and correlation with previous results," Report, ORNL-3541, February 1964. Also see J.C. Griess et al., ORNL-3230, 1961.

[8] R.L. Dillon, HW-61089, Hanford Laboratory, 1963.

[9] C.B. Lee and D.S. Sohn, "Evaluation of the Corrosion Behavior of the Aluminum Cladding in the KMRR Fuel," Journal of the Korean Nuclear Society, Vol.26, No.4, 526-535, 1994.

[10] F.W. Dittus, L.M.K. Boelter, "Heat transfer in automobile radiator of the tubular type," University of California at Berkley Publ. Eng. 2, 443-461, 1930.

[11] A.P. Colburn, "A method of correlating forced convection heat transfer data and a comparison with fluid friction," Trans. AIChE J. 29, 174-210, 1933.

[12] E.N. Sieder, G.E. Tate, "Heat transfer and pressure drop of liquids in tubes," Industrial and Engineering Chemistry 28, 1429-1435, 1936. 
[13] D. Jo, et al., "Experimental investigation of convective heat transfer in a narrow rectangular channel for upward and downward flows," Nuclear Engineering and Technology, Vol.46 No.2, 195-206, 2014.

[14] W.R. Marcum, D.M. Wachs, A.B. Robinson, M.A. Lillo, "Aluminum cladding oxidation of prefilmed in-pile fueled experiments," Journal of Nuclear Materials, Vol.471, 136-148, 2016.

[15] H.M. Sohn, "User manual of TH_Calc Win 1.0a," Report in Korean, KAERI Report, 2017.

[16] B. Kapusta, J. Garnier, B. Maugard, L. Allais, P. Lemoine, "Irradiation effects on 6061-T6 aluminum alloy used for JHR internal structures," $12^{\text {th }}$ IGORR meeting, Beijing, China, 2009.

[17] E. Shaber, G.L. Hofman, "Corrosion minimization for research reactor fuel," INL/EXT-0500256, Idaho National Laboratory, 2005.

[18] K. Farrell, Performance of Aluminum in Research Reactors. In: R.J.M. Konings, (ed.) Comprehensive Nuclear Materials, volume 5, pp. 143-175 Amsterdam: Elsevier, 2012. 


\section{Argonne $\mathbf{A}$}

\section{Nuclear Engineering Division}

Argonne National Laboratory

9700 South Cass Avenue, Bldg. 208

Argonne, IL 60439

www.anl.gov

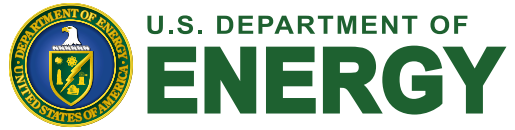

Argonne National Laboratory is a U.S. Department of Energy laboratory managed by UChicago Argonne, LLC 